NBSIR 85-3023

Reference pUBLICATIONS

\title{
CRYOGENIC PROPELLANT SCAVENGING
}

\section{FINAL REPORT}

August 1982 - March 1985

Prepared by

CHEMICAL ENGINEERING SCIENCE

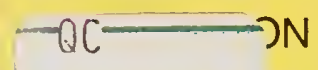

100 ALBUREAU OF STANDARDS

. U56 R, COLORADO 80303

$85-3023$

1985
Prepared for

NATIONAL AERONAUTICS AND SPACE ADMINISTRATION SPACE SHUTTLE PROJECT LYNDON B. JOHNSON SPACE CENTER HOUSTON, TEXAS 77058 



\title{
CRYOGENIC PROPELLANT SCAVENGING \\ FINAL REPORT FOR THE PERIOD
AUGUST 1, 1982 - MARCH 31, 1985
}

\author{
Prepared by \\ Chemical Engineering Science Division \\ National Bureau of Standards \\ Boulder, Colorado 80303
}

\author{
B. Louie \\ N. J. Kemp \\ D. E. Daney
}

Contract No. (T6077J)

\author{
Prepared for \\ National Aeronautics and Space Administration \\ Space Shuttle Project \\ Lyndon B. Johnson Space Center \\ Houston, Texas 77058
}

U.S. DEPARTMENT OF COMMERCE, Malcolm Baldrige, Secretary 



\section{CONTENTS}

\section{Page}

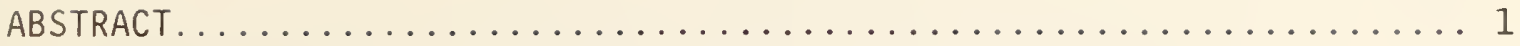

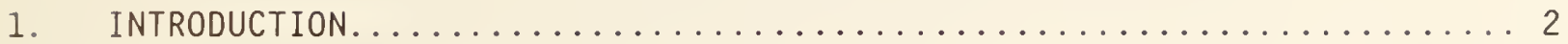

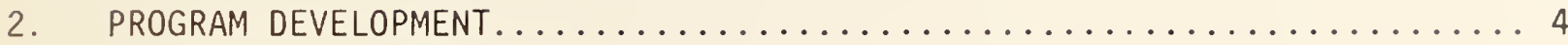

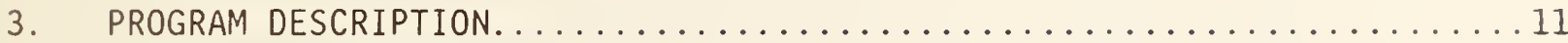

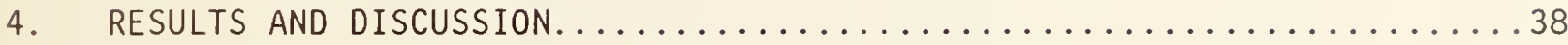

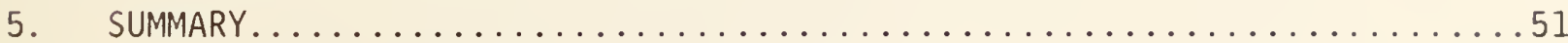

APPENDICES

A. Derivation of single-phase receiver tank equations..........53

B. Derivation of two-phase receiver tank equations............56

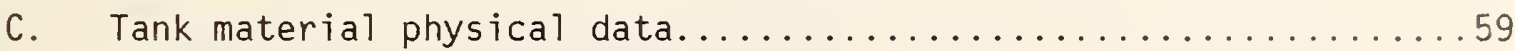

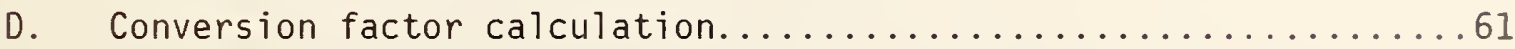

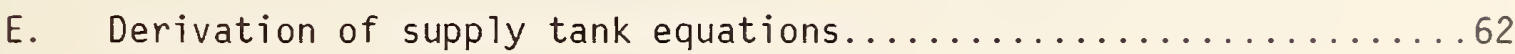

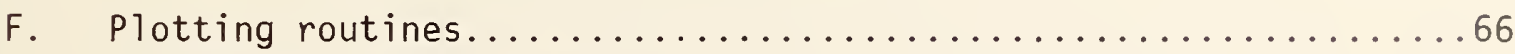

G. Program listings and sample plots $\ldots \ldots \ldots \ldots \ldots \ldots \ldots$ NOMENCLATURE. .................................... 114

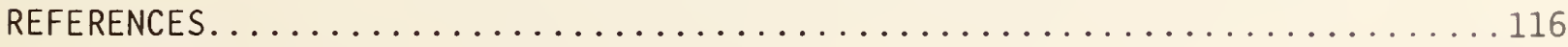





\section{FIGURES}

Page

Figure 1. Flow schematic for cryogenic propellant scavenging......... 4

Figure 2. Flow schematic for the receiver tank................... 6

Figure 3. Components of the computer model......................11

Figure 4a. Effect of varying the heat leak to the ET, LOX (default:

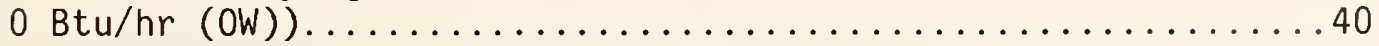

Figure 4b. Effect of varying the heat leak to the ET, $\mathrm{LH}_{2}$ (default:

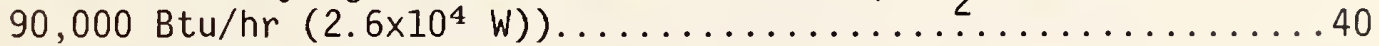

Figure 5a. Effect of varying the heat leak to the transfer piping, LOX

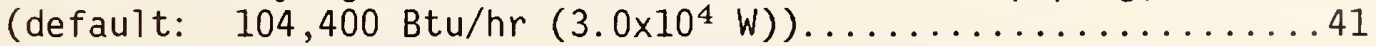

Figure 5b. Effect of varying the heat leak to the transfer piping, $\mathrm{LH}_{2}$ (default: $\left.50,400 \mathrm{Btu} / \mathrm{hr}\left(1.5 \times 10^{4} \mathrm{~W}\right)\right) \ldots \ldots \ldots \ldots \ldots \ldots \ldots \ldots \ldots \ldots$

Figure 6. Pressure history of LOX transfer for a heat leak of $2 \times 10^{6} \mathrm{Btu} / \mathrm{hr}$ $\left(5.8 \times 10^{5} W\right)$ to the transfer piping..........................

Figure 7a. Effect of varying the heat leak to the receiver tank, LOX

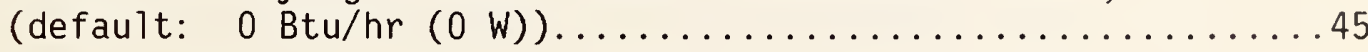

Figure 7b. Effect of varying the heat leak to the receiver tank, $\mathrm{LH}_{2}$

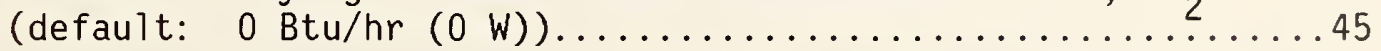

Figure 8a. Effect of varying the initial receiver tank temperature, LOX

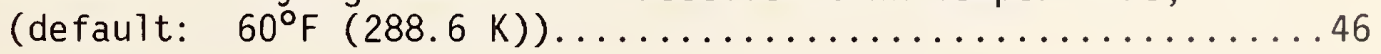

Figure 8b. Effect of varying the initial receiver tank temperature, $\mathrm{LH}_{2}$

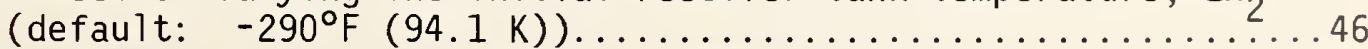

Figure 9. Pressure history of LOX transfer for an initial receiver tank

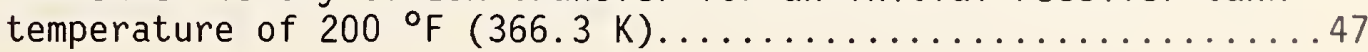

Figure 10a. Effect of varying the pump or transfer line sizes, LOX (default: 4 HP $(2982.8 \mathrm{~W}), 4$ in $(10.2 \mathrm{~cm})$ )

Figure 10b. Effect of varying the pump or transfer line sizes, $\mathrm{LH}_{2}$ (default: OHP (OW), 5 in $(12.7 \mathrm{~cm})$ ). 


\section{TABLES}

Page

Table 1. System Parameter Descriptions and Initialization Values..........13

Table 2. Description of Parameters in the COMMON Statements.............. 14

Table 3. Calculated Constants for Equivalent Length................... 15

Table 4. Variables Used to Plot System Parameters.....................20

Table 5. Tank Wall Heat Capacity Constants............................ 30

Table 6. Sample Output for Hydrogen............................... 36

Table 7. Final Conditions Using Default Values...................... 39 
Cryogenic Propellant Scavenging

Final Report

August 1982 - March 1985

\author{
B. Louie, N. J. Kemp, and D. E. Daney \\ Chemical Engineering Science Division \\ Nationa $\mathrm{T}$ Bureau of Standards \\ Boulder, Colorado 80303
}

This report is a detailed description of a computer model that has been developed for assessing the feasibility of low g cryogen propellant scavenging from the Space Shuttle External Tank (ET). Either pump-assisted or pressureinduced propellant transfer may be selected. The receiver tank is chilled by emitting a low flowrate of single-phase cryogen through small nozzles. When two phases are present the flowrate is increased to represent transfer through the main piping. The program will accept a wide range of input variables, including the fuel to be transferred ( $\mathrm{LOX}$ or $\mathrm{LH}_{2}$ ), heat leaks, tank temperatures, and piping and equipment specifications.

The model has been parametrically analyzed to determine initial design specification for the system. Pressure-induced transfer of $\mathrm{LH}_{2}$ can be accomplished in approximately 7 minutes with a 3 -inch $(0.076 \mathrm{~m})$ Tine size. Pump-assisted scavenging of LOX can be completed in less than 4 minutes by using a $2 \mathrm{HP}$ (1491.4 W) pump and a 3 -inch $(0.076 \mathrm{~m})$ Tine. To maximize the quantity of $\mathrm{LH}_{2}$ recovered, the receiver tank should be prechilled to $-290{ }^{\circ} \mathrm{F}$ (94.1 K). It was determined that the LOX receiver tank does not require prechilling and can have a temperature as warm as $300^{\circ} \mathrm{F}(421.9 \mathrm{~K}$ ) without significant venting of fluid.

Key words: computer model; cryogenic; fluid transfer; low-g; scavenging; thermodynamics. 


\section{INTRODUCTION}

The continuing success of the frequent Space Shuttle flights has encouraged interest in suborbital scavenging of propellants. Currently, the surplus liquid hydrogen $\left(\mathrm{LH}_{2}\right)$ and oxygen $(\mathrm{LOX})$ are jettisoned with the external tank (ET) or vented to space after the main-engine cutoff (MECO). Nearly 10,000 pounds* $(4535.9 \mathrm{~kg})$ of fuel remain after MECO, which can be compared to the full payload of 65,000 pounds $(29483.4 \mathrm{~kg})$. Significant savings can be realized immediately with the proposed scavenging. Accomplishment of this task would support the longer range concepts of tethered vessel storage or orbiting space station operations.

Brux and Stefan [1] have studied the physical phenomenon of cryogenic propellant transfer and discuss the logistics of the task, including receiver tank configuration and location, various heat fluxes, and the duration of a mated coast period after MECO required to meet settling thrust requirements for the ET. They find the concept feasible, provided a positive acceleration of $1 \times 10^{-4} \mathrm{~g}^{\prime} \mathrm{s}$ or greater is continued for a period of five to twenty minutes. A period of twenty minutes is required for the worst-case transfer of both fluids. The transfer of liquid oxygen requires a 2 to 7.5 -inch ( 5 to $19 \mathrm{~cm}$ ) line size and a boost pump. Liquid hydrogen transfer can be accomplished using a 4 -inch $(10 \mathrm{~cm})$ line size with no pump. Simulation of the transfer incorporates a receiver tank cooldown period, during which a low flowrate of cryogen is circulated.

*This report does not conform with NBS policy on SI units. At the request of the sponsoring agency, NASA-JSC, English units are used for the input and output of data. 
The present investigation was undertaken to determine the possibility of propellant scavenging and to evaluate the conditions required for successful ET residual transfer. A computer model written in FORTRAN IV (FORTRAN 66) is based on a thorough thermodynamic analysis of the shuttle receiver vessel, including cooldown of the vessel interior, and heat fluxes to the ET and shuttle tank. The model is analyzed parametrically in order to provide information to be used in the design of such a system.

This report summarizes our development of a computer model for cryogenic propellant transfer at the National Bureau of Standards. Fundamental equations, system description, and assumptions are presented in section 2 entitled PROGRAM DEVELOPMENT. Program logic and descriptions of parameters, subprograms, and numerical methods are discussed in section 3 entitled PROGRAM DESCRIPTION. The effect on the overall time of transfer and other operational characteristics is analyzed using parametric variations. Factors that are considered include heat leaks, vessel prechilling, and cooldown requirements. These topics are discussed in section 4 entitled RESULTS AND DISCUSSION. 


\section{PROGRAM DEVELOPMENT}

The physical situation described by the computer model is the transfer of cryogenic propellant between two tanks in a low-gravity environment. A simplified schematic of the propellant scavenging system is shown in Figure 1 . The points labeled 1 and 2 respectively denote the main fill line into and vent line from the receiver tank.

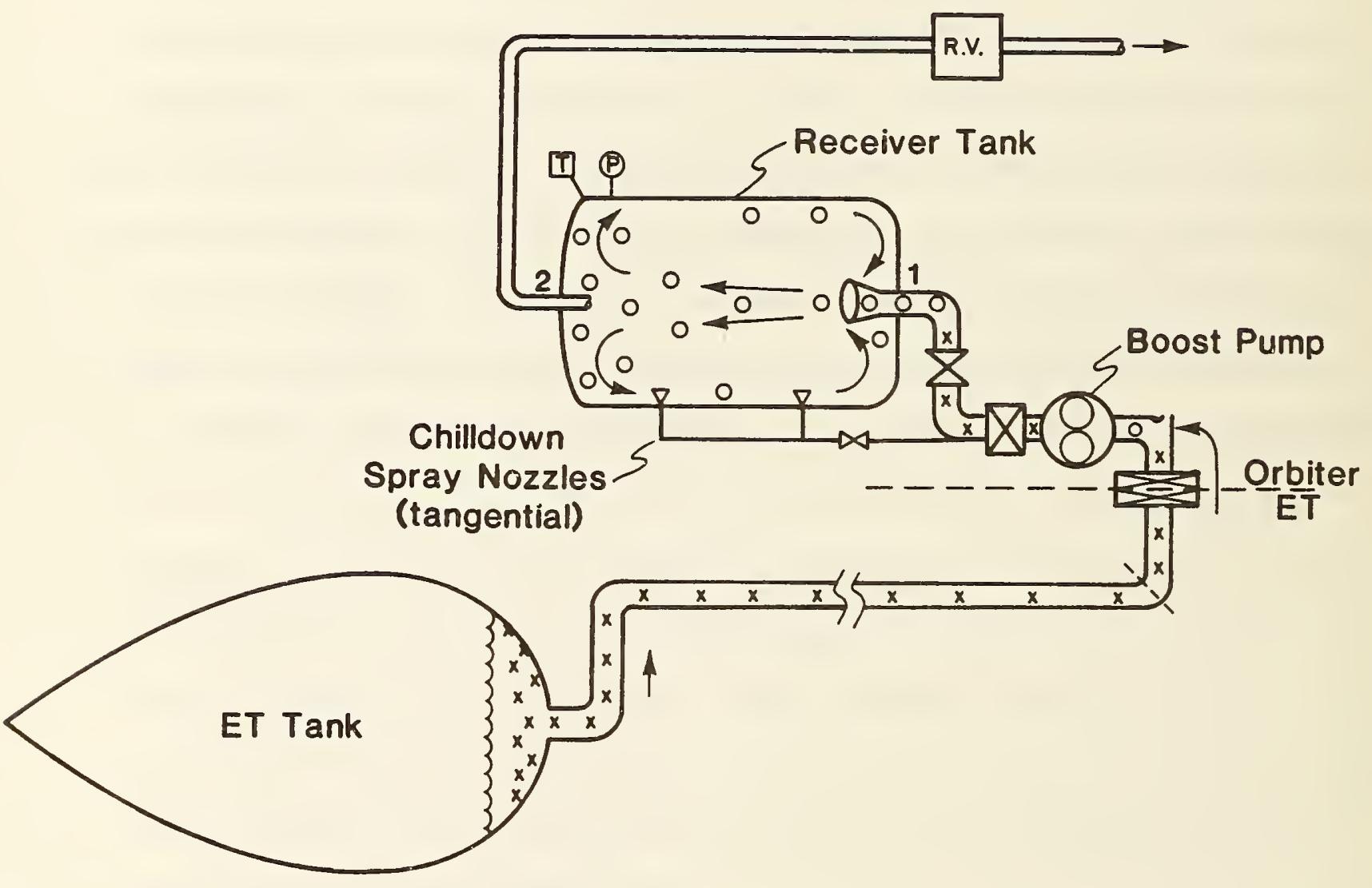

Figure 1. Flow schematic for cryogenic propellant scavenging 
The process begins with a cooldown of the receiver tank by spraying the tank walls with cryogen. This is accomplished by emitting a low flowrate of cryogen through tangential spray nozzles while the main fill line is closed. Following the cooldown period the cryogen is transferred through the main fill Tine by utilizing ullage pressure in the supply tank or by pumping. The transfer is complete when the receiver tank is full, when the supply tank is empty, or when the back pressure in the receiver tank becomes too large.

The model is developed from the differential mass and energy balances applied to the receiver and external (ET) tanks. There are two separate thermodynamic conditions which must be considered for the receiver tank. During the cooldown period, there is only vapor in the tank. Following this single-phase process, a two-phase transfer into the tank by the cryogen must be described. Allowances for pressure relief are made to cover those instances where the tank pressure becomes too great and venting of the vapor to space results. The receiver tank derivation is based on the following assumptions:

(1) Heat leaks into receiver and supply tanks ( $d Q$ and $d Q_{S}$ ) are independent of tank temperature and pressure.

(2) The enthalpy of the vented fluid $\left(h_{2}\right)$ is equal to the receiver tank vapor enthalpy $\left(h_{v}\right)$.

(3) Receiver tank vent pressure is independent of tank temperature.

(4) There is sufficient settling so that only liquid is drained from the supply tank, and only vapor is vented from the receiver tank.

A complete derivation of the single-phase receiver tank equations is given in Appendix A. Although the equations are derived for a differential mass, $d m$, they are equaliy valid when $d m$ is considered a flowrate. Figure 2 
shows the thermodynamic properties for the receiver tank associated with the fluid in the inlet, vent and tank. The equations are summarized as follows (definitions for the equation variables are found in the table of nomenclature):

Mass balance -

$$
d \rho=\frac{d m_{1}}{V}+\frac{d m_{2}}{V}
$$

Energy balance -

$$
d U=d Q+h_{1} d m_{1}+h_{2} d m_{2}
$$

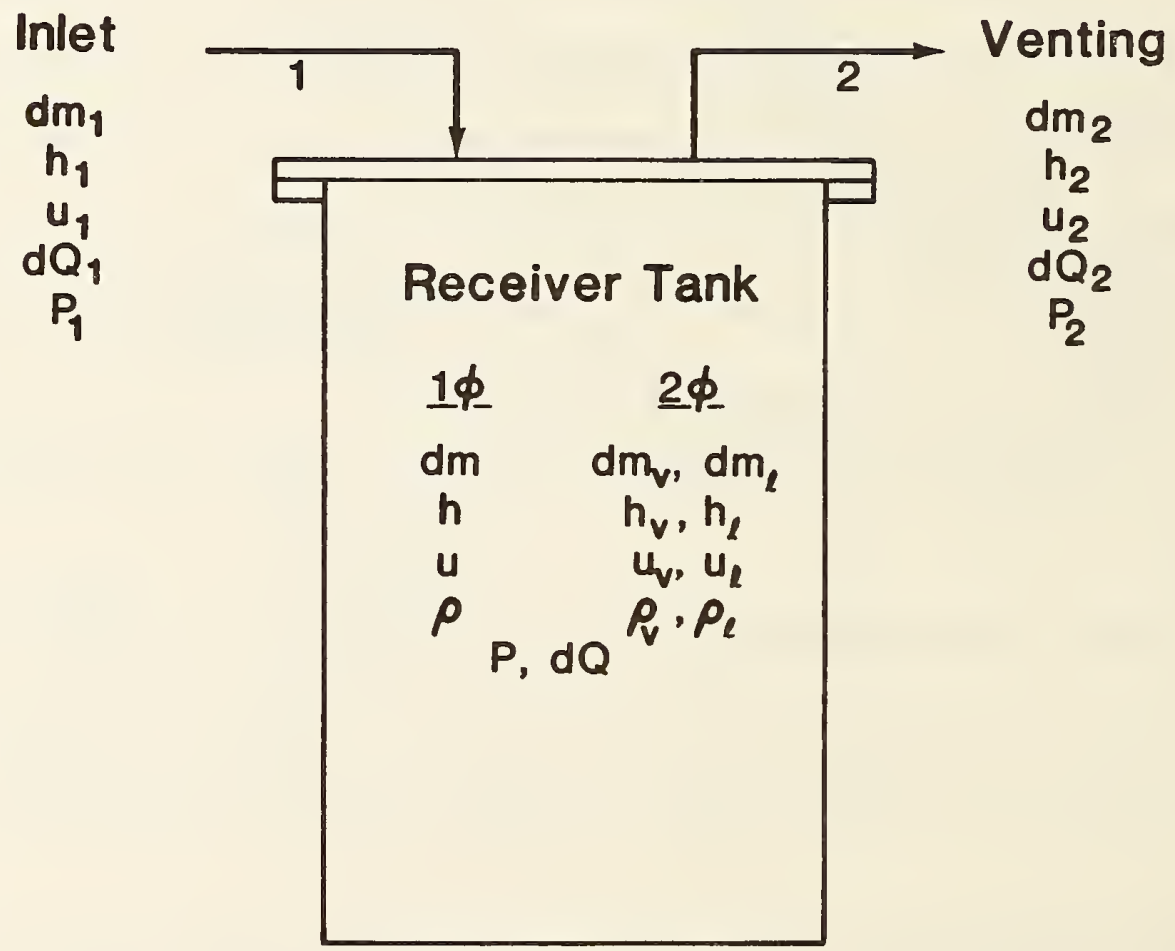

Figure 2. Flow schematic for the receiver tank 
Differential temperature equation -

$$
d T=\frac{\phi T d m+\frac{\left(h_{1}-h\right)}{C_{v}} d m_{1}+\frac{d Q}{C_{v}}}{\rho v+\frac{m_{w} C_{w}}{C_{v}}}
$$

Differential pressure equation -

for $P<$ vent pressure:

$$
\begin{aligned}
& d P=\frac{\phi\left[\theta d m+\left(h_{1}-h\right) d m+d Q-m_{w} C_{w} d T\right]}{V} \\
& d m=d m_{1} \text { and } d m_{2}=0
\end{aligned}
$$

for $P \geq$ vent pressure:

$$
\begin{aligned}
& d P=0 \\
& d m=\frac{\left.\left(h-h_{1}\right) d m_{1}-d Q+m_{w} C_{w} d T\right]}{\theta} \\
& {d m_{2}}_{d}=d m-d m_{1}
\end{aligned}
$$

A complete derivation of the two-phase receiver tank equations is given in Appendix B. These equations are summarized as follows:

Mass balance -

$$
d m_{1}+d m_{2}=d m_{v}+d m_{\ell}
$$

Energy balance -

$$
d U=d Q+h_{1} d m_{1}+h_{2} d m_{2}
$$


Constant volume -

$$
\begin{aligned}
& v=v_{\ell} m_{\ell}+v_{v} m_{v} \\
& 0=v_{\ell} d m_{\ell}+m_{\ell} d v_{\ell}+v_{v} d m_{v}+m_{v} d v .
\end{aligned}
$$

The density, $\rho_{\ell}$ or $\rho_{v}$, is substituted for the specific volume. Solving for the change in the mass of the liquid yields the following equation:

$$
d m_{\ell}=\frac{-\frac{\rho_{\ell}}{\rho_{v}}\left(\mathrm{dm}+\mathrm{dm}_{2}\right)-\rho_{\ell}\left[\mathrm{m}_{\ell} \frac{\partial v}{\partial P}{ }_{\ell}+m_{v} \frac{\frac{\partial v}{\partial P}}{v}\right] d P}{1-\frac{\rho_{\ell}}{\rho_{v}}}
$$

If the pressure is less than the vent pressure, the change in the pressure is given by:

$$
d P=\frac{\left[h_{1}-u_{v}+\frac{\rho_{\ell}}{\rho_{v}}\left(u_{\ell}-h_{1}\right)\right] d m_{1}+(d Q)\left(1-\frac{\rho_{\ell}}{\rho_{v}}\right)}{F(P)}
$$

where

$$
\begin{aligned}
F(P)= & m_{\ell}\left[\left(\frac{\partial u}{\partial P}\right)_{\ell}\left(1-\frac{\rho_{\ell}}{\rho_{v}}\right)+\rho_{\ell}\left(\frac{\partial v}{\partial P}\right)_{\ell}\left(u_{v}-u_{\ell}\right)\right] \\
& +m_{v}\left[\left(\frac{\partial u}{\partial P}\right)_{v}\left(1-\frac{\rho_{\ell}}{\rho_{v}}\right)+\rho_{v}\left(\frac{\partial v}{\partial P}\right)_{v}\left(u_{v}-u_{\ell}\right)\right] \\
& -m_{w} C_{w}\left(\frac{\partial T}{\partial P}\right)_{s a t}\left(1-\frac{\rho_{\ell}}{\rho_{v}}\right)
\end{aligned}
$$

and $\quad \mathrm{dm}_{2}=0$. 
If the pressure is the same as or exceeds the vent pressure, the tank pressure is constant. The differential pressure and mass flow through the vent are as follows:

$$
\begin{gathered}
d P=0 \\
d m_{2}=\frac{\left[u_{\ell}\left(\frac{v_{v}}{v \ell}\right)-u_{v}+h_{1}\left(1-\frac{v_{v}}{v \ell}\right)\right] d m_{1}+d Q\left(1-\frac{v_{v}}{v \ell}\right)}{\left(h_{v}-h_{\ell}\right) \frac{v_{v}}{v_{\ell}}}
\end{gathered}
$$

The ET model is based on the assumption of non-equilibrium (thermal stratification) between the liquid and vapor phases remaining in the supply tank. This assumption is valid because the prechilled supply tanks contain subcooled liquids and the nominal amounts of fuel remaining after MECO are extremely small. Thus, no significant mass transfer can take place between the phases unless the temperature increases enough to vaporize the liquid. When this occurs, the transfer of fuel stops since severe pump cavitation conditions are present.

The following set of equations describes the supply tank at any time:

Energy balance -

vapor phase: $\quad d h_{v}=\frac{d Q_{v}}{m_{v}}+v_{v} d P$

1 iquid phase: $\quad d h_{\ell}=\frac{\mathrm{dQ}_{\ell}}{m_{\ell}}+\nu_{\ell} \mathrm{dP}$

Pressure equation -

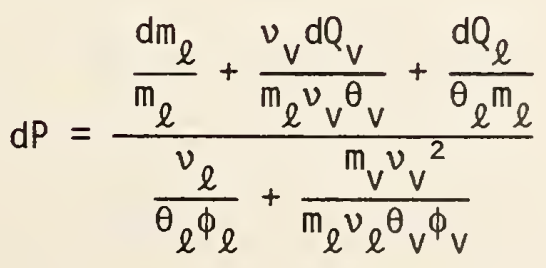


Temperature equation -

$$
\mathrm{dT}=\frac{1}{\mathrm{c}_{\mathrm{p}}}\left(\frac{\mathrm{dQ}_{\ell}}{\mathrm{m}_{\ell}}+v_{\ell} \alpha_{\ell} \mathrm{dP}\right)
$$

Derivations of the above equations can be found in Appendix $E$.

Once the supply tank liquid enthalpy is determined, the enthalpy of the fluid entering the receiver tank can be calculated by:

$$
h_{1}=h_{s}+\frac{d Q_{1}}{d m_{1}}+\frac{W}{d m_{1}}
$$

and

$$
d h_{s}=d Q_{s}
$$




\section{PROGRAM DESCRIPTION}

\subsection{Overview of the Computer Model}

Figure 3 shows the components of the computer simulation program and the communication paths as indicated by the direction of the arrows.

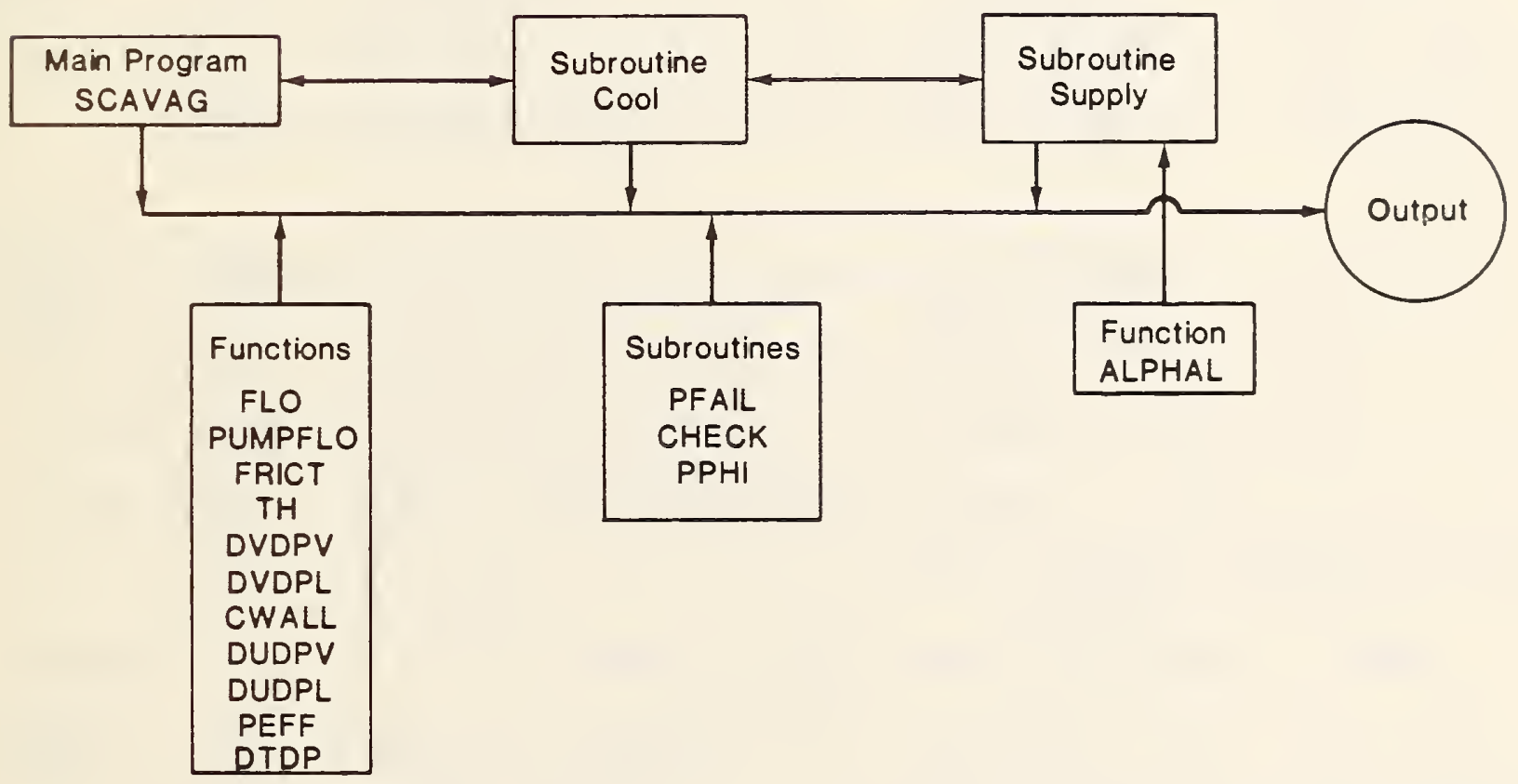

Figure 3 . Components of the computer mode 1

The program is written in FORTRAN IV and uses program subsections called subroutines and functions. The four major program sections are the main program SCAVAG and the subroutines COOL, SUPPLY and PFAIL. SCAVAG performs three distinct operations in modeling the scavenging of cryogenic propellant: 
1) it serves to initialize the system parameters and direct the program flow;

2) it transfers the calculations of the single-phase receiver tank and the external tank to subroutines; and 3) it performs the calculations of the two-phase receiver tank. COOL and SUPPLY perform the thermodynamic state calculations of the single-phase receiver tank and external tank, respectively. PFAIL sets up plotting arrays and prints messages signifying which completion procedure is chosen in the program.

Provision is made at the start of the main program to select the propellant for the simulation. The namelist option is used to select the propellant. The program default value is $N G A S=1$, which signifies that $\mathrm{LH}_{2}$ has been chosen. By using the namelist FUEL and setting NGAS=2, LOX can be selected.

The default values for the parameters for the entire system are initialized according to the propellant chosen. Many of these values are the same as those used by Brux and Stefan [1]. The parameters and their default values are given in Table 1. A namelist option called NAME is used to change any of the initialized values.

COMMON statements are used to pass the same value for a parameter between different portions of the program. For instance, the calculations in the main program and subroutines are dependent on the elapsed time or the quantity of propellant. Table 2 gives a general description of the parameters associated with each of the COMMON statements.

Propellant selection is important in determining the correct fluid thermodynamic properties. The properties data are part of the Fluids Pack computer programs [2] which use routines based on real fluid properties for oxygen and parahydrogen to calculate various thermodynamic properties $[3,4$, 5]. The thermodynamic properties, such as saturation pressure, density, 
Table 1. System Parameter Descriptions and Initialization Values*

\begin{tabular}{|c|c|c|c|c|c|}
\hline \multirow{2}{*}{$\begin{array}{l}\text { Location } \\
\text { Supply } \\
\text { Tank }\end{array}$} & \multicolumn{2}{|c|}{$\begin{array}{l}\text { Parameter } \\
\text { Name Description }\end{array}$} & \multicolumn{2}{|r|}{ Value } & \multirow{2}{*}{$\begin{aligned} \mathrm{LH}_{2} & \\
& \\
32 & (0.221) \\
-425 & (19.1) \\
90000 & (26376.3) \\
53518 & (1515415.7) \\
3098 & (1405.2)\end{aligned}$} \\
\hline & $\begin{array}{l}\text { PET } \\
\text { TET } \\
\text { QET } \\
\text { VET } \\
\text { TOTAL }\end{array}$ & $\begin{array}{l}\text { Pressure } \\
\text { Temperature } \\
\text { Heat leak } \\
\text { Volume } \\
\text { Mass of propellant } \\
\text { to be transferred }\end{array}$ & $\begin{array}{r}20 \\
-315 \\
0 \\
19786 \\
6270\end{array}$ & $\begin{array}{l}(0.138) \\
(80.2) \\
(0) \\
(560260.4) \\
(2844.0)\end{array}$ & \\
\hline $\begin{array}{l}\text { Receiver } \\
\text { Tank }\end{array}$ & $\begin{array}{l}\text { PRESS } \\
\text { TEMP } \\
Q \\
\text { VOL } \\
\text { MWALL } \\
\text { PVENT }\end{array}$ & $\begin{array}{l}\text { Pressure } \\
\text { Temperature } \\
\text { Heat leak } \\
\text { Volume } \\
\text { Mass of tank wall } \\
\text { Vent pressure }\end{array}$ & $\begin{array}{r}1 \\
60 \\
0 \\
300 \\
350 \\
30\end{array}$ & $\begin{array}{l}(0.007) \\
(288.6) \\
(0) \\
(8494.8) \\
(158.8) \\
(0.207)\end{array}$ & $\begin{aligned} 18 & (0.124) \\
-290 & (94.1) \\
0 & (0) \\
780 & (22086.5) \\
975 & (442.4) \\
30 & (0.207)\end{aligned}$ \\
\hline $\begin{array}{l}\text { Transfer } \\
\text { Piping }\end{array}$ & $\begin{array}{l}\text { DIAM } \\
\text { LENGTH } \\
\text { NELBOW } \\
\text { NGATE } \\
\text { NGLOBE } \\
\text { NANGLE } \\
\text { NBUTT } \\
\text { METER } \\
\text { QPIPE } \\
\text { POWER }\end{array}$ & $\begin{array}{l}\text { Pipe diameter } \\
\text { Length of straight pipe } \\
\text { Number of elbow fittings } \\
\text { Number of gate valves } \\
\text { Number of globe valves } \\
\text { Number of angle valves } \\
\text { Number of butterly valves } \\
\text { Number of flow meters } \\
\text { Heat leak } \\
\text { Pump power }\end{array}$ & $\begin{array}{r}4 \\
100 \\
20 \\
0 \\
2 \\
1 \\
0 \\
1 \\
104400 \\
4\end{array}$ & $\begin{array}{l}(30596.5) \\
(2982.8)\end{array}$ & $\begin{aligned} & 5(12.70) \\
& 70(21.34) \\
& 10 \\
& 0 \\
& 2 \\
& 0 \\
& 0 \\
& 1 \\
& 50400 \\
& 0(14770.7) \\
& 0(0)\end{aligned}$ \\
\hline $\begin{array}{l}\text { Cooldown } \\
\text { Piping }\end{array}$ & $\begin{array}{l}\text { CDLENG } \\
\text { NNOZ } \\
\text { NOZDIA } \\
\text { HEADIA } \\
\text { CONST }\end{array}$ & $\begin{array}{l}\text { Léngth of straight pipe } \\
\text { Number of nozzles } \\
\text { Nozzle diameter } \\
\text { Header diameter } \\
\text { 1./orifice constant }\end{array}$ & $\begin{array}{r}20 \\
6 \\
0.25 \\
1.000 \\
1.639\end{array}$ & $\begin{array}{l}(6.10) \\
\left(6.4 \times 10^{-3}\right) \\
\left(2.5 \times 10^{-2}\right)\end{array}$ & $\begin{aligned} 20 & (6.10) \\
6 & \\
0.500 & \left(1.3 \times 10^{-2}\right) \\
2.000 & \left(5.1 \times 10^{-2}\right) \\
1.639 & \end{aligned}$ \\
\hline
\end{tabular}

*Units used to initialize parameters: pressure - psia (MPa), temperature ${ }^{\circ} \mathrm{F}(\mathrm{K})$, heat leak - Btu/hr (W), volume - cubic feet (liters), mass - pounds $(\mathrm{kg})$, power - horsepower $(W)$, length - feet $(\mathrm{m})$, diameter - inches $(\mathrm{cm})$. 
and thermal conductivity, are found by using subroutines and functions built into Fluids Pack. When $\mathrm{LOX}$ or $\mathrm{LH}_{2}$ is chosen, the subroutines DATA 02 or DATA PH2 are called.

The distinction between propellants is considered at other points in the computer code. The plotting and numerical integration routines are dependent on the propellant chosen. PFAIL writes the propellant name into a data file which is used in producing the output plots. The time step in each numerical integration is based on the values of the flowrate into the receiver tank and which propellant is used. Also, since the receiver tank construction materials are different for $\mathrm{LOX}$ and $\mathrm{LH}_{2}$, the heat capacity calculation for the tank wall in FUNCTION CWALL requires this distinction.

Table 2. Description of Parameters in the COMMON Statements

\begin{tabular}{ll}
\hline Name & \multicolumn{1}{c}{ Description of parameters } \\
\hline PARAM & initialized, constant values \\
SUB & time dependent \\
FLOW & time dependent and transfer piping \\
NOZZLE & cool-down piping \\
PUMP & pump values \\
NGAS & choice of propellant \\
ETANK & supply tank \\
PROB & programmed exit designation \\
\hline
\end{tabular}

After the parameters have been initialized, they are converted to SI units. This is done to ensure compatibility with the thermodynamic data required from the Fluids Pack routines. All subsequent calculations are performed in SI units, with the exception of those in the plotting routine. 
Before the transfer of fluid begins, the equivalent length of pipe between the supply and receiver tanks is calculated. Data for equivalent lengths of various pipe fittings are taken from Bennett and Meyers [6]. The equivalent length of each fitting is linearly proportional to the pipe diameter as given by

$$
L_{e q}=C_{I} D+C_{I I}
$$

The constants are shown in Table 3 . The total equivalent length is calculated by summing all the individual equivalent lengths. The equivalent length is then used by FUNCTION FLO and FUNCTION PUMPFLO to calculate a flowrate between supply and receiver tanks.

Table 3. Calculated Constants for Equivalent Length

\begin{tabular}{lcc}
\hline & $C_{\text {I }}$ & $C_{\text {II }}$ \\
\hline $90^{\circ}$ elbow & 2.53 & 0.414 \\
Gate valve & 0.571 & -0.0125 \\
Globe valve & 38.1 & 0.107 \\
Angle valve & 14.2 & -1.18 \\
Butterfly valve & 1.79 & -0.147 \\
\hline
\end{tabular}

After parameter initialization and unit conversion has been accomplished, the thermodynamic condition of the supply tank is established. This procedure involves determining the quantity of ullage vapor in the tank. The initial flowrate between the tanks is calculated using the pressure difference between the tanks and the pressure drop through the piping with FUNCTION FLO. If the flow is aided by a pump, the increased flowrate as calculated in FUNCTION PUMPFLO is used. 


\subsection{Description of Program Sections}

SCAVAG

The main program SCAVAG directs the sequence of calculations in the simulation. Following parameter initialization and unit conversion, the cool-down of the receiver tank takes place by calling SUBROUTINE COOL. When the receiver tank is cooled, there are two phases present and a return is made to SCAVAG. It is assumed that the transfer piping is simultaneously chilled.

The remaining propellant is transferred in two phases. First, the enthalpy of the fluid entering the receiver tank is computed by using an energy balance on the transfer piping. The density and enthalpy of the liquid and vapor are found with Fluids Pack functions. These values are used in the first law of thermodynamics to find the internal energy of both phases in the receiver tank. Next, the integration of the differential pressure and mass equations, Eq. (10)-(12), is carried out over an incremental time step (forward Euler method) and incorporates the thermodynamic values above. A check is made to see if the pressure in the receiver tank exceeds the vent pressure; the mass of propellant in the tank is adjusted accordingly. Following this, the supply tank properties are updated by calling SUBROUTINE SUPPLY. Finally, the values for the pressure, flowrate, and propellant vapor and liquid quantities are stored in arrays for plotting.

This calculation procedure is repeated within a loop until the receiver tank is full, until all the propellant has been transferred, or until another condition has been encountered which causes the program to be terminated. For instance, should the pressure in the tank exceed that of the entering stream, the transfer stops. If the simulation proceeds normally, SCAVAG calls SUBROUTINE PFAIL to prepare the data for graphic display. 
The single-phase cool-down of the receiver tank is performed by SUBROUTINE COOL until the receiver is at the correct pressure and temperature for a twophase propellant. Contained in the call and subroutine statements are three parameters that are needed to transfer into and return from COOL. SCAVAG provides values for the mass of vapor in the tank and the mass of vented vapor. COOL returns to SCAVAG the differential pressure and the current values of the mass of vapor in the tank and the quantity vented. A calculation procedure similar to that in SCAVAG is followed to solve Eq. (1)-(6).

Several thermodynamic quantities are needed to solve the single-phase differential equations. COOL calls SUBROUTINE PPHI which calculates the Grüneisen parameter for the single-phase (vapor) propellant in the receiver tank. A heat balance analysis on the transfer pipe affords the enthalpy for the entering stream. The Fluids Pack functions are used to find the density, enthalpy, and specific heat of the fluid in the receiver tank. When all of these thermodynamic values are known, the equations are solved incrementally, with the appropriate checks for venting and back pressure. If all the propellant has been transferred before any liquid is present in the receiver tank, a call is made to PFAIL to prepare the plotting data and terminate the program. Again, the supply tank fluid properties are updated by calling SUPPLY.

To determine when two phases are present in the receiver tank, saturation and actual gas densities are compared. If the gas saturation density at the receiver tank pressure is greater than the actual tank density, the receiver tank is two-phase. SUBROUTINE COOL returns to the main program following this determination. 
When updated supply tank conditions are required in either the main program or SUBROUTINE COOL, SUBROUTINE SUPPLY is accessed to perform the necessary thermodynamic calculations. The fraction of the supply tank occupied by either phase is determined first so that the heat flux to the tank can be proportioned accordingly. The vapor phase is assumed to be at the tank pressure and slightiy above the saturation temperature, thereby ensuring that condensation will not occur. Next, the Fluids Pack routines are called upon to provide thermodynamic values for the vapor and liquid phases. The Grüneisen parameter and heat of expulsion for both phases are calculated by using SUBROUTINE PPHI and FUNCTION TH, respectively. Finally, the incremental changes in the tank pressure and liquid temperature and enthalpy are found by using Equations (14), (15) and (13b) and the appropriate time step.

\section{SUBROUTINE PFAIL}

SUBROUTINE PFAIL, with ENTRY FULL and ENTRY DONE, terminates the program and sets up the data and parameters to be plotted. The different entry points are accessed by unique call statements. PFAIL is called when: 1) the flow between tanks has stopped due to back pressure from the receiver tank; 2) when receiver and supply tank pressures are equal and a pump is not used; or 3 ) when there is excessive pressure in the receiver tank and a pump is used. PFAIL writes a message indicating why the simulation stopped and what the final conditions are. The other entries into PFAIL address other conditions and bypass inappropriate operations. ENTRY FULL is called when the main program or SUBROUTINE COOL determines that the receiver tank is full of propel- 
lant. When all the fluid has been emptied out of the supply tank, ENTRY DONE is called. ENTRY PDATA is called when a programmed exit has been executed.

Each entry into the subroutine follows a similar computational procedure. Initially, the units for the parameters to be printed in the termination message are converted to English from SI. Following this conversion, the message is printed on the output file stating the cause for program termination, the quantity of propellant transferred, and the temperature and pressure for each tank. The quantity of fluid vented from the tank is also given.

Preparation of the data and parameters for plotting involves several steps. The upper and lower limits for the plots are determined first. The descriptions for the plotting parameters are shown in Table 4 . Since each of the plots depicts a parameter as a function of time, the lower value is set to zero and the upper value is either 10 or a multiple of 50 minutes. Should the total time required for transfer be more than 10 minutes, the greater value will be used.

The lower limit for the receiver tank temperature is based on the initial temperature in the supply tank, and the upper limit depends on the initial receiver tank temperature. Both values are multiples of 100 and in units of Fahrenheit.

The limits on the receiver tank pressure are zero and 50 psia $(0.345$ $\mathrm{MPa}$ ), unless a value in the pressure array exceeds the upper limit. When this is the case, the value is incremented by $50 \mathrm{psia}(0.345 \mathrm{MPa}$ ) iteratively until the maximum pressure data point is less than the newly set limit. The upper limit for the transfer flowrate is $2000 \mathrm{lb} / \mathrm{min}(907.2 \mathrm{~kg} / \mathrm{min})$ for $\mathrm{LH}_{2}$ or $10,000 \mathrm{lb} / \mathrm{min}(4535.9 \mathrm{~kg} / \mathrm{min})$ for $\operatorname{LOX}$. 
Table 4. Variables Used to Plot System Parameters

Simulation variable Units Array $\begin{gathered}\text { Location of low, } \\ \text { high bounds }\end{gathered}$

\begin{tabular}{lcll}
\hline TIME & Minutes & $X$ & \\
TEMP & ${ }^{\mathrm{F}}$ & $\mathrm{Y} 1$ & OPLOT(1), OPLOT(2) \\
PRESS & Psia & OPLOT(3), OPLOT(4) \\
FLOW1 & Pounds/min & Y3 & OPLOT(5), OPLOT(6) \\
MVAP & Pounds & OPLOT(7), OPLOT(8) & OPLOT(9), OPLOT(10) \\
MLIQ & Pounds & Y5 & OPLOT(11), OPLOT(12) \\
TOTAL & Pounds & Y & OPLOT(13), OPLOT(14) \\
ETQ & Dimensionless & Y7 & OPLOT(15), OPLOT(16) \\
TANK & Dimensionless & Y8 & OPLOT(17), OPLOT(18)
\end{tabular}

The quantity of propellant in the receiver tank is graphically displayed by plotting the vapor, liquid, and combined amounts over time. All these limits are dependent on the initial quantity of propellant (TOTAL) to be transferred. The upper limit for the vapor quantity is initially set to 500 lbs $(226.8 \mathrm{~kg})$, but it is increased iteratively by $500 \mathrm{lbs}(226.8 \mathrm{~kg}$ ) if one-tenth of TOTAL is larger than the limit. The upper limits for the liquid and combined quantities are 10 times the value determined for the vapor quantity. The quality of the propellant in the supply tank and entering the receiver tank is stored in the array as percent vapor. The upper limit for the quality is $100 \%$ vapor and the iower limit is 100 percent liquid.

\subsection{Descriptions of Other Subroutines}

\section{SUBROUTINE PPHI}

The thermodynamic quantity called the Grüneisen parameter, $\phi$, appears frequently in single-phase flow [7]. It is found in the equations describing the single-phase cooldown of the receiver tank (Eq. (3)-(4)) and the subcooled 
liquid propellant in the supply tank (Eq. (14)) in the present study. Both subroutines COOL and SUPPLY call PPHI during their computational procedures for values of $\phi$.

The dimensionless Grüneisen parameter is given by

$$
\phi=\frac{1}{\rho}\left(\frac{\partial P}{\partial u}\right)_{\rho}
$$

or

$$
\phi=\left(\frac{\partial P}{\partial T}\right)_{\rho}\left(\frac{1}{\rho C_{v}}\right)
$$

When the second form of $\phi$ is used, the Fluids Pack subroutine DPDT can be used to find the partial derivative and the constant volume specific heat of the fluid. The density and temperature are passed from either COOL or SUPPLY to PPHI which returns a value for $\phi$.

\section{SUBROUTINE CHECK}

Calls to this subroutine are routinely made to determine the quality of propellant. Both SCAVAG and COOL call CHECK to find the quality of the fluid entering the receiver tank. SCAVAG, COOL, and SUPPLY utilize CHECK to find the amount of vapor in the supply tank fluid. Because pump cavitation can be severe with a small quantity of vapor, the run will be terminated with this determination. A message is printed which states the percentage of vapor in the fluid.

For inputs of pressure, temperature and enthalpy, SUBROUTINE CHECK determines if the fluid is single-phase or two-phase and the mole fraction in each phase. First, the liquid saturation enthalpy is obtained from Fluids Pack using the input pressure. Next, if the input enthalpy is less than liquid saturation enthalpy, the stream is subcooled, and CHECK returns an indication 
that no vapor is present (i.e. $x=0$ ). If the input enthalpy is greater than the liquid saturation enthalpy, the proportion of fuel in the liquid and vapor phases is determined by:

$$
h=h_{\ell, s a t}(1-x)+h_{v, \text { sat }}(x)
$$

or rearranging,

$$
x=\left(h_{\ell, s a t}-h\right) /\left(h_{\ell, s a t}-h_{v, s a t}\right)
$$

Since the flow equations were developed for an incompressible fluid, there may be significant error if the fraction of vapor is much greater than zero.

\subsection{Descriptions of Functions}

Several thermodynamic quantities in the form of partial derivatives are required in the two-phase calculations in SCAVAG. While Fluids Pack directly calculates some partial derivatives such as DPDT (which is used in determining $\phi)$, other partial derivatives must be calculated using an iterative approximation. The approximation is written so that thermodynamic properties from Fluids Pack may be utilized.

\section{FUNCTIONS DVDPV and DVDPL}

FUNCTION DVDPV and FUNCTION DVDPL calculate the partial derivative of specific volume with respect to pressure for saturated vapor and liquid respectively. The pressure is the required parameter in the function statement. 
These partial derivatives are required by Eq. (10) for the two-phase integration. The partial derivative is approximated by the equation:

$$
\left(\frac{\partial v}{\partial P}\right)_{\text {sat }}=\frac{v_{\text {sat }}(P+\Delta P)-v_{\text {sat }}(P-\Delta P)}{2 \Delta P}
$$

The values for the specific volume at saturation conditions are the inverse of the density computed by Fluids Pack at the same temperature and pressure. The pressure increment $\Delta P$ is initially set at 0.05 atm $(0.005 \mathrm{MPa})$ and decreased until the partial derivative changes insignificantly.

FUNCTIONS DUDPV and DUDPL

FUNCTION DUDPV and FUNCTION DUDPL, given the pressure as an input, determine the partial derivative of internal energy with respect to pressure for saturated vapor and liquid, respectively, as required by Equation (11b). The partial derivative is approximated in a similar manner to DVDPV and DVDPL by:

$$
\left(\frac{\partial u}{\partial P}\right)_{s a t}=\frac{u_{s a t}(P+\Delta P)-u_{s a t}(P-\Delta P)}{2 \Delta P}
$$

The internal energy, usat, is calculated using enthalpy values from Fluids Pack at the saturation temperature and pressure and the (First Law) energy relationship as given by:

$$
\mathrm{u}=\mathrm{h}-(\mathrm{Pv})
$$

or

$$
u=h-(P / \rho)
$$

Again, $\Delta P$ is initially $0.05 \mathrm{~atm}(0.005 \mathrm{MPa})$ and decreased until the desired accuracy is obtained. 
This function determines the partial derivative of temperature with respect to pressure for the saturated fluid (liquid and vapor). The partial derivative is approximated by the expression

$$
\left(\frac{\partial T}{\partial P}\right)_{\text {sat }}=\frac{T_{\text {sat }}(P+\Delta P)-T_{s a t}(P-\Delta P)}{2 \Delta P} .
$$

Pressure is required as an input for the function and is subsequently used in the Fluids Pack function FINDTV to obtain the saturated temperature. The temperature is found at a pressure that is a small iricrement above and below the input. The increment, $\Delta P$, is decreased from an initial value of $0.05 \mathrm{~atm}$ $(0.005 \mathrm{MPa})$ until the convergence criterium is met.

\section{FUNCTION ALPHAL}

The temperature equation in SUPPLY contains the term for the liquid phase bulk expansivity, $\alpha_{\ell}$, which is defined as (7):

$$
\alpha_{\ell}=-\frac{T}{\rho}\left(\frac{\partial \rho}{\partial T}\right)_{p}
$$

FUNCTION ALPHAL calculates this value by approximating the partial derivative in an iterative manner. This approximation is given by:

$$
\left(\frac{\partial \rho}{\partial T}\right)_{p}=\frac{\rho(T+\Delta T)-\rho(T-\Delta T)}{2 \Delta T}
$$

A temperature increment $\Delta T$ is used to find values of the density at temperatures slightly above or below the liquid temperature. The temperature increment $\Delta T$ is initially set at $0.05 \mathrm{~K}$ and decreased until the partial derivative changes insignificantly from one iteration to the next. 
The functions used to calculate the transfer flowrate are dependent on the pressure in the receiver tank and are themselves interdependent. These functions are used to calculate the flowrate of propellant between the supply and receiver tanks. FLO and PUMPFLO are accessed from SCAVAG and COOL. FRICT is used in FLO and PUMPFLO, and PEFF is used in PUMPFLO only. A description of each follows.

\section{FUNCTION FLO}

FUNCTION FLO calculates the flowrate between tanks for a given pressure drop. This function is used to initialize the flowrate, and the value it provides is an input for FUNCTION PUMPFLO. SCAVAG passes the receiver tank pressure through the function statement.

The flowrate between the tanks is related to the pressure drop in the system. The overall pressure drop can be stated as the sum of the individual pressure drops as follows:

$$
\Delta P_{\text {system }}=\Delta P_{\text {main }}\left(\mathrm{dm}^{2}\right)+\Delta P_{\text {meter }}+\Delta P_{\text {cooldown }}\left(\mathrm{dm}^{2}\right) \text {, }
$$

where $\left(d m^{2}\right)$ is the functional dependence, not the multiplier. The overall pressure drop is the difference between the pressures in ET and receiver tank. The pressure drop in the meter is five percent of the overall pressure drop. The remaining terms in Eq. (27) are functions of the flowrate. The pressure drop through the main transfer line and the cooldown line are given by:

$$
\Delta P_{\text {main }}=\frac{32 C f_{\text {main }} L_{\text {main }}(d m)^{2}}{\rho \pi^{2} D_{\text {main }}^{5}} .
$$


and

$$
\Delta P_{\text {cool }}=\frac{32 C f_{C 001} L_{c o 01}(d m)^{2}}{\rho \pi^{2} D_{\text {cool }}^{5}} .
$$

(For the derivation of $C$, see Appendix D.)

The pressure drop in the cool down nozzles can be expressed as

$$
\Delta P_{\text {nozzle }}=\left(\frac{d m}{C^{1} D_{0}^{2} C_{d}}\right)^{2}\left(\frac{\rho}{g_{C}}\right)\left[1-\left(\frac{D_{0}}{D_{C o 0}}\right)\right]^{4}
$$

When Eq. (27) is solved for the flowrate dm by substituting into it Eq. (28) (30), the following expression is obtained:

$$
\mathrm{dm}^{2}=\frac{P_{\mathrm{S}}-P_{\mathrm{RT}}-\Delta \mathrm{P}_{\text {meter }}}{C_{\text {main }}{ }_{\text {main }}+C_{\text {cool }}{ }^{f}{ }_{\text {cool }}+C_{\text {nozzle }}},
$$

where $C_{i}=C_{\text {main }}, C_{\text {cool }}$, or $C_{\text {nozzle }}$ refers to the right hand side of the individual equations without the flowrate term.

Since the Fanning friction factors in Eq. (28) and (29) also are functions of the flowrate, an iterative procedure is used to calculate $f_{\text {main }}$ and $\mathrm{f}_{\text {cool }}$. The friction factors are initially set to 0.005 and used to compute the flowrate. The flowrate is used as the input parameter to FUNCTIO FRICT, which computes new values for the friction factors. The new values fo $f_{\text {main }}$ and $f_{\text {cool }}$ are used to recalculate the flowrate. This continues until the friction factors change by less than 0.1 percent.

After the receiver tank has been chilled to allow two phases of the propellant to be present, the nozzle constant, $C_{d}$, and the length of the cool down piping, $L_{\text {cool }}$, are set to zero. The contribution of the cooldown line and nozzles to Eq. (27) and (31) is negated. This simulates the switching of a three-way valve to the closed position in the cooldown line. 


\section{FUNCTION FRICT}

FUNCTION FRICT calculates the Fanning friction factor corresponding to flow through a pipe. Input variables are the flowrate, temperature, density, and pipe diameter.

The Fanning friction factor is related to the Reynolds number and pipe diameter. While a variety of functions are available [8], the following relationship was chosen:

$$
f=\left\{-4 \log _{10}\left(\frac{\varepsilon / D}{3.7}-\frac{5.02}{N_{R e}} \log _{10}\left(\frac{\varepsilon / D}{3.7}+\frac{14.5}{N_{R e}}\right)\right)\right\}^{-2}
$$

The pipe roughness $\varepsilon$ is assumed to be $0.00015 \mathrm{ft}(0.004572 \mathrm{~cm})$, the value for commercial steel pipe [6]. The Reynolds number is calculated from the equation:

or

$$
\mathrm{N}_{\operatorname{Re}}=\mathrm{Du} u_{b} \rho / \mu
$$

$$
N_{R e}=\frac{4(d m) M}{\pi D \mu}
$$

The viscosity as a function of pressure and temperature for hydrogen cannot be calculated with the Fluids Pack thermophysical properties computer programs. However, since relatively small changes in hydrogen viscosity do not significantly change the friction factor, an average viscosity is used. This value is $1.8 \times 10^{-4} \mathrm{~g} /(\mathrm{cm} \cdot \mathrm{s})$ [3] and produces 1 ess than $0.5 \%$ error in the friction factor. 
FUNCTION PUMPFLO calculates the flowrate between the ET and receiver tank and accounts for the use of a pump in the transfer. The overall pressure drop can be expressed as

$$
\Delta \mathrm{P}_{\text {system }}=\Delta \mathrm{P}_{1 i n e}\left(\mathrm{dm}^{2}\right)+\Delta \mathrm{P}_{\text {meter }}+\Delta \mathrm{P}_{\text {cool }}\left(\mathrm{dm}^{2}\right)-\Delta \mathrm{P}_{\text {pump }}\left(\frac{1}{\mathrm{dm}}\right) .
$$

See the previous discussion in the section on FUNCTION FLO for descriptions of the terms $\Delta \mathrm{P}_{\text {system }}, \Delta \mathrm{P}_{1 \text { ine }}, \Delta \mathrm{P}_{\text {meter }}$, and $\Delta \mathrm{P}_{\text {cool }}$. The term $\Delta \mathrm{P}_{\text {pump }}$ is a function of the inverse flowrate, $1 / \mathrm{dm}$, and is given by

$$
\Delta P_{\text {pump }}=\frac{b p \rho \eta}{d m}
$$

The effect of $\Delta P_{\text {pump }}$ is opposite that of the other terms in Eq. (34); hence, the opposite sign.

An initial guess for the flowrate is used to calculate the theoretical pressure drop or rise. The flowrate $\mathrm{dm}$ is iterated by using a modified Newton method [9] which is found to be stable for this application:

$$
d m_{n+1}=d m_{n}-\frac{\left(\Delta P-\Delta P_{n}\right)\left(d m_{n}-d m_{n-1}\right)}{\left(\Delta P_{n-1}-\Delta P_{n}\right)}
$$

The iteration ceases when calculated and actual pressure drops differ by less than $0.01 \%$. 


\section{FUNCTION PEFF}

The pump efficiency is calculated for an input of the flowrate from FuncTION PUMPFLO. Two different sizes of pumps are used to transfer the LOX and $\mathrm{LH}_{2}$ propellant. A linear least squares fit of data for the pump efficiency versus flowrate $[10,11]$ is used to provide a five-coefficient, fourth order equation for each pump.

The equation for the pump efficiency for $\mathrm{LH}_{2}$ is:

$$
\begin{aligned}
\eta= & 0.39213+0.096620(\mathrm{dm})+2.7793 \times 10^{-5}(\mathrm{dm})^{2} \\
& -8.1723 \times 10^{-8}(\mathrm{dm})^{3}+2.5008 \times 10^{-11}(\mathrm{dm})^{4} .
\end{aligned}
$$

The equation for the pump efficiency for LOX is:

$$
\begin{aligned}
\eta= & 0.32031+0.48261(\mathrm{dm})-1.6223 \times 10^{-3}(\mathrm{dm})^{2} \\
& +3.9836 \times 10^{-6}(\mathrm{dm})^{3}-4.8853 \times 10^{-9}(\mathrm{dm})^{4} .
\end{aligned}
$$

FUNCTION TH

SUBROUTINE COOL uses FUNCTION TH to calculate a value for the heat of expulsion for the vapor phase calculations. This thermodynamic value is defined as:

$$
\theta=v\left(\frac{\partial h}{\partial v}\right)_{P}
$$

or

$$
\theta=C_{p} \rho \frac{\left(\frac{\partial p}{\partial \rho}\right)_{T}}{\left(\frac{\partial p}{\partial T}\right)_{\rho}}
$$

The Fluids Pack subroutines DPDD and DPPT are used to find the partial derivatives in the numerator and denominator, respectively, and Fluids Pack functions are used for the specific heat and density. 
FUNCTION CWALL returns the heat capacity of the receiver tank wall at a particular temperature. It is assumed that the oxygen tank is constructed using Inconel $X-750^{\star}$ and the hydrogen tank is constructed using aluminum. The heat capacity-temperature data for these materials are of the form:

$$
C_{W}=\frac{\exp \left(C_{1}+C_{2} / T+C_{3} / T^{2}\right)}{1000}
$$

The constants $C_{1}, C_{2}$ and $C_{3}$ were determined by taking heat capacitytemperature data and applying a least-squares technique to the above equation. These values are shown in Table 5. The data used are found in Appendix $C$ $[12,13]$.

Table 5. Tank Wall Heat Capacity Constants

\begin{tabular}{ccc}
\hline & Inconel & Aluminum \\
\hline$c_{1}$ & 6.482 & 7.293 \\
$c_{2}$ & -106.3 & -121.9 \\
$C_{3}$ & 329.1 & 347.9 \\
\hline
\end{tabular}

\subsection{Program Termination}

SUBROUTINE PFAIL is the normal route for program termination. ENTRY DONE is used when the supply tank is empty, i.e., when all the propellant has been

* Such identification does not imply recommendation or endorsement by the National Bureau of Standards. 
transferred. ENTRY FULL is used when the receiver tank is full. This condition occurs if the receiver tank volume is too small, if the quantity of propellant is increased with the tank volume remaining the same, or if the mass balance on the fluid in tank is wrong. The main entry PFAIL is used to indicate a high backpressure condition. This can happen when the receiver tank pressure is greater than the supply tank pressure and a pump is not used, or when the flowrate is very small. The program will terminate if there is improper venting, i.e., when there is a measured flow through the vent, but the receiver tank pressure is less than the set vent pressure.

ENTRY PDATA in SUBROUTINE PFAIL is used when a programmed stop is executed. This exit is used in several locations in the main program and cool down subroutine, and it is also used by functions DVDPV, DVDPL, DUDPL, DTDP, ALPHAL, FLO, and PUMPFLO and subroutine SUPPLY. The COMMON parameter DUMP normally has a value of zero until a cause for termination is reached in one of the previously 1isted program sections. DUMP is reset to a value of 1.0 . When the condition for termination occurs in a function, the program flow is returned to either SCAVAG or COOL. The run continues to the end of the present integration 10op, when the parameter DUMP is evaluated. If DUMP equals 1.0, ENTRY PDATA is called, and the output files are replaced prior to termination.

Several subprograms use convergence criteria to obtain specific thermodynamic conditions. SUBROUTINE COOL checks for the condition when the density in the tank is greater than the saturation density, i.e. both liquid and vapor are present in the tank, and the calculations return to the main program. If two phases are not obtained within the array size limit, the program prints an error message and stops.

Functions DVDPV, DVDPL, DUDPV, DUDPL, DTDP, and ALPHAL use derivative approximations that depend on the change in thermodynamic properties about a small interval. The first five functions listed above evaluate the specific 
volume, internal energy, or temperature about a small pressure interval, while ALPHAL evaluates the density about a small temperature interval. In all cases, the program will terminate should the convergence of the properties about the specified interval not be reached within 100 iterations. The message, "KOUNT exceeds 100," noting the particular function, will be printed.

FUNCTION FLO uses the Fanning friction factor calculated in FUNCTION FRICT as its convergence criterion. The flowrate found in FLO is an input for FRICT, which in turn determines the friction factor used in the flowrate calculation. The convergence of the successive values should occur within 100 iterations, or the message, "KOUNT exceeds 100 for FLO," is printed on program termination.

FUNCTION PUMPFLO checks the convergence of the actual pressure difference between the tanks and the calculated pressure drop through the piping using a pump. If the convergence between the two does not happen within 100 iterations, a message is printed and the program is stopped.

The supply tank thermodynamics are checked for errors in calculation or intolerable operating conditions in SUBROUTINE SUPPLY. When the calculated liquid enthalpy is significantly different from the enthalpy found in Fluids Pack, the program terminates with the message, "ENTHALPY DISPARITY," and prints the two values in disagreement. If the quality of the fluid is greater than one part in one million, there exists the possibility for cavitation. The program terminates with this condition and an error message, "ET LIQ BOILING. STOP TRANSFER."

\subsection{Programming Information}

A brief description will be given for a typical run of the program. The information provided in this section is based on procedures used with the CDC 
Cyber 750 Computer System and the NOS Version 1 operating system on location at NBS in Boulder. The program is written in FORTRAN IV. These procedures should be transferable to the computer system at NASA-JSC with minor modifications. See Appendix G for program listings.

\section{File Manipulation}

All computer programs, data, and control procedures for running PROGRAM SCAVAG are stored in files. At NBS, SCAVAG is stored in filename COMBO; the input data are stored in filenames DATAIN or FUEL; output data are located in filenames PSDATA and PSOUT; and the control procedure is stored in filename SUBCOM.

Before running PROGRAM SCAVAG, the operator must prepare the control procedure and the input files. The control procedure that NBS has used, SUBCOM, retrieves COMBO, DATAIN, and BOXB (containing Fluids Pack) from permanent storage and places them into a local or usable state. SUBCOM compiles COMBO and, if the compilation is free of errors, loads and executes the compiled version.

The operator enters the following command on a time-sharing terminal to run the program:

\section{SUBMIT, SUBCOM}

This statement is a batch command which means the operator cannot interact, alter, or stop the execution of the program or job. To determine when the program has stopped, the operator can check the status of the job, or a file named DAYF. This file is created by SUBCOM to record the real time sequence of control procedures performed by the computer during program execution. 
The program operator must determine which propellant and values for the initialized parameters are to be used. If LOX is the desired propellant, the namelist FUEL must be modified to the following form:

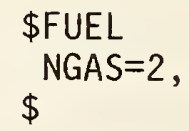

If $\mathrm{LH}_{2}$ is chosen, FUEL should have either of the following forms:

or

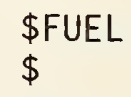

Namelist FUEL is contained in a file named FUEL. No decimal point is used since NGAS is an integer.

To change values for the initialized variables, similar steps are used with namelist NAME. NAME is contained in a file called DATAIN. Any number of changes can be made for the parameters listed in Table 1 . For instance, to change the initial supply tank temperature and pressure, the quantity of propellant to be transferred, the pump power, and the length of straight pipe for the $\mathrm{LH}_{2}$ system, one would alter NAME to the following form:

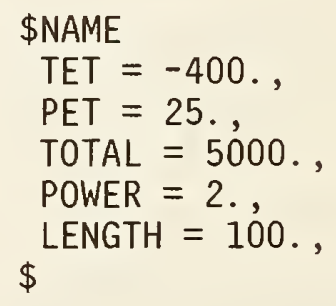

Since all the chosen variables are real, the values must have decimal points. A1l values are entered in English units. If no changes are desired, NAME must have the following form: 
The program statement defines TAPE5 and TAPE7 for use during the program. SUBCOM, which directs the sequence of operating steps for running the program, sets TAPE5 equal to filename DATAIN, or namelist NAME, and TAPE7 equal to filename FUEL, or namelist FUEL. These files must exist in order to run the program.

\section{Output}

The output from program SCAVAG is directed to two locations. While SCAVAG is running, the graphic display data is written to TAPE8 and stored in filename PSDATA. When SCAVAG terminates, the termination message and initialized parameters are written to TAPE6 and stored in filename PSOUT. See Table 6 for sample output for $\mathrm{LH}_{2}$. The operator can access PSOUT at a later point for further evaluation.

Two FORTRAN programs utilize the data in PSDATA to produce plots describing the transfer. The first program is called PLOT. At NBS PLOT is attached to the job by the control procedure SUBCOM and run after SCAVAG has terminated. The plots that are drawn use the computer systems mathematics library (called STARPAC at NBS in Boulder) and are written to TAPE6, following the output described above. The entire contents of TAPE6 are stored in PSOUT. (Further explanation is given in Appendix F.)

The second program which uses PSDATA is called DEMO. The graphics package called DISSPLA (15) is utilized to produce plots which are more refined than those generated through PLOT. (Additional details about DEMO can be found in Appendix F.) The plots are directed to one of three output devices by selecting the appropriate CALL statement in DEMO. For the computer system at NBS CALL HP7221 accesses a multiple pen plotter; CALL TK4010(960) accesses 
Supply tank initial conditions:

Pressure
Temperature
Hydrogen Mass
Heat Leak

Receiver tank initial conditions:

$\begin{array}{rll}32.000 & \text { psia } & (0.221 \mathrm{MPa}) \\ -425.000 & \mathrm{~F} & (19.1 \mathrm{~K}) \\ 3098.00 & \text { Pounds } & (1405.2 \mathrm{~kg}) \\ 90000.000 & \text { Btu/hr } & (26376.3 \mathrm{~W})\end{array}$

18.000 psia $-290.000 \mathrm{~F}$

30.000 psia 780.000 Cubic Feet

975.000 Pounds

$0.000 \mathrm{Btu} / \mathrm{hr}$

$(0.124 \mathrm{MPa})$

(94.1 K)

$(0.207 \mathrm{MPa})$

$(22086.5 \mathrm{~kg})$

$(442.2 \mathrm{~kg})$

$(0.0 \mathrm{~W})$

Transfer Parameters:

Pipe Diameter

Length of Straight Pipe

10 Elbow(s)

$$
\begin{aligned}
& 0 \text { Gate Valve(s) } \\
& 2 \text { Globe Valve(s) } \\
& 0 \text { Angle Valve(s) } \\
& 0 \text { Butterfly Valve(s) } \\
& 1 \text { Flow Meter (s) }
\end{aligned}
$$

Heat Leak Into Piping

Pump Power

$\begin{aligned} 5.000 & \text { Inches } \\ 70.000 & \text { Feet }\end{aligned}$

$(12.7 \mathrm{~cm})$

70.000 Feet

$(21.34 \mathrm{~m})$

$\begin{array}{cll}50400.000 & \mathrm{Btu} / \mathrm{hr} & (14770.7 \mathrm{~W}) \\ 0.0 & \mathrm{HP} & (0.0 \mathrm{~W})\end{array}$

Coo1-Down Parameters:

Length of Piping

Number of Nozzles

Nozzle Diameter

Header Diameter
20.000 Feet
0.500 Inches
2.000 Inches
0.1754 minutes

At 2.344 minutes from start of propellant transfer the supply tank is empty. At this time the, receiver tank is at $-422.89^{\circ} \mathrm{F}(20.3 \mathrm{~K}), 16.23$ psia $(0.112$ $\mathrm{MPa})$, and contains 3098.00 pounds $(1405.2 \mathrm{~kg})$.

During the simulation 0.00 pounds $(0.0 \mathrm{~kg})$ were vented.

Supply tank is at $-424.9907^{\circ} \mathrm{F}(19.1 \mathrm{~K}), 31.55 \mathrm{psia}(0.218 \mathrm{MPa})$. 
a graphics terminal; CALL FR80(0.0) accesses microfilm. The running of program DEMO is separate from running SCAVAG and PLOT. Examples of plots from program DEMO are found in Appendix G. 


\section{RESULTS AND DISCUSSION}

The feasibility of low-g propellant transfer is analyzed parametrically with the computer model. Particular emphasis is placed on the thermodynamic changes to the system caused by varying the temperature, pressure, or heat leak at any point. The principal parameter in this investigation is the overall time of transfer, since the transfer is to take place during a mated coast period after MECO. Other parameters of interest in the design of such a system are the pump size and piping requirements.

Nozzles are used during the cooldown of the receiver tank to induce a flowrate of propellant lower than the flowrate during the main part of the transfer. The sizes of the associated piping and nozzles, which are simply small orifices situated around the header, have been parametrically determined to accomplish a low flowrate without causing an excessive pressure drop. This specification holds except in those cases where the transition from the main piping to the cooldown piping is great. (Further explanation is provided later.) When two phases occur in the tank, the nozzles are shut off; the transfer via the main line resumes for the remainder of the simulation.

Because the transfer can require a pump, the liquid from the ET must be subcooled to prevent cavitation. This is most notably the case for LoX which has insufficient ullage pressure to accomplish a complete pressurized transfer. Single-phase flow from the supply tank also requires sufficient thrust to settle the liquid against the outlet port. We assume such a thrust for the purposes of this modelling effort.

When the program is run with the default parameters, the time required to complete the transfer of either propellant is relatively short. Transfer of LOX with a moderately sized booster pump takes 1.94 minutes; pressurized transfer of $\mathrm{LH}_{2}$ requires 2.34 minutes. If the MECO mated coast period is 
scheduled to continue to 20 minutes, the scavenging of both cyrogenic

propellants can be completed in less than 12 percent of the alloted time. The final system conditions are shown in Table 7. Plots of the transfer are found in Appendix G.

Table 7. Final Conditions Using Default Values

\begin{tabular}{|c|c|c|c|c|}
\hline & $\mathrm{O}_{2}$ & & $\mathrm{H}_{2}$ & \\
\hline Time of Transfer, min & 1.936 & & 2.344 & \\
\hline $\begin{array}{l}\text { Receiver Tank } \\
\text { Temperature, }{ }^{\circ} \mathrm{F}(\mathrm{K}) \\
\text { Pressure, psia (MPa) } \\
\text { Mass in Tank, } 1 \mathrm{~b}(\mathrm{~kg}) \\
\text { Mass Vented, } 1 \mathrm{~b}(\mathrm{~kg})\end{array}$ & $\begin{array}{c}-312.35 \\
6.72 \\
6270 . \\
0 .\end{array}$ & $\begin{array}{l}(81.69) \\
(0.046) \\
(2846.6)\end{array}$ & $\begin{array}{c}-422.89 \\
16.23 \\
3098 . \\
0 .\end{array}$ & $\begin{array}{l}(20.28) \\
(0.112) \\
(1405.2)\end{array}$ \\
\hline $\begin{array}{l}\text { Supply Tank } \\
\text { Temperature, }{ }^{\circ} \mathrm{F}(\mathrm{K}) \\
\text { Pressure, psia (MPa) }\end{array}$ & $\begin{array}{c}-314.9998 \\
19.88\end{array}$ & $\begin{array}{l}(80.22) \\
(0.137)\end{array}$ & $\begin{array}{c}-424.9907 \\
31.55\end{array}$ & $\begin{array}{l}(19.12) \\
(0.217)\end{array}$ \\
\hline
\end{tabular}

\subsection{Heat Leaks to the System}

The conditions in the ET are governed by two opposing influences: outflow and heat leak. In the absence of heat leak, outflow gives an adiabatic expansion of the vapor and a resulting decay in temperature. In the absence of outflow, heat leak gives an increase in temperature and pressure. Figures 4 and 5 show the expected results of varying the amount of heat to the ET. Figure 4 shows that a large rate of heat flow into the LOX ET must be present for a significant change in the system parameters to occur. 


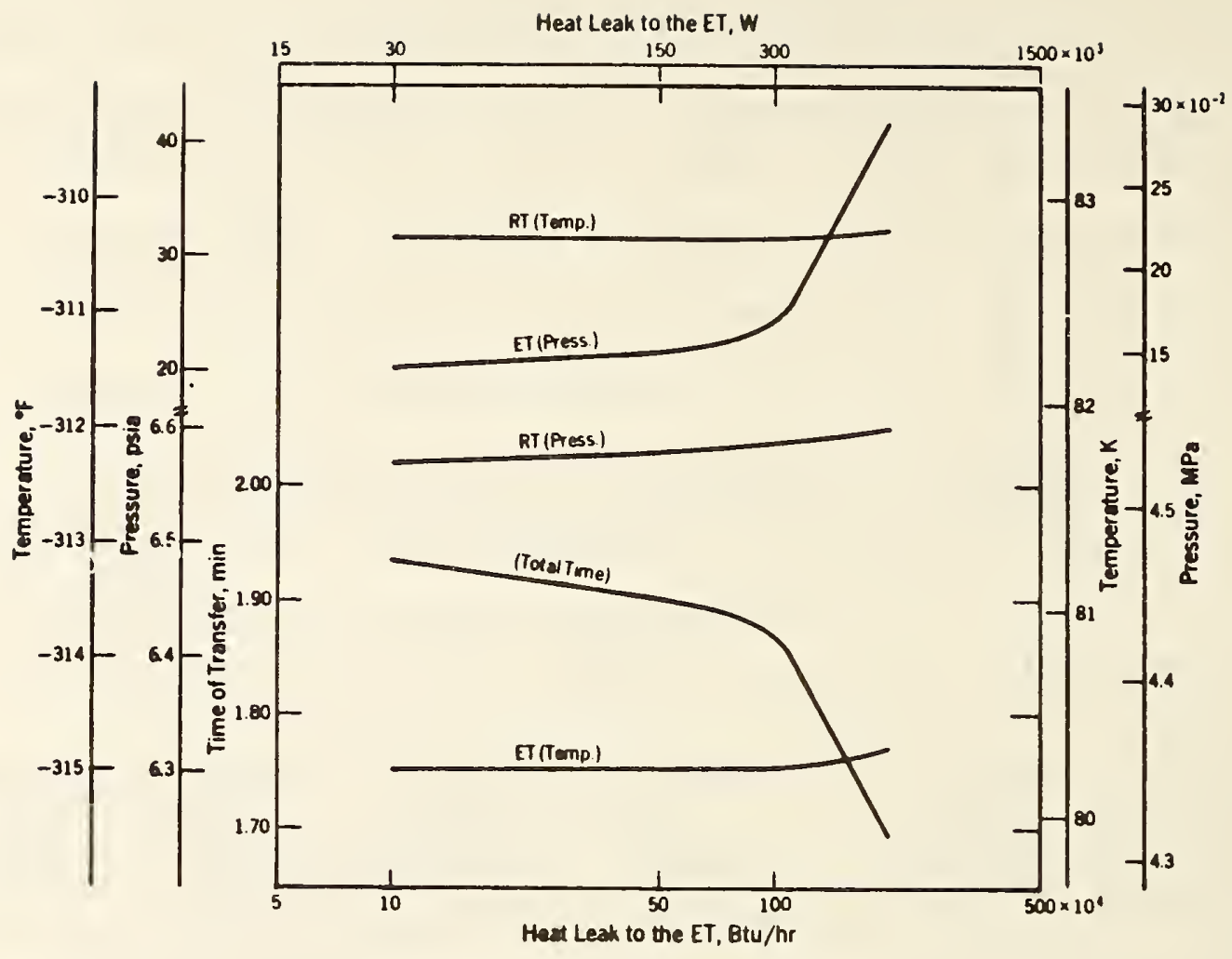

Figure 4a. Effect of varying the heat leak to the ET, LOX (default: $0 \mathrm{Btu} / \mathrm{hr}(\mathrm{OW})$ )

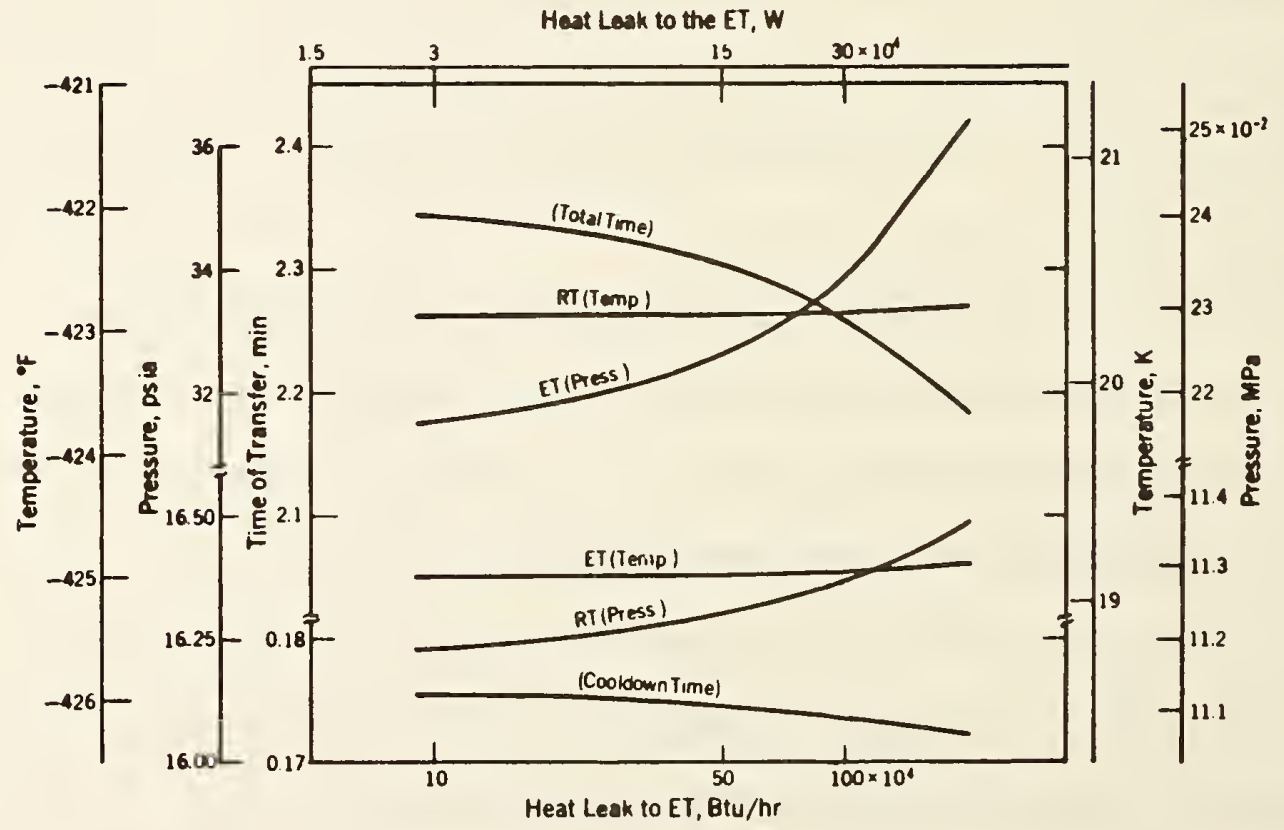

Figure 4b. Effect of varying the heat leak to the ET, LH 2 (default: $\left.90,000 \mathrm{Btu} / \mathrm{hr}\left(2.6 \times 10^{4} \mathrm{~W}\right)\right)$ 


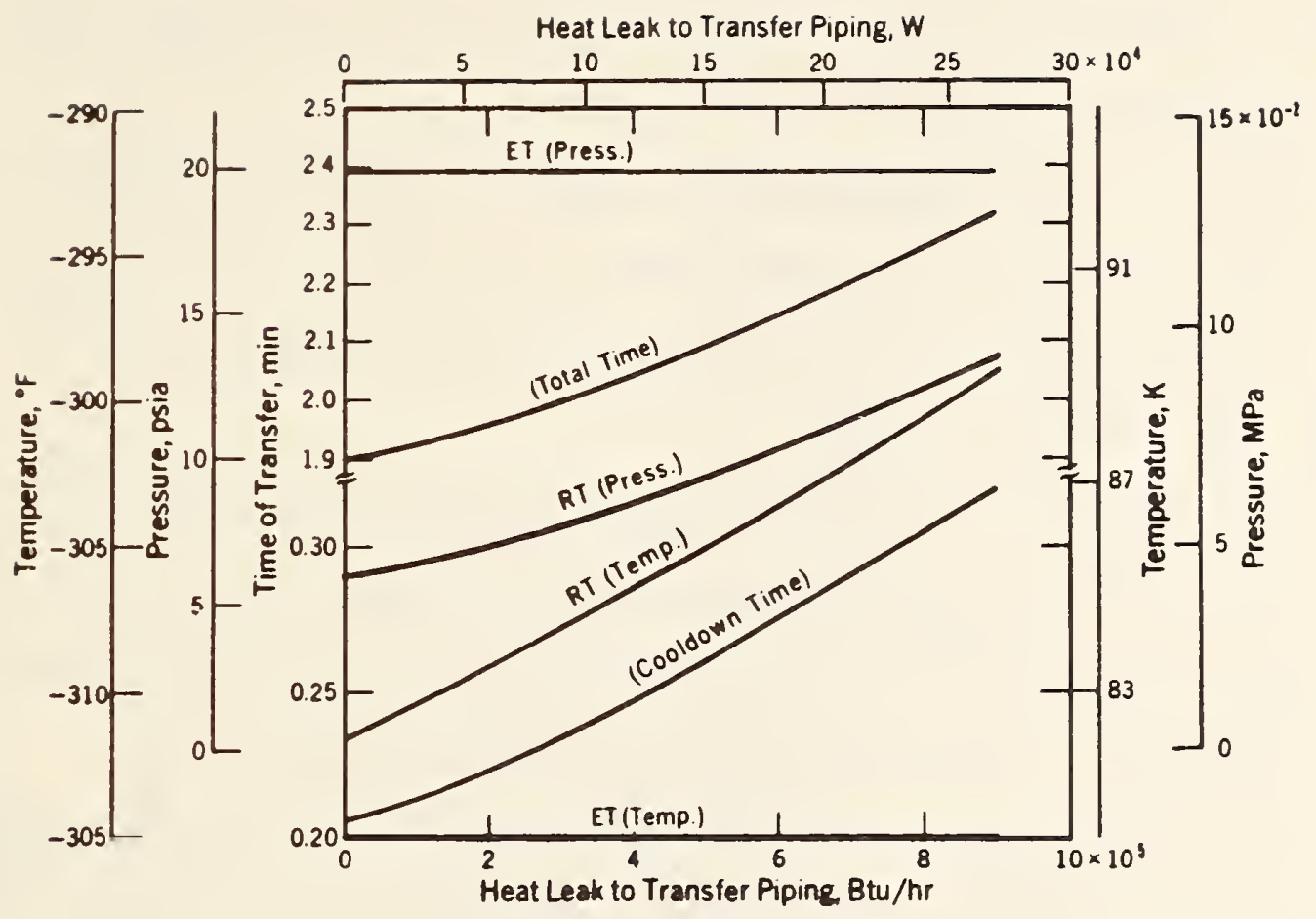

Figure 5a. Effect of varying the heat leak to the transfer piping, LOX (defualt: $104,400 \mathrm{Btu} / \mathrm{hr}\left(3.0 \times 10^{4} \mathrm{~W}\right)$ )

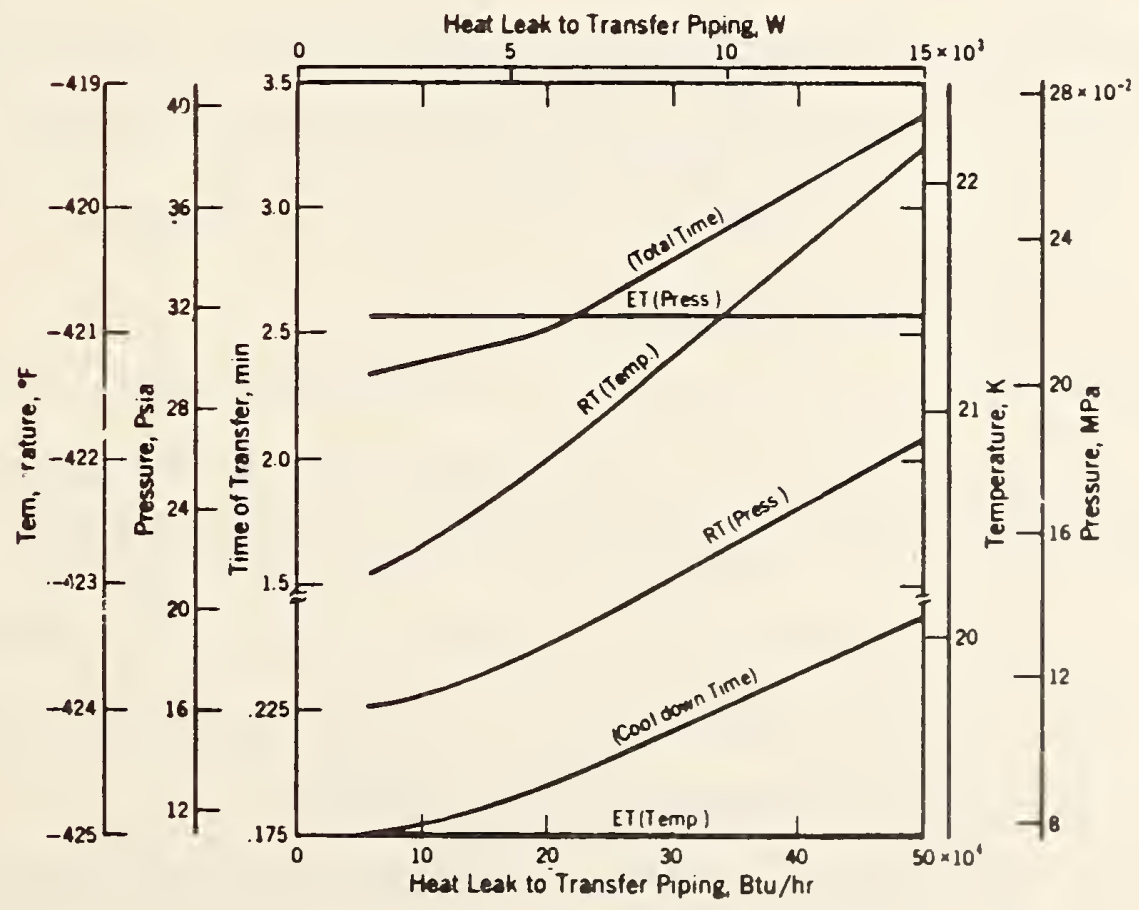

Figure 5b. Effect of varying the heat leak to the transfer piping, $\mathrm{LH}_{2}$ (default: $50,400 \mathrm{Btu} / \mathrm{hr}\left(1.5 \times 10^{4} \mathrm{~W}\right)$ ) 
The value at which this occurs is on the order of $10^{6} \mathrm{Btu} / \mathrm{hr}\left(2.9 \times 10^{5} \mathrm{~W}\right)$. The pressures in both tanks undergo rapid increases, while the temperatures show slight increases.

The changes in temperature and pressure that the $\mathrm{LH}_{2}$ system experiences are less abrupt than those of the LOX system. They do show the same trends, however. As the heat leak to the ET is increased, the pressures and temperatures show gradual increases.

As the heat leak to the transfer piping is increased, the final conditions in the receiver tanks for both propellants show a corresponding rise greater than the results for a heat leak to the ET. The results are presented in Figure 5. Venting occurs for LOX when the heat input is increased to $5 \times 10^{6} \mathrm{Btu} / \mathrm{hr}\left(1.5 \times 10^{6} \mathrm{~W}\right)$; approximate $1 \mathrm{y} 28 \%$ of the prope 11 ant is vented. The LOX temperature of $-284.29^{\circ} \mathrm{F}(97.28 \mathrm{~K})$ at the vent pressure is located at the liquid-vapor boundary. The pressure history for this transfer is shown in Figure 6 .

Similar observations can be stated for the case of $\mathrm{LH}_{2}$. When the heat leak to the transfer piping is increased to $10^{6} \mathrm{Btu} / \mathrm{hr}\left(2.9 \times 10^{5} \mathrm{~W}\right)$, a small amount of fuel is vented. This occurs at the end of the transfer, as the fluid reaches the liquid-vapor boundary.

Conditions in the ET do not vary with an increased heat leak to the piping. This is due to the flow of cryogen from the tank which directs any potential effects to the receiver tank. The overall time of transfer increases linearly for both $\mathrm{LOX}$ and $\mathrm{LH}_{2}$. The time required to transfer LOX remains quite brief, but the transfer requires an additional minute when $5 \times 10^{5} \mathrm{Btu} / \mathrm{hr}\left(1.5 \times 10^{5} \mathrm{~W}\right)$ leaks into the $\mathrm{LH}_{2}$ piping.

The effect of heat leak into the receiver tank is similar to that into the transfer piping. For $\mathrm{LH}_{2}$ the transfer time is increased by nearly a minute for a heat rate of $4 \times 10^{5} \mathrm{Btu} / \mathrm{hr}\left(1.2 \times 10^{5} \mathrm{~W}\right)$. Increasing the heat 


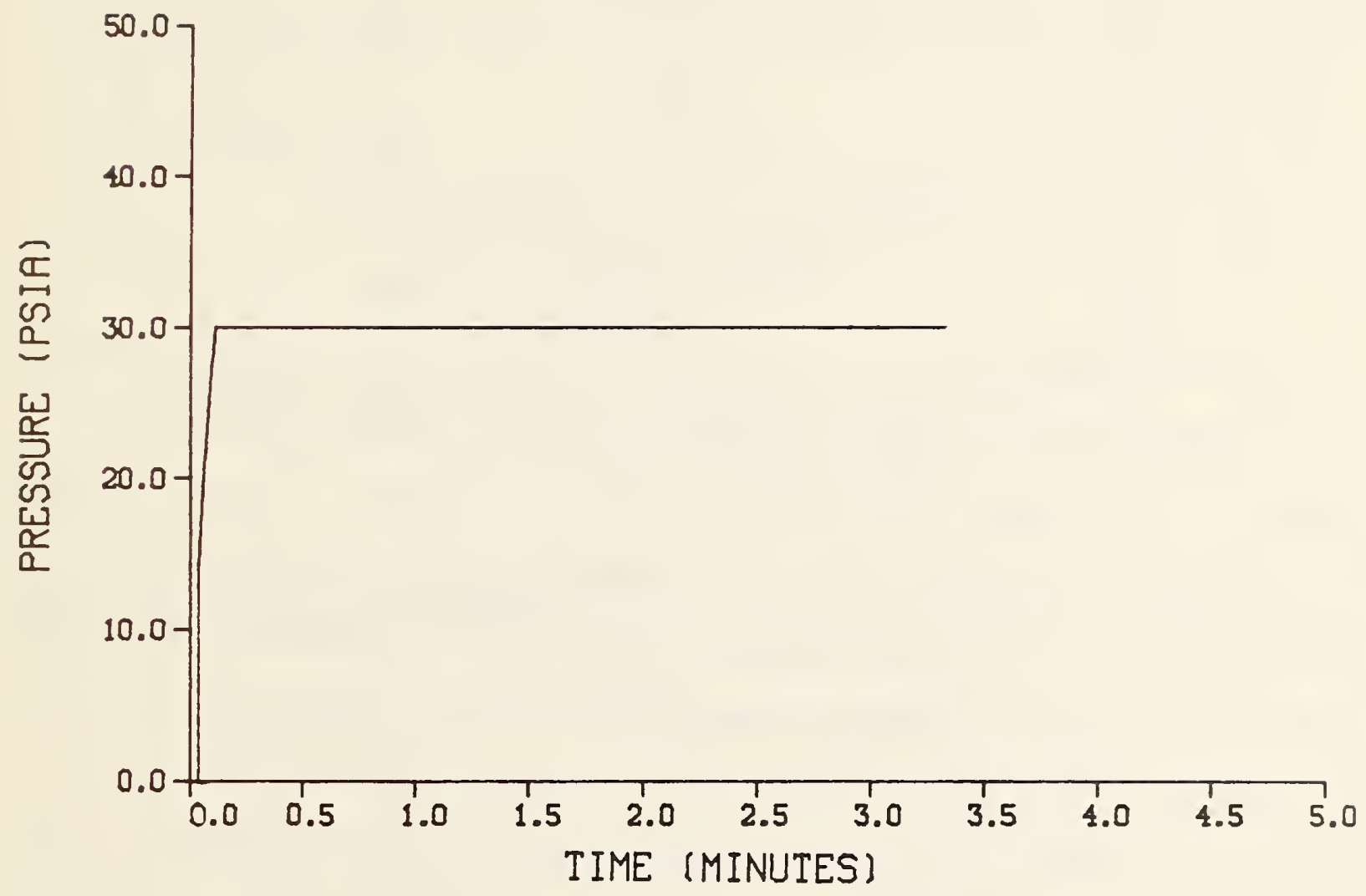

Figure 6. Pressure history of LOX transfer for a heat leak of $2 \times 10^{6} \mathrm{Btu} / \mathrm{hr}$ $\left(5.8 \times 10^{5} \mathrm{~W}\right)$ to the transfer piping 
leak to the receiver tank at the rate of $10^{6} \mathrm{Btu} / \mathrm{hr}\left(2.9 \times 10^{5} \mathrm{~W}\right)$ causes $\mathrm{LH}_{2}$ to vent. The transfer time for LOX rises smoothly with increased heat input; an additional minute is required to transfer LOX at a heat leak of $1.2 \times 10^{6}$ $\mathrm{Btu} / \mathrm{hr}\left(3.5 \times 10^{5} \mathrm{~W}\right)$. Also, venting takes place at this rate of heat addition. These results are shown in Figure 7.

\subsection{Receiver Tank Temperature}

Since the temperature for the LOX receiver tank is unspecified in the study by Brux and Stefan [1], the effects of several temperatures were examined in this study. The results are shown in Figure 8 . It can be assumed that the receiver tank will receive some soakback heat leak from the insulation as well as radiation prior to MECO. Thus, temperatures higher than cryogenic are realistic and allow examination of the chilldown process. A wide range of initial temperatures neither significantly alters the time required to transfer the oxygen nor the final receiver tank temperature. The coolest temperature input of $-100^{\circ} \mathrm{F}$ ( $199.7 \mathrm{~K}$ ) would require the vessel to be prechilled on the ground. For temperatures above $120^{\circ} \mathrm{F}(321.8 \mathrm{~K})$ a small amount of venting (less than 1 percent) takes place at the beginning of transfer. This rapid increase of the RT pressure to the vent pressure is shown in Figure 9.

The study by Brux and Stefan [1] recommends that the $\mathrm{LH}_{2}$ receiver tank be prechilled to $-290^{\circ} \mathrm{F}(94.1 \mathrm{~K})$ to prevent venting during the transfer after MECO. They state that at higher temperatures, a large amount of venting would be required to achieve chilldown of the receiver tank. We find that only minor venting at the start of the transfer takes place when given an initial temperature between $-250^{\circ} \mathrm{F}(116.3 \mathrm{~K})$ and $-50^{\circ} \mathrm{F}(227.4 \mathrm{~K})$. For all cases, the overall time of transfer is less than 2.80 minutes. 


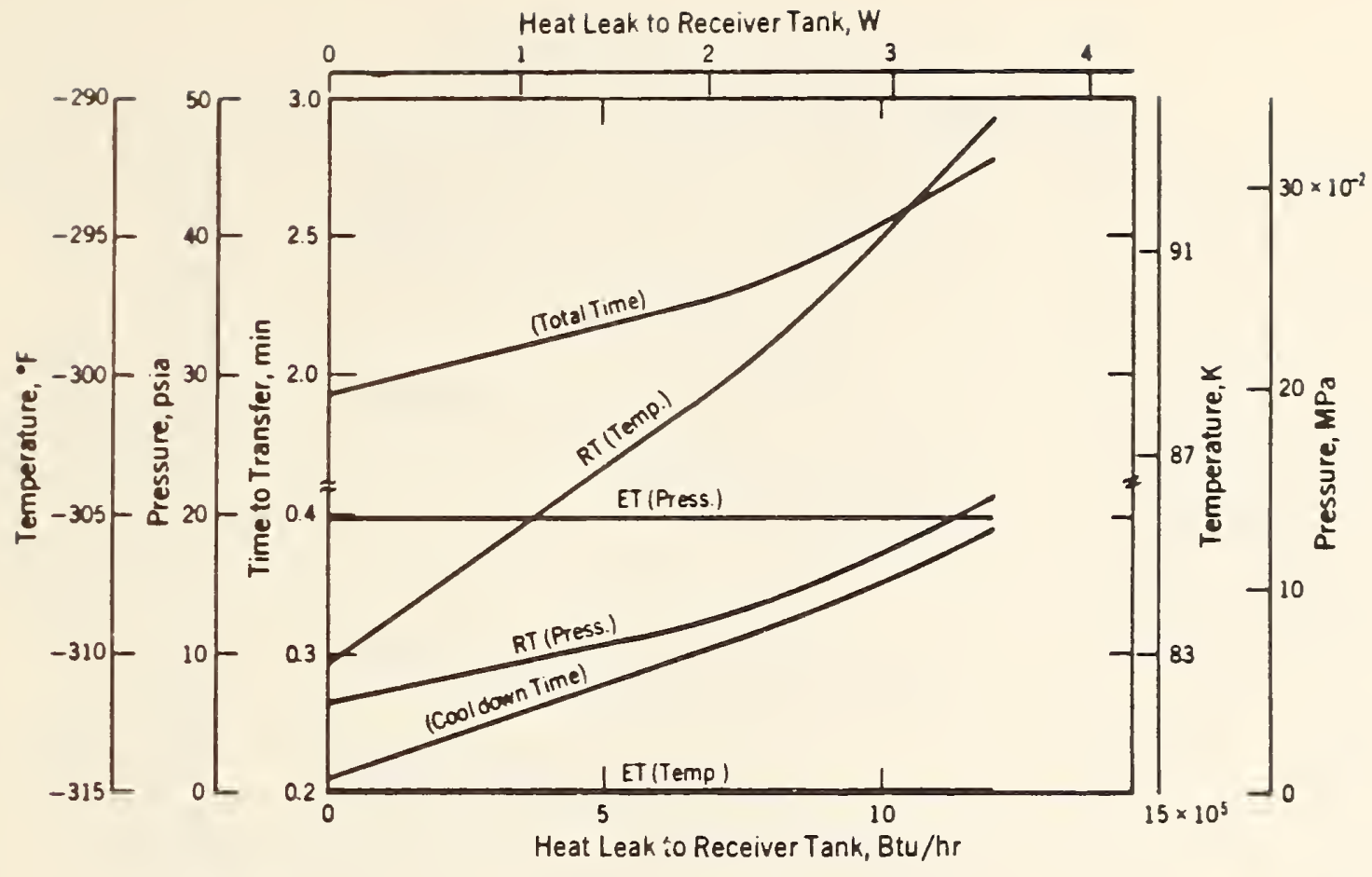

Figure 7a. Effect of varying the heat leak to the receiver tank, LOX (default: 0 Btu/hr $(0 \mathrm{~W})$ )

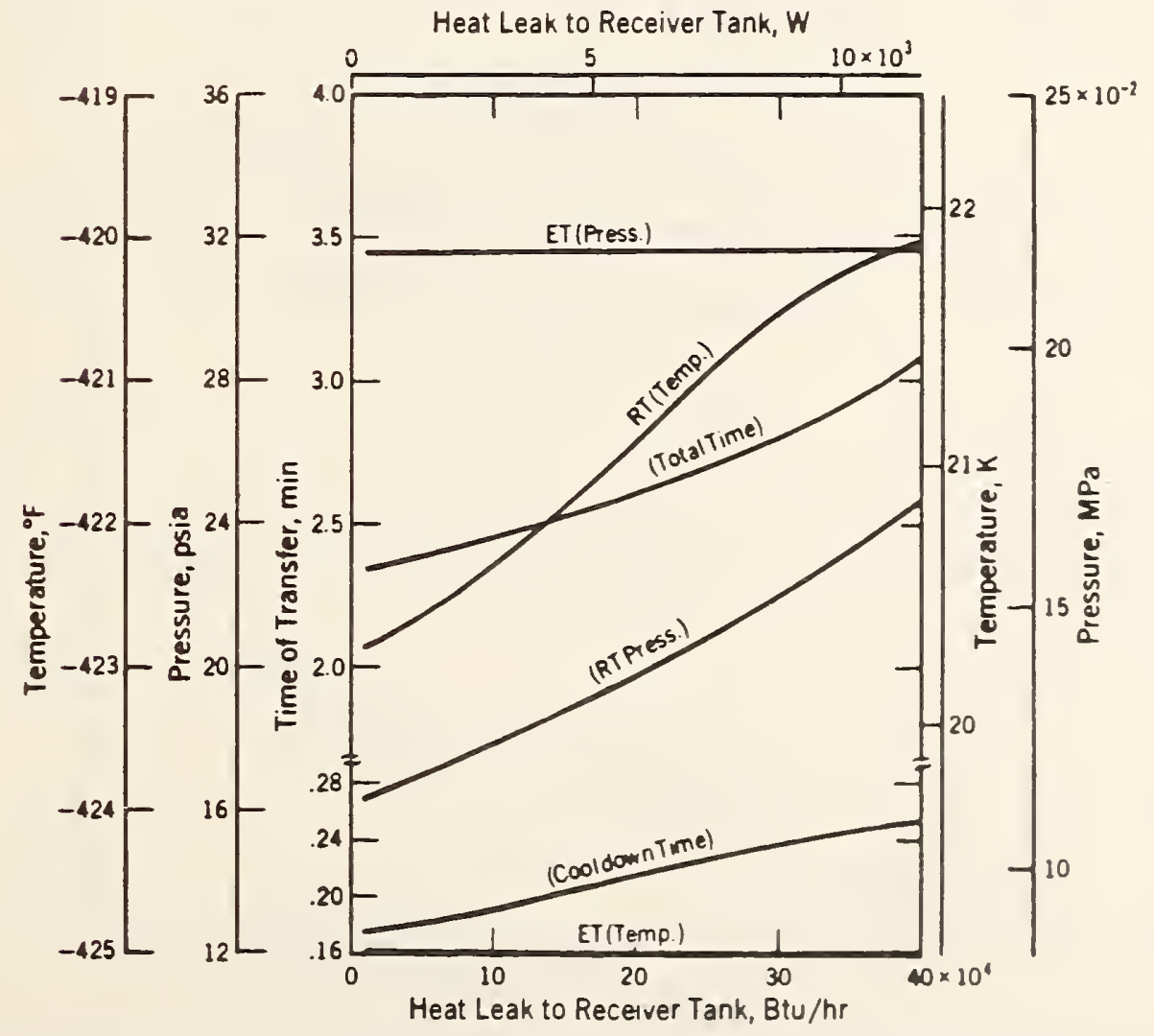

Figure 7b. Effect of varying the heat leak to the receiver tank, $\mathrm{LH}_{2}$
(default: $0 \mathrm{Btu} / \mathrm{hr}(\mathrm{OW})$ ) 


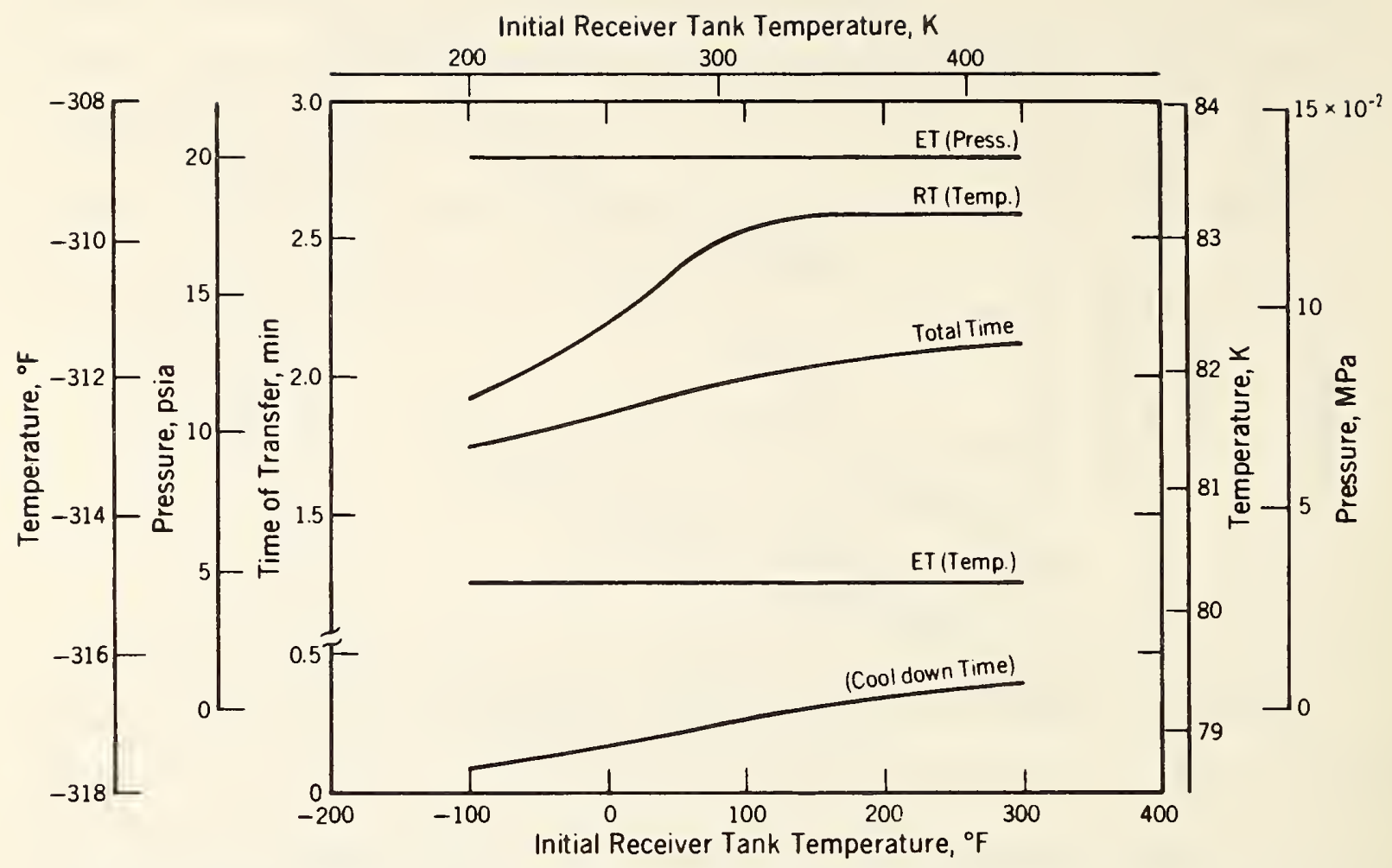

Figure 8a. Effect of varying the initial receiver tank temperature, LOX (default: $60^{\circ} \mathrm{F}(288.6 \mathrm{~K})$ )

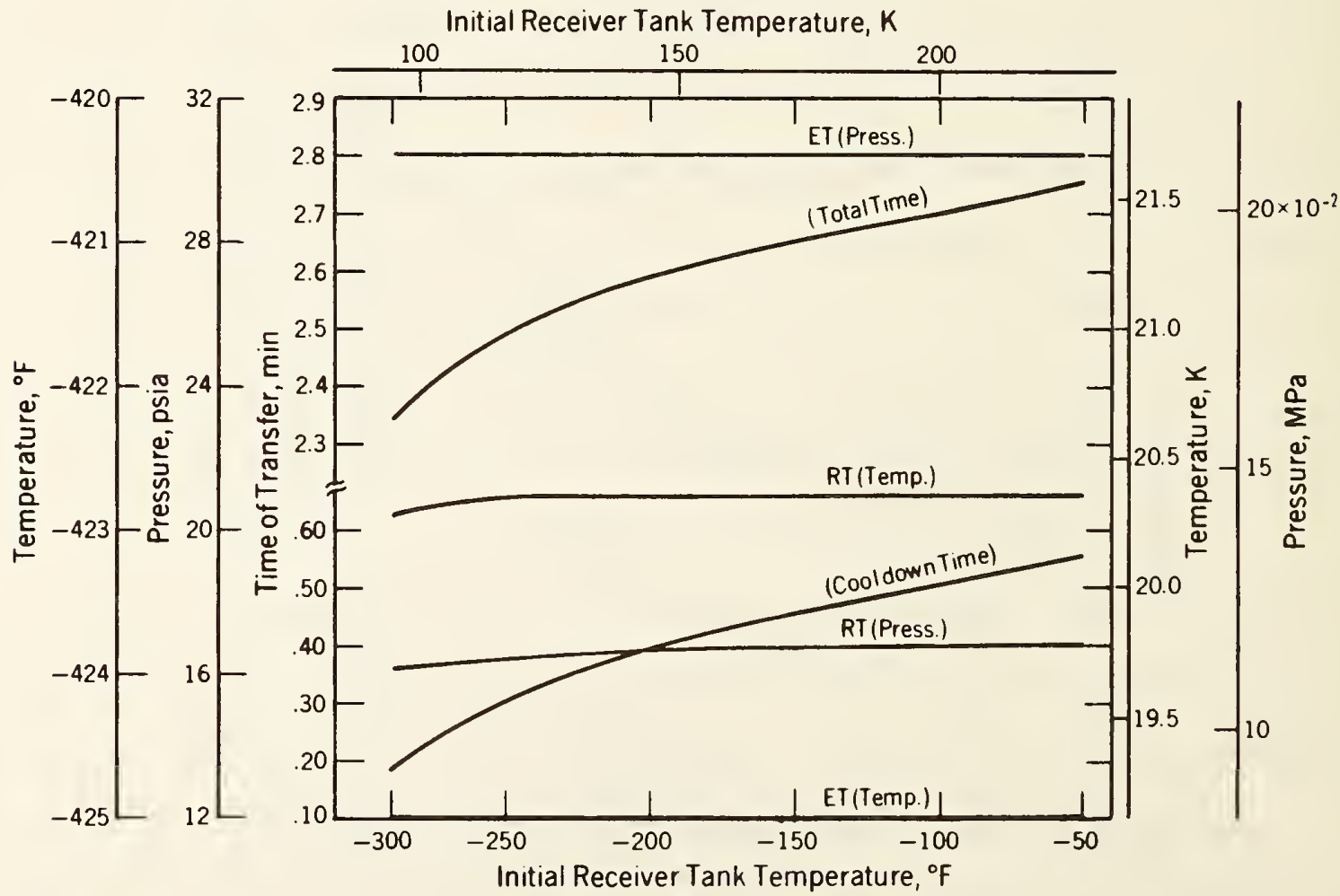
Figure 8b. Effect of varying the initial receiver tank temperature, $\mathrm{LH}_{2}$
(default: $-290^{\circ} \mathrm{F}(94.1 \mathrm{~K})$ ) 


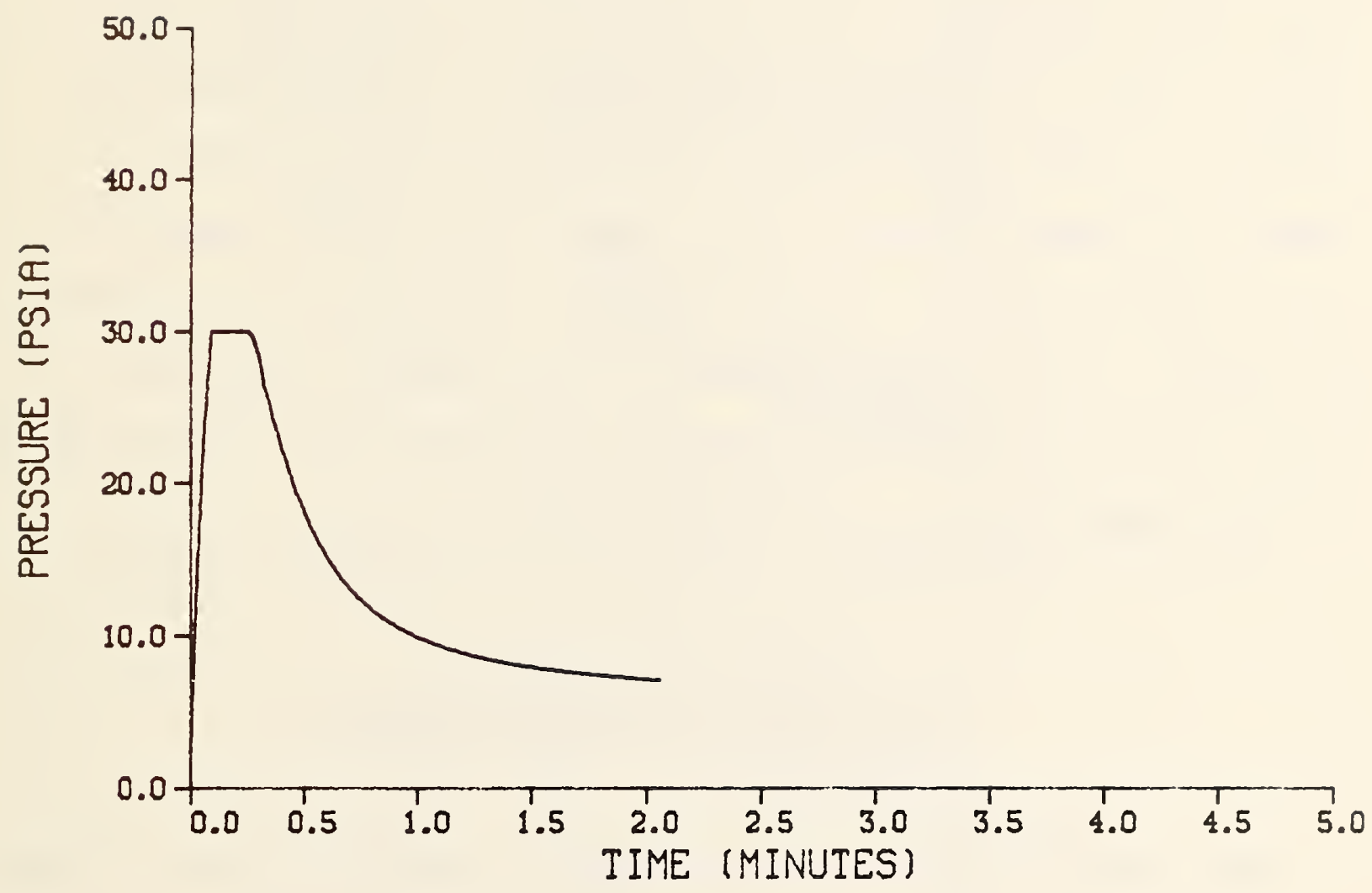

Figure 9. Pressure history of LOX transfer for an initial receiver tank temperature of $200^{\circ} \mathrm{F}(366.3 \mathrm{~K})$ 


\subsection{ET Temperature}

Since the previous study [1] indicates the ET fluid is subcooled, the default initial temperatures in this study were between the melting line and the liquid-vapor boundary $[3,4,5]$. Increasing the ET initial temperatures cause longer transfer times, while additional cooling accomplishes the transfer faster. As the melting line temperature of either propellant is approached, failure of the Fluids Pack [2] routine occurs. When the temperature reaches the vapor-liquid boundary, the simulation stops due to vapor induced cavitation. Because the transfer of $\mathrm{LH}_{2}$ is pressure induced, the transfer times are significantly affected by warmer ET temperatures. Additional cooling time is required before the switch to the transfer mode through the main piping.

\subsection{Pipe Size and Pump Requirement}

When the values for line size and pump power suggested by Brux and Stefan [1] are used in the model, the time required to transfer the nominal quantity of either propellant is less than 3 minutes. Because the mated coast period after MECO probably will be somewhat longer than this, transfer times of approximately 8 minutes or less appear reasonable. Such transfer times are obtained with a number of cases where the transfer pipe diameter or the pump size is changed. Figure 10 illustrates these changes.

If the LOX default pump size remains unchanged at 4 HP (2982.8 W) while the line size is reduced to 2 inches $(5.1 \mathrm{~cm})$, the transfer time is slightly less than 7 minutes. When the pump size is reduced by half, the transfer time is less than 4 minutes for a $3-i n c h(7.6 \mathrm{~cm})$ diameter pipe. Line sizes of 


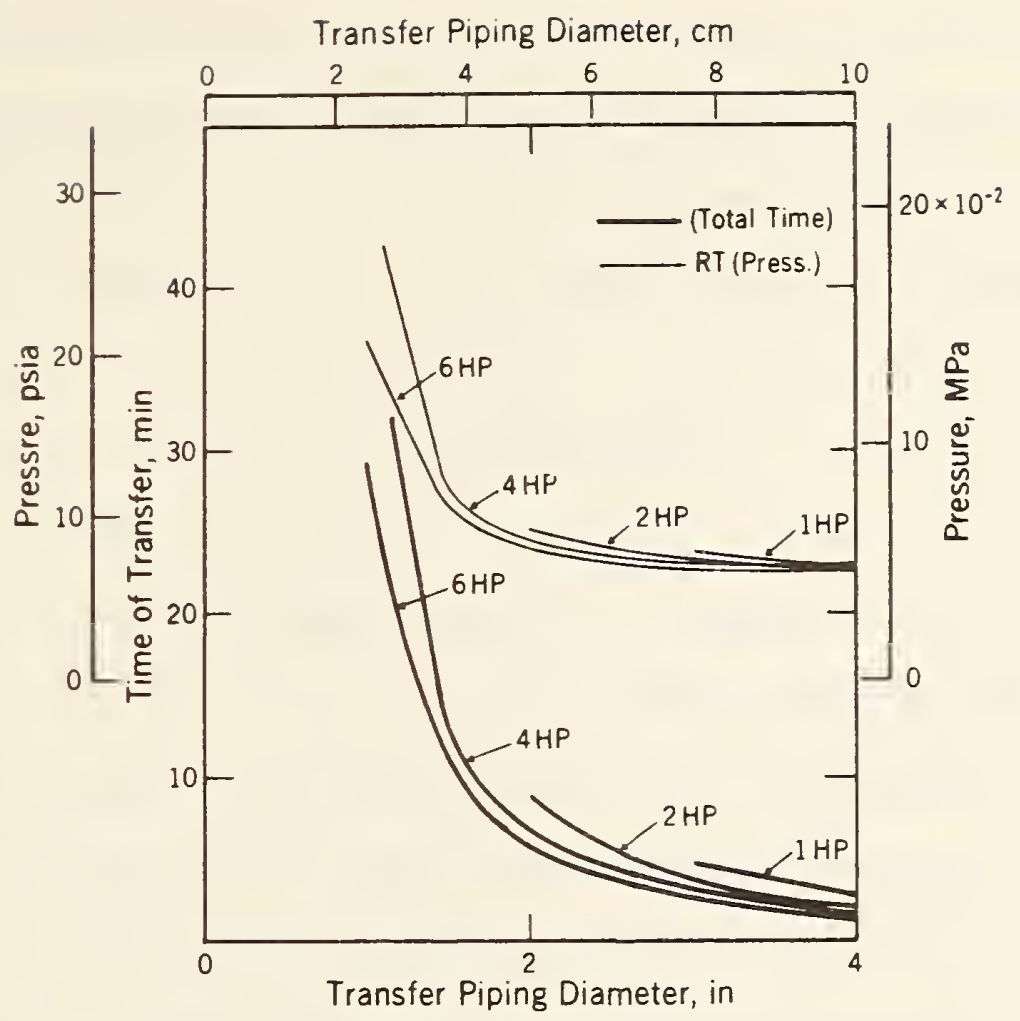

Figure 10a. Effect of varying the pump or transfer line sizes, LOX (default: $4 \mathrm{HP}(2982.8 \mathrm{~W}), 4$ in $(10.2 \mathrm{~cm})$ )

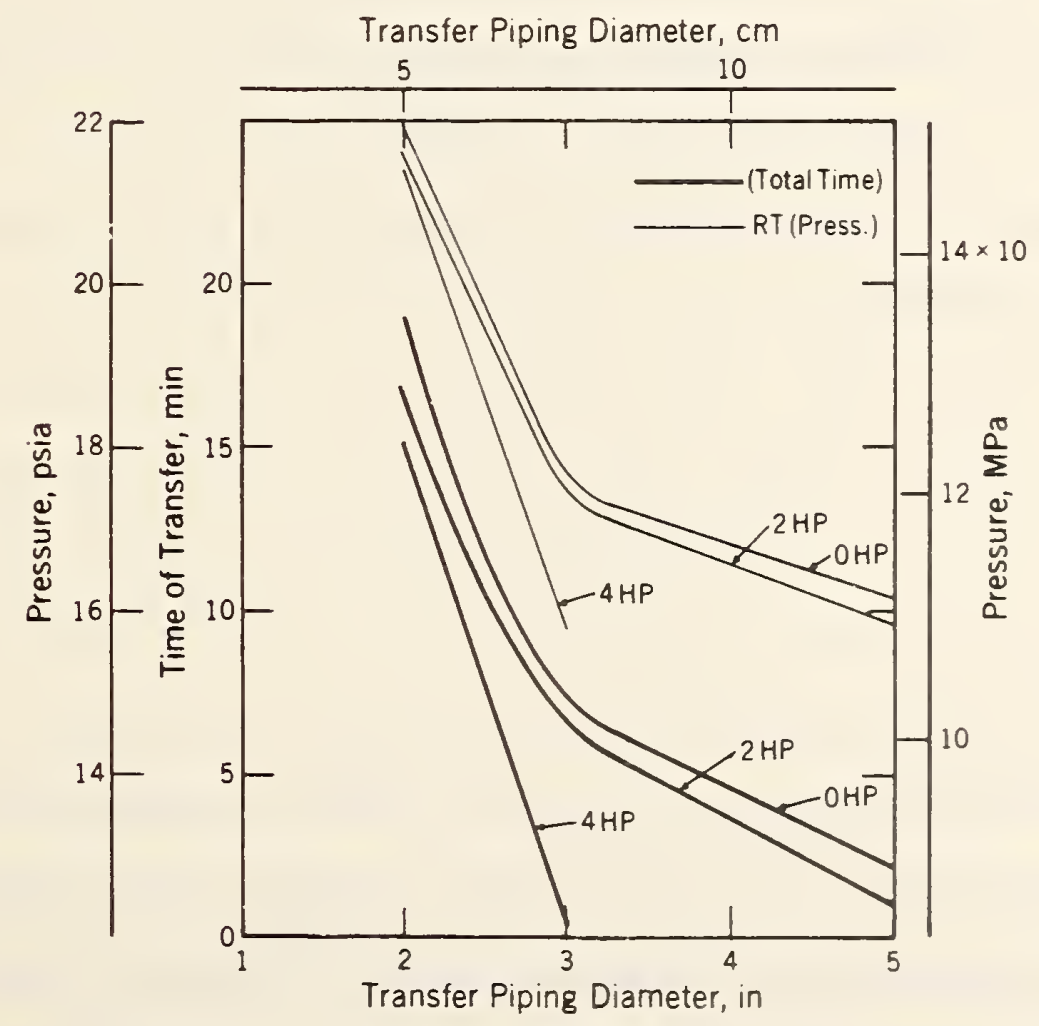

Figure 10b. Effect of varying the pump or transfer line sizes, $\mathrm{LH}_{2}$ (default: OHP (OW), 5 in $(12.7 \mathrm{~cm})$ ) 
approximately 1 inch $(2.5 \mathrm{~cm})$ appear to restrict the flow too much and cause venting in the receiver tank and extremely long transfer times. A 6-inch $(15.2 \mathrm{~cm})$ line size promotes a fast transfer of the remaining Lox propellant, but it also is heavy; no further study of this line size was done. Since the smaller line sizes would be lighter, easier to design around the existing equipment, and less costly, reducing the line size from the default value of 4 inches $(10.1 \mathrm{~cm})$ to 3 inches $(7.6 \mathrm{~cm})$ is a reasonable exchange for the increase in transfer time. A pump size of 2 HP (14914.4 W) would not tax the energy requirements in the system.

Similar results are seen for $\mathrm{LH}_{2}$ scavenging. A reasonable transfer time of slightly more than 7 minutes is obtained when a 3 -inch $(7.6 \mathrm{~cm})$ line size is used without pump assist. However, there appears to be too much flow resistance in smaller line sizes, even with the assistance of a pump. Hence, longer transfer times are seen for these cases, even when a large pump is used. When a $2 \mathrm{HP}$ (14914.4 W) pump is used with 3 -inch $(7.6 \mathrm{~cm}$ ) piping, the time is reduced to slightly less than 6.5 minutes. Reducing the line size to 3 or 4 inches $\left(7.6\right.$ or $10.1 \mathrm{~cm}$ ) and pressurized transfer of $\mathrm{LH}_{2}$ is an optimum combination for the system.

\subsection{Limitations}

Accuracy for the results is limited by the size of the time step used in program. When a very small step is used, the amount of computer time required is large and consequently quite costly. Thus, the time steps used in the previously discussed analyses are large enough to allow speedy computation, yet small enough to yield reasonable accuracy. When the time step is reduced by a factor of seven in SUBROUTINE COOL and by a factor of thirteen 
in SCAVAG, the total time required to transfer LOX propellant changes by less

than 1.5 percent. However, the computer time required for this run increases by a factor of 80 .

\section{SUMMARY}

We have developed a computer model to investigate the scavenging of cryogenic propellant from the ET to shuttle mounted receiver tanks in the cargo bay. Based on the requirement that sufficient thrust exists to settle the liquid in the ET, the model predicts the successful transfer of liquid oxygen and hydrogen in short periods of time, typically less than 2.5 minutes for both $\mathrm{LOX}$ and $\mathrm{LH}_{2}$ using the default parameters in the program. A parametric analysis was performed to evaluate the effects of heat fluxes to various system components, prechilling the receiver tank, and line and pump size variations.

Moderate to large heat fluxes affect the pressurized transfer of $\mathrm{LH}_{2}$ more than the pump-assisted transfer of oxygen. Heat leaks to the ET increase the pressure, and thus speed up the transfer of $\mathrm{LH}_{2}$. Heat leaks to the piping or receiver tank slow down the transfer of both propellants due to additional receiver tank chilling demands, and cause venting at sufficiently high fluxes.

Prechilling the receiver tank for $\mathrm{LH}_{2}$ is a critical requirement. The $\mathrm{LH}_{2}$ receiver tank must be approximately $-290^{\circ} \mathrm{F}(94.1 \mathrm{~K})$ in order to transfer the fluid without venting. The LOX receiver tank can be close to $300^{\circ} \mathrm{F}$ (421.9 K) without the significant venting of fluid.

Line and pump size selection are dependent on the time allowed, the piping design constraints and energy demands of the transfer system. 
Pump-assisted transfer in the LOX scavenging is needed, and by using a 2 HP (1491.4 W) pump and a 3-inch pipe diameter, a relatively lightweight, fast system can be used. Liquid hydrogen can be transferred by pressure difference in a 3 -inch line. The smaller line and pump sizes allow the transfer to be completed in less than 8 minutes. 


\section{APPENDIX A}

Derivation of single-phase receiver tank equations:

\section{First Law}

$$
d U=d Q_{\text {total }}+h_{1} d m_{1}+h_{2} d m_{2}
$$

Mass Balance $\quad d m=d m_{1}+d_{2}$

By applying the mass balance to the system and assuming $h=h_{2}$, the first law may be expressed as:

$$
\begin{aligned}
& m d u+u d m=d Q_{\text {total }}+h_{1} d m_{1}-h\left(d m_{1}-d m\right) \\
& d u=\frac{d Q_{\text {total }}}{m}+\frac{h_{1} d m_{1}}{m}-\frac{h\left(d m_{1}-d m\right)}{m}-\frac{u d m}{m} \\
& d u=\frac{d Q_{\text {total }}}{m}+\frac{d m_{1}}{m}\left(h_{1}-h\right)+\frac{d m P v}{m}
\end{aligned}
$$

Because we wish to find temperature as a function of mass flow we next expand du. The total differential energy equation with respect to temperature and density is given by

$$
\begin{aligned}
& \lambda u=\left(\frac{\partial u}{\partial T}\right)_{\rho} d T+\rho\left(\frac{\partial u}{\partial \rho}\right)_{T} \frac{d \rho}{\rho} \\
& d u=C_{v} d T-v\left(\frac{\partial u}{\partial v}\right)_{T} \frac{d \rho}{\rho} .
\end{aligned}
$$

By using the thermodynamic relationship

$$
d u=T d s-P d v
$$

we can obtain

$$
v\left(\frac{\partial u}{\partial v}\right)_{T}=T v\left(\frac{\partial s}{\partial v}\right)_{T}-P v
$$

The definitions for $C_{v}$ and the Grüneisen parameter $\phi$ are

$$
\begin{aligned}
& c_{v}=T\left(\frac{\partial s}{\partial T}\right)_{v} \\
& \phi=\frac{\rho}{T}\left(\frac{\partial T}{\partial \rho}\right)_{s}
\end{aligned}
$$


and the chain rule gives

$$
v\left(\frac{\partial u}{\partial v}\right)_{T}=\phi T C_{v}-\frac{P}{\rho} \text {. }
$$

Equation (2) then becomes

$$
\mathrm{du}=\mathrm{C}_{v} \mathrm{dT}-\left(\phi \mathrm{T} \mathrm{C}_{v}-\frac{\mathrm{P}}{\rho}\right) \frac{\mathrm{dm}}{\mathrm{m}} \text {. }
$$

Combining Equations ( 1 ) and ( 3 ) and solving for dT yields:

$$
C_{v} d T-\left(\phi T C_{v}-\frac{P}{\rho}\right) \frac{d m}{m}=\frac{d Q_{\text {total }}}{m}+\frac{d m_{1}}{m}\left(h_{1}-h\right)+\frac{d m P v}{m}
$$

or

$$
\mathrm{dT}=\frac{1}{\mathrm{~m}}\left\{\left(\phi T \mathrm{dm}+\frac{\left(\mathrm{h}_{1}-\mathrm{h}\right)}{\mathrm{C}_{v}}\right) \mathrm{dm}_{1}+\frac{\mathrm{dQ} \text { total }_{\text {ota }}}{\mathrm{C}_{v}}\right\} \text {. }
$$

The heat flux is the sum of the heat leak through the tank and the heat in the wall of the tank,

$$
\begin{aligned}
& d Q_{\text {total }}=d Q+d Q_{W} \\
& d Q_{W}=-m_{W} C_{p_{W}} d T
\end{aligned}
$$

Substituting these expressions into the temperature equation yields the following expression:

$$
d T+\frac{{ }_{w} C_{p_{w}}}{C_{v}^{m}} d T=\frac{1}{m}\left(\phi T d m+\frac{\left(h_{1}-h\right)}{C_{v}} d m_{1}+\frac{d Q}{C_{v}}\right)
$$

Upon rearrangement the following relationship is obtained:

$$
d T=\frac{\phi T d m+\left(h_{1}-h\right) d m_{1} / C_{v}+d Q / C_{v}}{m+m_{w} C_{p_{w}} / C_{v}} .
$$

We next wish to find pressure as a function of mass flow. The total differential energy equation with respect to pressure and density is given by

$$
d u=\left(\frac{1}{\rho}\right) \rho\left(\frac{\partial u}{\partial P}\right)_{\rho} d P+\rho\left(\frac{\partial u}{\partial \rho}\right)_{P} \frac{d \rho}{\rho} .
$$


The first term on the right-hand side contains the Grüneisen parameter which is also defined as

$$
\phi=\frac{1}{\rho}\left(\frac{\partial P}{\partial u}\right)_{\rho} .
$$

The second term on the right-hand side may be expressed with the heat of expulsion

$$
\theta=-\rho\left(\frac{\partial h}{\partial \rho}\right)_{p}
$$

and by using the definition of enthalpy to give

$$
\rho\left(\frac{\partial u}{\partial \rho}\right)_{P}=\rho\left(\frac{\partial h}{\partial \rho}\right)_{P}+\frac{p}{\rho} .
$$

The differential energy equation may then be written as

$$
d u=\frac{1}{\rho \phi} d P-\left(\Theta-\frac{P}{\rho}\right) \frac{d \rho}{\rho} .
$$

Combining Equations (A.1) and (A.6) and solving for $d P$ when $d m_{1}=d m$ yields the following expression:

$$
d P=\frac{1}{V}\left(\phi\left[\theta+h_{1}-h\right] d m+\phi\left(d Q-m_{w} C_{W} d T\right)\right) .
$$

When $\mathrm{dm}_{1}$ is not equal to $\mathrm{dm}$, there is flow through the vent. Thus, $d P=0$ and

$$
\mathrm{dm}=\frac{\left[\left(h-h_{1}\right) \mathrm{dm}_{1}-\mathrm{dQ}+\mathrm{m}_{\mathrm{w}} \mathrm{C}_{\mathrm{w}} \mathrm{dT}\right]}{\theta}
$$


Appendix B

Derivation of two-phase receiver tank equations:

First Law

$$
d U=d Q-d W+\sum h_{1} d m_{1}
$$

Since there is no work done, the first law may be expressed as:

$$
m_{\ell} d u_{\ell}+m_{v} d u_{v}+u_{\ell} d m_{\ell}+u_{v} d m_{v}=d Q_{\text {total }}+h_{1} d m_{1}+h_{2} d m_{2}
$$

Continuity

$$
d m_{\ell}+d m_{v}=d m_{1}+d m_{2}
$$

Constant volume

$$
v_{\ell} d m_{\ell}+m_{\ell} d v_{\ell}+v_{v} d m_{v}+m_{v} d v_{v}=0
$$

Solving for $\mathrm{dm}_{\ell}$

$$
d m_{\ell}=-\frac{v_{v}}{v_{\ell}} d m_{v}-\frac{1}{v_{\ell}}\left(m_{\ell} d v_{\ell}+m_{v} d v_{v}\right)
$$

Let

$$
d v_{\text {sat }}=\left(\frac{\partial v}{\partial p}\right)_{\text {sat }} d p
$$

The equation for the differential mass of the liquid in the tank is:

$$
d m_{\ell}=-\frac{v_{v}}{v_{\ell}} d m_{v}-\frac{1}{v_{\ell}}\left[m_{\ell}\left(\frac{\partial v}{\partial p}\right)_{\ell}+m_{v}\left(\frac{\partial v}{\partial p}\right)_{v}\right] d p
$$

Substituting Equation (B.4) into Equation (B.2) produces the following expression:

$$
-\frac{v_{v}}{v_{\ell}} d m_{v}+d m_{v}-\frac{1}{v_{\ell}}\left[m_{\ell}\left(\frac{\partial v}{\partial p}\right)_{\ell}+m_{v}\left(\frac{\partial v}{\partial p}\right)_{v}\right] d p=d m_{1}+d m_{2}
$$


Solving for the differential mass of the vapor:

$$
d m_{v}=\frac{d m_{1}+d m_{2}+\frac{1}{v_{\ell}}\left[m_{\ell}\left(\frac{\partial v}{\partial p}\right)_{\ell}+m_{v}\left(\frac{\partial v}{\partial p}\right)_{v}\right] d P}{\left(1-v_{v} / v_{\ell}\right)}
$$

Substituting Equation (B.5) into Equation (B.4), we obtain the following equation for $\mathrm{dm}_{\ell}$

$$
\mathrm{dm}_{\ell}=\frac{-\left(v_{v} / v_{\ell}\right)\left(d m_{1}+d m_{2}\right)-\frac{1}{v_{\ell}}\left[m_{\ell}\left(\frac{\partial v}{\partial p}\right)_{\ell}+m_{v}\left(\frac{\partial v}{\partial P}\right)_{v}\right] d P}{\left(1-v_{v} / v_{\ell}\right)} .
$$

Combining Equations (B.1), (B.5) and (B.6), we obtain

$$
\begin{aligned}
& m_{\ell}\left(\frac{\partial u}{\partial P}\right)_{\ell} d P+m_{v}\left(\frac{\partial u}{\partial p}\right)_{v} d P-u_{\ell}\left\{\frac{v_{v}}{v_{\ell}} \frac{d m_{1}+d m_{2}}{\left(1-v_{v} / v_{\ell}\right)}\right. \\
& \left.+\frac{\frac{1}{v_{\ell}} m_{\ell}\left(\frac{\partial v}{\partial p}\right)_{\ell}+m_{v}\left(\frac{\partial v}{\partial P}\right)_{v} d P}{\left(1-v_{v} / v_{\ell}\right)}\right\}+\left\{u_{v} \frac{d m_{1}+d m_{2}}{\left(1-v_{v} / v_{\ell}\right)}\right. \\
& \left.+\frac{\frac{1}{v_{\ell} m_{\ell}\left(\frac{\partial v}{\partial p}\right)_{\ell}+m_{v}\left(\frac{\partial v}{\partial p}\right)_{v} d P}}{\left(1-v_{v} / v_{\ell}\right)}\right\}=d Q_{\text {total }}+h_{1} d_{1}+h_{2} d m_{2} .
\end{aligned}
$$

We can solve Equation (B.7) for the differential pressure when there is no venting:

$$
d P=\frac{\left[h_{1}-u_{v}+\frac{v_{v}}{v_{\ell}}\left(u_{\ell}-h_{1}\right)\right] d m_{1}+d Q_{\text {total }}\left(1-v_{v} / v_{\ell}\right)}{F(p)} .
$$


where

$$
\begin{aligned}
& F(p)=m_{\ell}\left[\left(\frac{\partial u}{\partial P}\right)_{\ell}\left(1-\frac{v_{v}}{v_{\ell}}\right)+\frac{1}{v_{\ell}}\left(\frac{\partial v}{\partial P}\right)_{\ell}\left(u_{v}-u_{\ell}\right)\right] \\
& +m_{v}\left[\left(\frac{\partial u}{\partial P}\right)_{v}\left(1-\frac{v_{v}}{v_{\ell}}\right)+\frac{1}{v_{\ell}}\left(\frac{\partial v}{\partial P}\right)_{v}\left(u_{v}-u_{\ell}\right)\right] \\
& -m_{w} C_{w}\left(\frac{\partial T}{\partial P}\right)_{\text {sat }}\left(1-\frac{v_{v}}{v_{\ell}}\right) .
\end{aligned}
$$

When there is venting, the pressure is constant. Since $d P=0$, the following equation is obtained when Equation (B.7) is solved:

$$
\begin{aligned}
0= & u_{\ell}\left(\frac{v_{v}}{v_{\ell}} \frac{d m_{1}+d m_{2}}{\left(1-v_{v} / v_{\ell}\right)}\right)-\left(u_{v} \frac{d m_{1}+d m_{2}}{\left(1-v_{v} / v_{\ell}\right)}\right) \\
& +d Q-m_{W} C_{w} d T+h_{1} d m_{1}+h_{2} d m_{2} .
\end{aligned}
$$

Finally, an expression for the differential mass through the vent is obtained:

$$
d m_{2}=\frac{\left[u_{\ell} \frac{v_{v}}{v_{l}}-u_{v}+h_{1}\left(1-\frac{v_{v}}{v_{l}}\right)\right] d m_{1}+d Q\left(1-\frac{v_{v}}{v_{l}}\right)}{\left(h_{v}-h_{\ell}\right) \frac{v_{v}}{v_{l}}}
$$


Appendix C

Tank Material Physical Data

INCONEL ${ }^{\star}[12]$

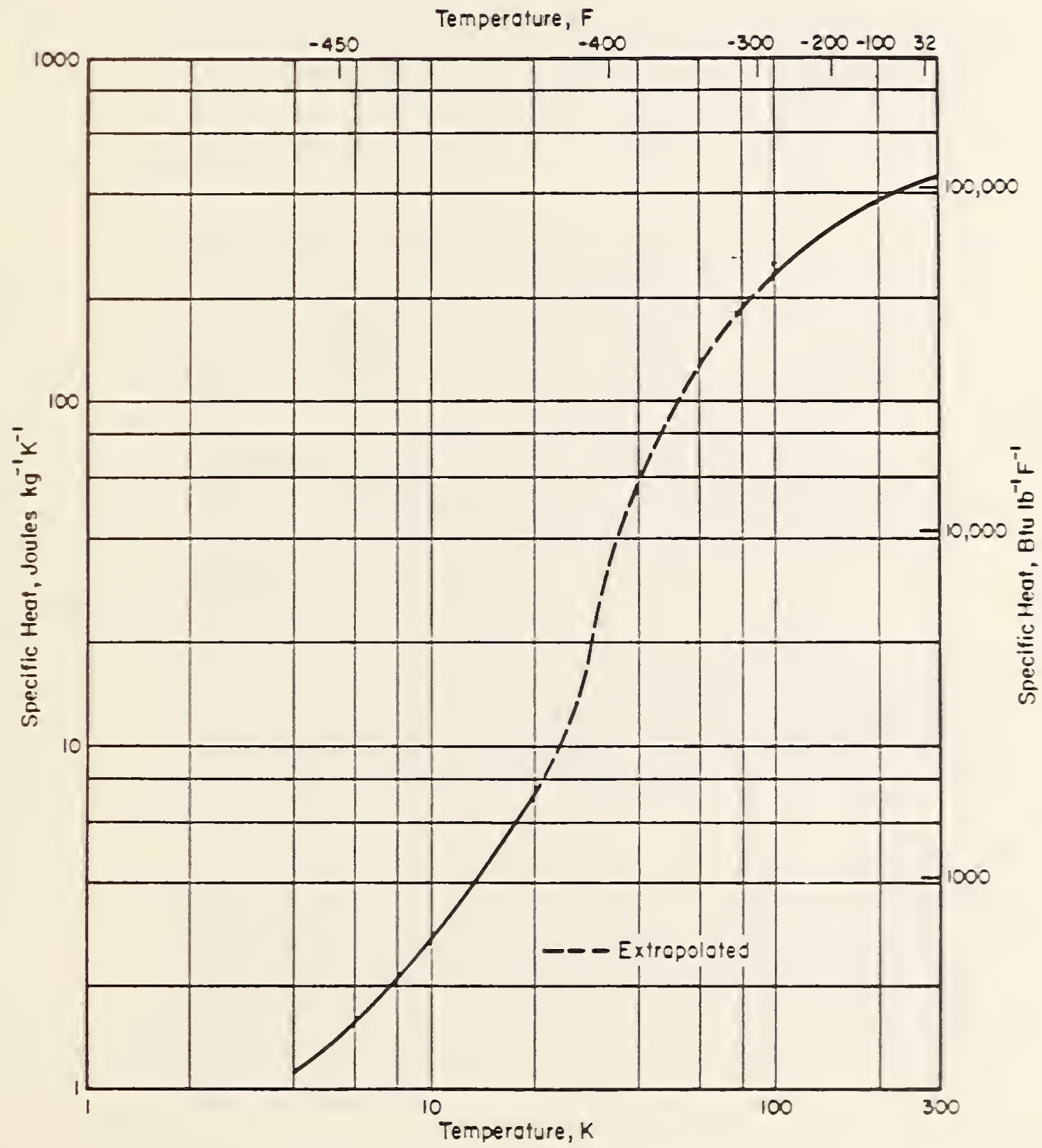

* Such recommendation does not imply recommendation or endorsement by the National Bureau of Standards. 


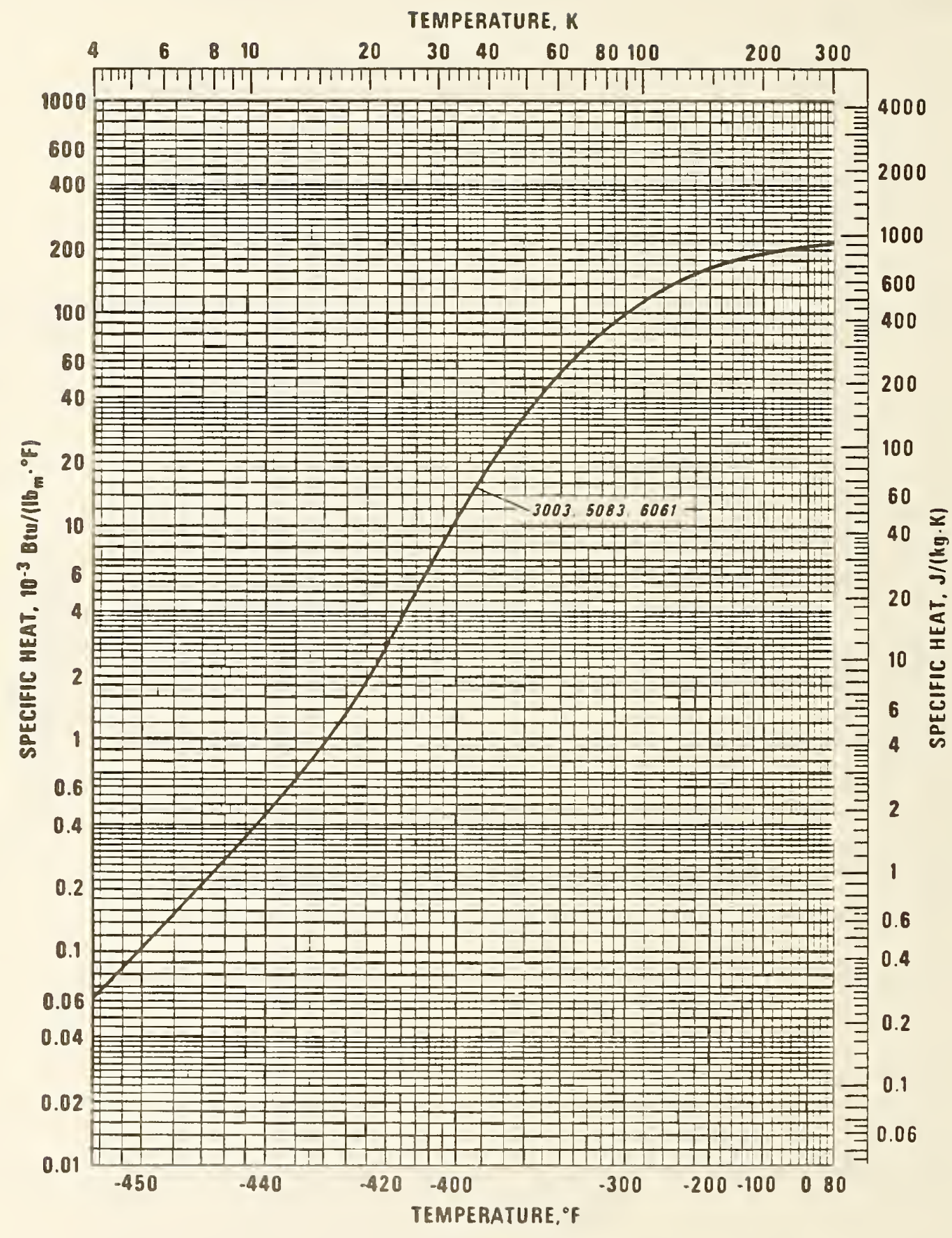


Appendix D

Conversion factor calculation

The conversion factor $C$ for Equation (26) may be derived as follows:

$$
32 C=\frac{\Delta P \rho \pi^{2} D^{5}}{f L(d m)^{2 M}}
$$

where

$$
\begin{aligned}
& \Delta P=a t m \\
& \rho=g m o l / \ell \\
& D=\mathrm{cm} \\
& L=\mathrm{m} \\
& M=\mathrm{g} / \mathrm{gmol}
\end{aligned}
$$

Therefore,

$$
\begin{aligned}
32 \mathrm{C}= & \frac{(\mathrm{atm})(\mathrm{gmol} / \mathrm{l})\left(\mathrm{cm}^{5}\right)}{(\mathrm{m})(\mathrm{gmol} / \mathrm{s})^{2}\left(\mathrm{~g} / \mathrm{gmol}^{\prime}\right)}\left(\frac{1 \mathrm{~m}}{100 \mathrm{~cm}}\right)^{5}\left(\frac{1 \mathrm{l}}{0.001 \mathrm{~m}^{3}}\right)^{2}\left(\frac{1 \mathrm{~kg} \mathrm{~m} 2}{\mathrm{~J} \mathrm{~s}^{2}}\right) \\
& \times\left(\frac{1000 \mathrm{~g}}{1 \mathrm{~kg}}\right)\left(\frac{101.325 \mathrm{~J}}{1 \ell \mathrm{atm}}\right) \\
32 \mathrm{C}= & 3.158 \frac{(\mathrm{atm})\left(\mathrm{s}^{2}\right)\left(\mathrm{cm}^{5}\right)}{(\mathrm{m})(\mathrm{l})(\mathrm{g})}
\end{aligned}
$$




\section{Appendix E}

Derivation of the supply tank equations:

\section{First Law}

$$
d U=d Q-d W+\sum h_{i} m_{i}
$$

The first law can be written for both phases, and when the mass of vapor is held constant we have the following expression:

$$
\text { vapor phase } \quad m_{v} d u_{v}=d Q_{v}-P\left(m_{v} d v_{v}\right)
$$

Since

$$
m_{v} h_{v}=m_{v} u_{v}+P m_{v} v_{v}
$$

then

$$
d h_{v}-v_{v} d P=d u_{v}+P d v_{v}
$$

Upon substitution and rearrangement, the vapor phase enthalpy equation becomes:

$$
d h_{v}=\frac{d Q_{v}}{m_{v}}+v_{v} d P
$$

For the liquid the first law may be expressed as

$$
\text { liquid phase } m_{\ell} d u_{\ell}+u_{\ell} d m_{\ell}=d Q_{\ell}-P m_{\ell} d v_{\ell}-P v_{\ell} d m_{\ell}+h_{\ell} d m_{\ell} \text {. }
$$

By using the previous substitution and rearrangement, the liquid phase enthalpy equation can be written as

$$
d h_{\ell}=\frac{d Q_{\ell}}{m_{\ell}}+v_{\ell} d P
$$

Volume

Since the ET volume is constant the following expression is used:

$$
v=\text { constant }=v_{\ell} m_{\ell}+v_{v} m_{v}
$$


Upon rearrangement,

$$
v_{\ell} d m_{\ell}=-\left(m_{\ell} d v_{\ell}+m_{v} d v_{v}\right) .
$$

The total derivative for volume with respect to pressure and enthalpy is expressed as

$$
d v=\left(\frac{\partial v}{\partial h}\right)_{P} d h+\left(\frac{\partial v}{\partial P}\right)_{h} d P
$$

We recall the definition for the heat of expulsion $\theta$ and substitute it for the first term in the total volume derivative as follows:

$$
\begin{aligned}
& \theta=-\rho\left(\frac{\partial h}{\partial \rho}\right)_{P}=v\left(\frac{\partial h}{\partial v}\right)_{P} \\
& \left(\frac{\partial v}{\partial h}\right)_{p} d h=\frac{v}{\theta} d h .
\end{aligned}
$$

To elucidate the thermodynamic nature of the second partial derivative, the following thermodynamic identity is used:

$$
\left(\frac{\partial v}{\partial P}\right)_{h}\left(\frac{\partial h}{\partial v}\right)_{P}\left(\frac{\partial P}{\partial h}\right)_{v}=-1 \text {. }
$$

The term $\left(\frac{\partial v}{\partial P}\right)_{h}$ can be expressed in terms of $\theta$

$$
\left(\frac{\partial v}{\partial P}\right)_{h}=-\left(\frac{\partial v}{\partial h}\right)_{P}\left(\frac{\partial v}{\partial P}\right)_{v}=-\frac{v}{\theta}\left(\frac{\partial h}{\partial P}\right)_{v} \cdot
$$

The definition for the Grüneisen parameter can be used with the first law to eliminate the remaining partial derivative. The Grüneisen parameter is:

$$
\phi=\frac{1}{\rho}\left(\frac{\partial P}{\partial u}\right)_{\rho}=v\left(\frac{\partial P}{\partial u}\right)_{v} .
$$

By writing the first law in terms of derivatives with respect to pressure at constant volume, we can make the following substitutions: 


$$
\begin{aligned}
\left(\frac{\partial h}{\partial P}\right)_{v} & =\left(\frac{\partial u}{\partial P}\right)_{v}+v \\
& =\frac{v}{\phi}+v \\
& =v\left(\frac{\phi+1}{\phi}\right) .
\end{aligned}
$$

The second term in Equation (E.4) can be expressed as:

$$
\left(\frac{\partial v}{\partial P}\right)_{h}=-\frac{v}{\theta}\left(\frac{v(\phi+1)}{\phi}\right) .
$$

Equation (E.4) can now be expressed by the following relationship

$$
\mathrm{d} v=\frac{v}{\theta} \mathrm{dh}-\frac{v^{2}(\phi+1)}{\theta \phi} \mathrm{dP}
$$

We can substitute Equation (E.5) into (E.3) to obtain the following relationship:

$$
\begin{aligned}
\frac{d m_{\ell}}{m_{\ell}}= & -\frac{d h_{\ell}}{\theta_{\ell}}-\frac{m_{v} v_{v}}{m_{\ell} \nu_{\ell}} \frac{d h_{v}}{\theta_{v}}+\frac{v_{\ell}}{\theta_{\ell}}\left(\frac{\phi+1}{\phi}\right)_{\ell} \\
& +\frac{m_{v} v_{v}^{2}}{m_{\ell}{ }^{\nu_{\ell} \theta_{v}}}\left(\frac{\phi+1}{\phi}\right)_{v} d P .
\end{aligned}
$$

By solving Equations (E.1), (E.2), and (E.3) simultaneously, a relationship for the ET pressure is found:

$$
\mathrm{dP}=\frac{\frac{\mathrm{dm}_{\ell}}{\mathrm{m}_{\ell}}+\frac{v_{v} \mathrm{dQ}_{v}}{\mathrm{~m}_{\ell} \nu_{\ell} \theta_{v}}+\frac{1}{\theta_{\ell}} \frac{\mathrm{dQ}_{\ell}}{\mathrm{m}_{\ell}}}{\frac{v_{\ell}}{\theta_{\ell} \phi_{\ell}}+\frac{\mathrm{m}_{v} v_{v}^{2}}{m_{\ell} v_{\ell} \theta_{v} \phi_{v}}} .
$$

An expression for the temperature of the liquid can be obtained by using the liquid enthalpy equation (E.2) and the total enthalpy derivative. 
The total enthalpy derivative with respect to temperature and pressure is given by:

$$
d h=\left(\frac{\partial h}{\partial P}\right)_{T} d P+\left(\frac{\partial h}{\partial T}\right)_{P} d T
$$

The second partial derivative in Equation (E.8) is the definition of the constant pressure heat capacity $C_{p}$. The first partial can be expressed as [14]

$$
\left(\frac{\partial h}{\partial P}\right)_{T}=v-T\left(\frac{\partial v}{\partial T}\right)_{P} .
$$

The definition for the bulk thermal expansivity $\alpha$ of a fluid is given by [7]

$$
\alpha=-\frac{T}{\rho}\left(\frac{\partial \rho}{\partial T}\right)_{P}=\frac{T}{v}\left(\frac{\partial v}{\partial T}\right)_{P} .
$$

The partial derivative may be expressed as

$$
\left(\frac{\partial h}{\partial P}\right)_{T}=v(1-\alpha) .
$$

By substituting for the partial derivatives as discussed, Equation (E.8) may be written as follows for the ET liquid phase

$$
d h_{\ell}=v\left(1-\alpha_{\ell}\right) d P+C_{p} d T .
$$

By substituting Equation (E.2, for $\mathrm{dh}_{\ell}$ in the previous equation and solving for $\mathrm{dT}$, the temperature equation is given by the relationship

$$
\mathrm{dT}=\frac{1}{\mathrm{c}_{p}} \frac{\mathrm{dQ}_{\ell}}{\mathrm{m}_{\ell}}+v_{\ell} \alpha_{\ell} \mathrm{dP}
$$


Appendix F

Plotting routines

The data which describe the transfer of fluid are stored in file PSDATA (see printout of file in Appendix C). These data are used in two plotting programs called PROGRAM PLOT and PROGRAM DEMO. Both programs are written in FORTRAN IV and are fully described below. The data file is described first.

\section{FILE PSDATA/TAPE8}

The first four lines of the file are data points for identifying and initializing the plots for either PROGRAM PLOT or DEMO. The first line of data contains four identifying parameters -- the transfer line size, pump size, and the initial receiver tank temperature and pressure. The second line contains the alphanumeric name of the propellant, HYDROGEN or OXYGEN. The total number of data lines, $N$, is written on the third line. Finally, the fourth line holds the lower and upper limits for each of the plots to be drawn. The order of these pairs of values is the time, receiver tank temperature and pressure, the flowrate, the mass of vapor, mass of liquid, total mass of fluid transferred, the quality of fluid in the ET, and the quality of fluid entering the receiver tank.

Following these lines are the $\mathrm{N}$ lines of data. Each entry holds the data describing the transfer for each increment of time. The values in each line are the elapsed time, the receiver tank temperature, receiver tank pressure, the flowrate, the mass of vapor, liquid, and total mass of propellant transferred, the ET fluid quality, and the quality of fluid entering the receiver tank. 
PROGRAM PLOT

The NBS computer system in Boulder has a mathematics library called STARPAC from which subroutines may be called to perform assigned tasks. For program PLOT the SUBROUTINE PPC is used to produce four plots and is accessed by the statement CALL $\operatorname{PPC}(A 1, A 2, A 3, A 4, A 5, A 6, A 7, A 8, A 9, A 10)$. Each parameter is described as follows:

A1 Array containing the value to be plotted on the vertical axis. A2 Array containing the values for the elapsed time during the transfer to be plotted on the horizontal axis.

A3 The number of lines of data to be read.

$A 4, A 5, A 6$ Parameters describing whether the plot is to be logarithmic, the size of the plot is to be altered, or the plot is to be reprinted. All are set equal to zero.

A7,A8 Lower and upper values for the vertical axis.

A9,A10 Lower and upper values for the horizontal (time) axis.

PLOT first assigns single array dimension sizes for the time, temperature, pressure, flowrate, mass of vapor, and mass of liquid. Second, the first four lines of data are read into appropriate variable names. Following these assignments the data points are read into the dimension arrays.

The first call to PPC enables a plot to be drawn of the receiver tank temperature as a function of time. The second call to PPC is for a plot of the receiver tank pressure as a function of time. The third call plots the mass of propellant in the vapor phase as a function of time. The fourth call to PPC produces a plot of the mass of liquid phase propellant as a function of time. Each plot has an appropriate heading. There are 10 vertical and horizontal axis divisions for each plot.

When batch control procedure SUBCOM is used, the plots are located after the output from program SCAVAG and all output subsequently are written to 
TAPE6 and PSOUT. Should the operator choose to have the output separated, two other batch control procedures are used. First, SCAVAG is run with NOPLOT, in the same manner as has been described in the main text for SUBCOM. Output is written to TAPE6/PSOUT and PSDATA as before. To generate the plots for the transfer with program PLOT, control procedure LIBPLOT is used. Output is directed to TAPE6 and stored in filename TRACE. (See Appendix G for the program, data, control procedure listings, and sample plots.)

\section{PROGRAM DEMO}

The DISSPLA graphics package [15] is available at NBS in Boulder and at NASA-JSC. Since it produces high quality plots and is quite versatile, DISSPLA was chosen for graphic display of some of the results of this study. It is used by program DEMO to produce seven plots. Two plots, each allowed half of a standard page, are placed on the first three pages, and the remaining plot is located on the upper half of the fourth page.

DEMO assigns dimension sizes and variable names in a manner very similar to that of program PLOT. However, additional arrays and variable names are required for the parameters used in the DISSPLA subroutine calls. After the lower and upper bounds for each of the plots are read from PSDATA, DEMO calculates the division size for the axes of each plot. After the data points are read into their respective arrays, the program is fully initiated and proceeds with a succession of DISSPLA subroutine calls which set up and plot the curves. A ful1 description of each subroutine can be found in the DISSPLA user's manua1. (The program 1isting and sample plots are located in Appendix G.)

Several items are unique to program DEMO. Whereas PLOT reads the first line of data into four dummy variables, DEMO uses these data as identifiers located in the corner of the first plot. The name of the propellant is not used in PLOT, but in DEMO it is used in the heading for each page. In 
addition to the four plots which are generated by both PLOT and DEMO, DEMO also plots the total mass of propellant transferred, the flowrate into the receiver tank, and the percent of vapor and liquid phases in the receiver tank, as a function of time.

DEMO is run interactively by the operator. Instead of storing the output in files which are accessed at a later time (i.e., batch operation, SCAVAG with control procedures SUBCOM or NOPLOT, and PLOT with control procedures SUBCOM or LIBPLOT), output is generated immediately at the terminal or other output device. To run DEMO at NBS, the operator types in at the terminal

$$
\begin{aligned}
& \text { GET, DEMO } \\
& \text { DEMO } \\
& \text { or BEGIN, DEMO, DEMO }
\end{aligned}
$$

The first line instructs the computer system to retrieve program DEMO from storage and place it in the local mode and ready for use. When DEMO is typed, the procedure for running the program is activated. The alternative command identically performs both statements. The procedure is located in the lines prior to the program statement and uses a sequence of control statements similar to those contained in the batch control procedures SUBCOM, NOPLOT, or LIBPLOT.

Output is generated at the terminal screen when the appropriate call is made and graphics capabilities are available. Other output options are a multiple pen plotter or microfilm. The first page, or two plots, are drawn automatically. The operator types

$$
\text { COPYBR, Z }
$$

to have each subsequent page drawn at the terminal or the pen plotter. All plots are automatically drawn on microfilm. 
Appendix G

Program listings and sample plots 
PR RGRAM SCAVAG (INPUT, TAPE5, TAPEG, TAPET, CUTPUT = TAPE6, TAPEB)

C THIS PROGRAM SIMULATES THE FILLING OF A RECEIVER TANK IN LOH G USING A SUPPLYIEXTERNAL TANK.

COMMON/PARAMI MW, MWALL, O, VOL, OPIPE, OET, TOTAL, PVENT

COMMON/SUB / FLOHI, FLOHZ, PRESS, TEMP, TIME, HET

CIMMON/FLOW/ DIAM, DET, TET, PET,LENGTH, PMETER

CIMMON/NOZZLE / COIAM, NOZOIA, HEADIA, NNOZ, CONST, CDLENG

COMMON/PUMP/ POHER, EFF

CCMMON/PLOT / NPLOT, X,Y $1, Y 2, Y 3, Y 4, Y 5, Y 6, Y 7, Y 8$

COMMIN/PROP/NGAS

COMMIN/ETANK/ETLIO, ETVAP, VET, ETO

CTMMON/PROB/DUMP

REAL MVAP, MLIO, MH, MHALL, LENGTH, NOZOIA

REAL $X(600), Y 1(600), Y 2(600), Y 3(600), Y 4(600), Y 5(600), Y 6(600)$

C

$+, Y 7(600), Y 8(600)$

THE NAMELIST WNAME CONTAINS ALL PARAMETERS THAT CAN BE VARIED

FROM DEFAULT VALUES.

NAMELIST/NAME / PET, TET, OET, TOTAL, DIAM, NELBCW, NANGLE, NGATE,

- NGLOBE, NBUTT, LENGTH, METER, OPIPE, POWER, VOL, MWALL, TEMP, PRESS,

+ PVENT, $Q$, CDLENG, HEADIA, NNJZ, NOZOIA, VET, CONST

C

C

NGAS - I FOR HYDROGEN

NAMELIST/FUEL INGAS

NGAS 1

READ (7, FUEL)

INITIALIZE FLUID PROPERTIES HITH FLUIDS PACK SUBROUTINE. IF (NGAS .EO.2) EO TO 2

CALL DATA P HZ

INITIALIZE MOLECULAR HEIGHT

$M W=2.01594$

SET DEFAULT VALUES FOR THE SIMULATION.

INPUT DARAMETERS FOR SUPOLY TANK:

PET = TANK PRESSURE, PSIA

TET : TANK TEMPERATURE, DEG. F

OET = HEAT FLUX INTO SUPPLY TANK, BTU/HR

TOTAL = TOTAL PROPELLANT IN SUPPLY TANK, POUNOS

VET = TANK VOLUME, CUBIC FEET

$P F T=32$.

TET $=-425$.

QET 90000 .

TITAL $=3098$.

VET $=53518$.

INPUT PARAMETERS FOR PIDING BETHEEN TANKS:

DIAM - PIPE DIAMETER, INCHES

NELBOW = NUMBER OF RIGHT-ANGLE ELBOUS

NGATE - NUMBER OF GATE VALVES

NGLOBE - NUMBER OF GLOBE VALVES

NANSLE = NUMBER OF ANGLE VALVES

NBUTT = NUMBER OF BUTTERFLY VALVES

LENGTH - LENGTH OF STRAIGHT PIPE, FEET

METER - NUMBER OF FLOW METERS 


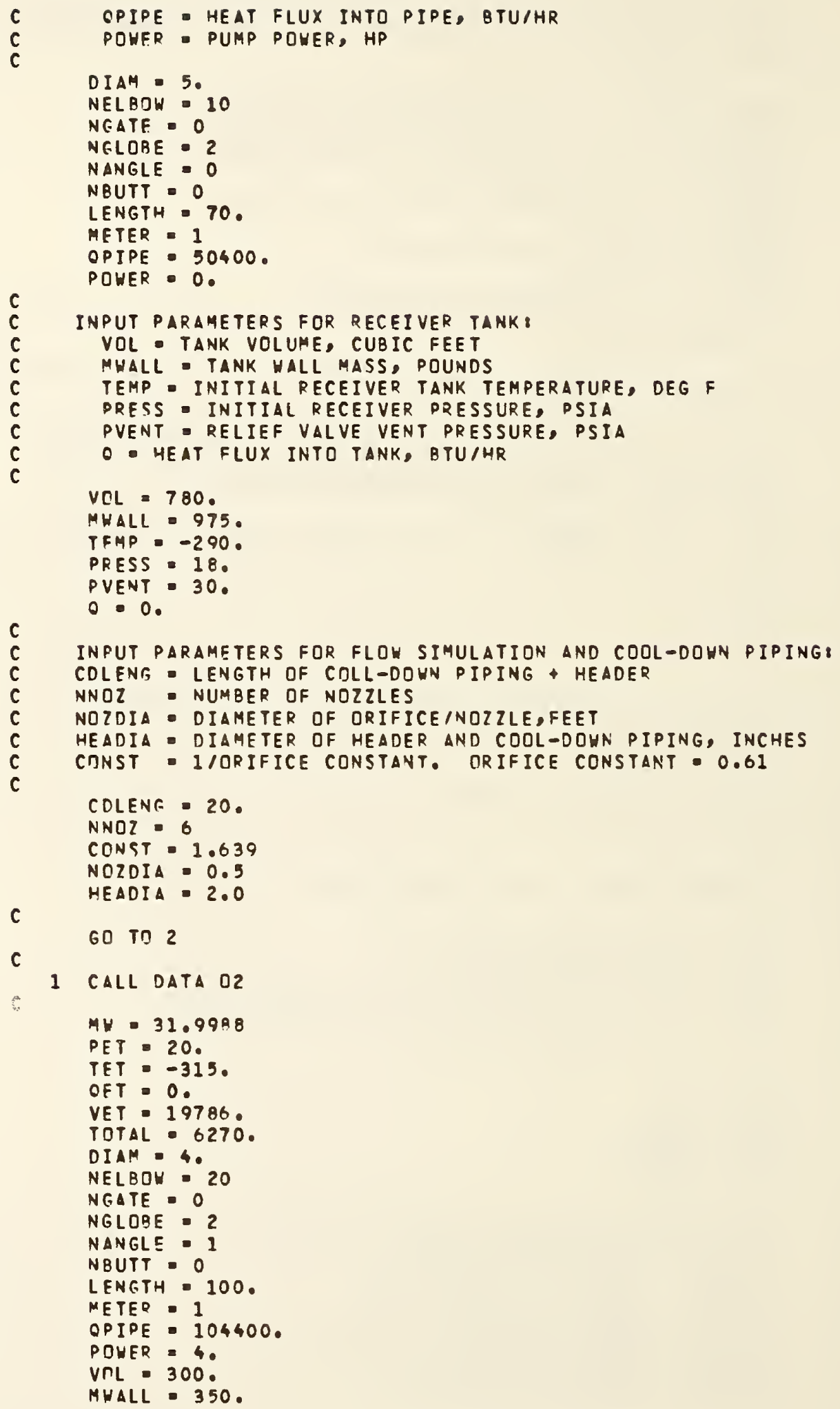




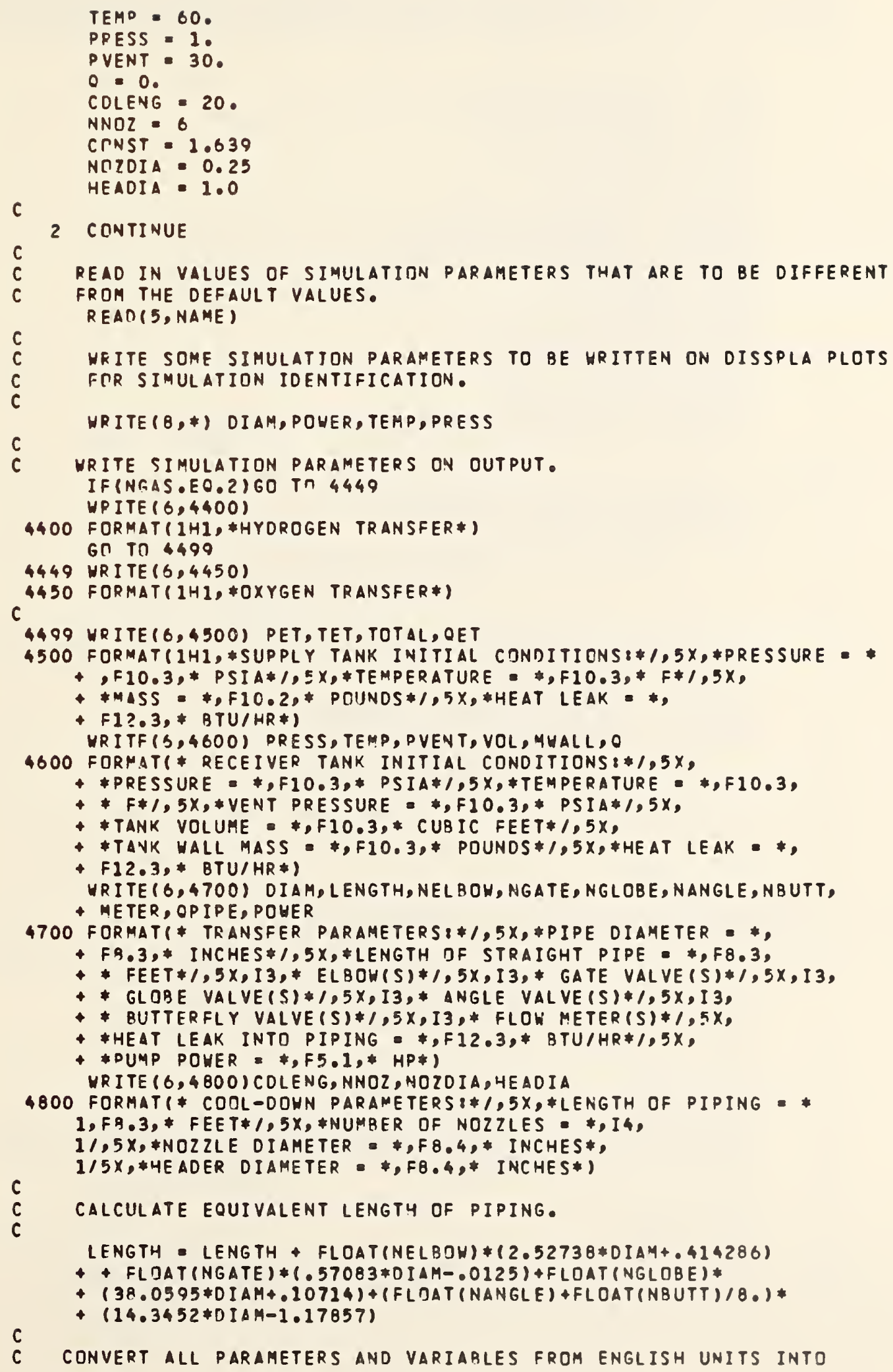




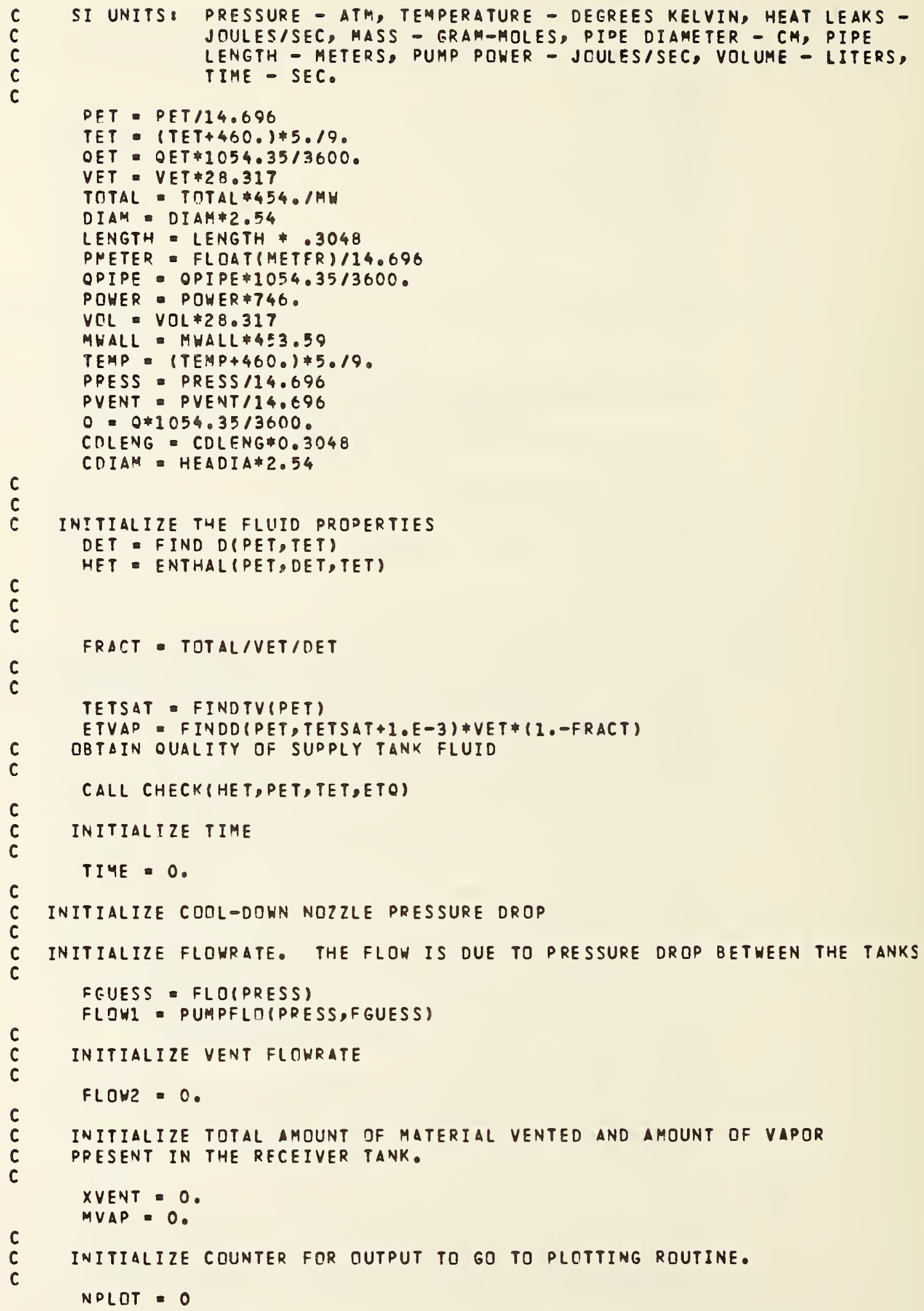


initialize vent flae to ingicate that the recfiver tank vent IS CLISED.

NVFNT $=0$

INITIALIZE PROGRAMMEO STOD PAPAMETER

$O L M D=0$.

CALL SIJRROUTINE THAT MCDELS THE CJOL-DOWHN CF THE RECEIVER TANK UNTIL TUM PHASES ARE PRFSENT IN THF RECFIVER TANK.

CALL COCL (MVAP, XVENT, DPRESS) NPRT $=0$

CALCULATE THE ENTHALPY DF THE FLUID EVTERINE THE RECEIVER TANK ANR CHECK THE OUALITY CF THE FLUID.

4] - HET+OPIDE/FLCVI + POdER/FLCHI

CALL CHECK(HI, PRFSS, TEMD, TANKQ)

$c$
$c$
$c$

SET THE TIME STEP FOR THE SI WILATION. NCTEI DTIME = 2COO./FLOWI

FOR LU? ANO 3NO./FLOWI FOR LIX ON NASA-JSC COMPUTER

DTIME = VOL/FLOWI/:00.

IFINGAS. EQ. ?IDTINE = DTIME/2.

IFINGAS.EO. IIDTIME $=$ DTIME 2 .

DTIME = DTIME*50.

C. DTIME = DTIME/3.14159

C INITIALTIE THE AMOUNT OF LIOUIN PRESENT IN THE RECEIVER TANK.

C

$M L I O=n$.

c

DLIO = FIND D(DPESS+1,E-3,TEMP)

DVAD = FIND D (PDESS-1, E-5, TFMD)

C

C LITP FOR TWD-PHASE SIMULATIOV.

$I=n$

1000 CONTINUE

$I=I+I$

$c$
$c$
$c$

OPTAIN VAPIR AND LIOLID ENTHALPY (J/GMOL)ANN INTERNAL ENERGY (J/GMOL)

HVAP = ENTHAL (PRESS-1.E-5, DVAP, TEMP)

HLIC = ENTHAL (PRFSS+1.E-5, DLIO,TEMP)

IUVAP = HVAD -PRESS\$10 I. 327IDVAP

ULIQ = HLIO-DRESS\$101.327/DLI?

C CALCULATE FUNCTION! FOR DELTA P.

$F P=M L I Q \#((1,-D L I O / \cap V A P) * D U D D L(P R E S S)+C L I O \#[V D P L(P F E S S)$

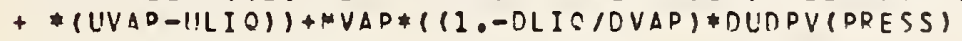

$++I L I Q * D V D P V(P R E S S) *(U V A P-U L I Q))$

$F D P=F P+M U \Delta L L$ * $V A L L(T E N P) * C T D P(P R E S S)$ *

$+(1 .-D L I O / D V A P)$

DELTAT = DTDP(PRESS) $\#$ DFRESS

C

CalCulatF nELTA D

DDRESR = ((HI-IIVAD+DLIOIDVAO* (ULIO-4I)) \#ELTVI+(C)*

$+(1 .-\cap L I O / D V A P) / / F P P$

32 CTNTINUE 


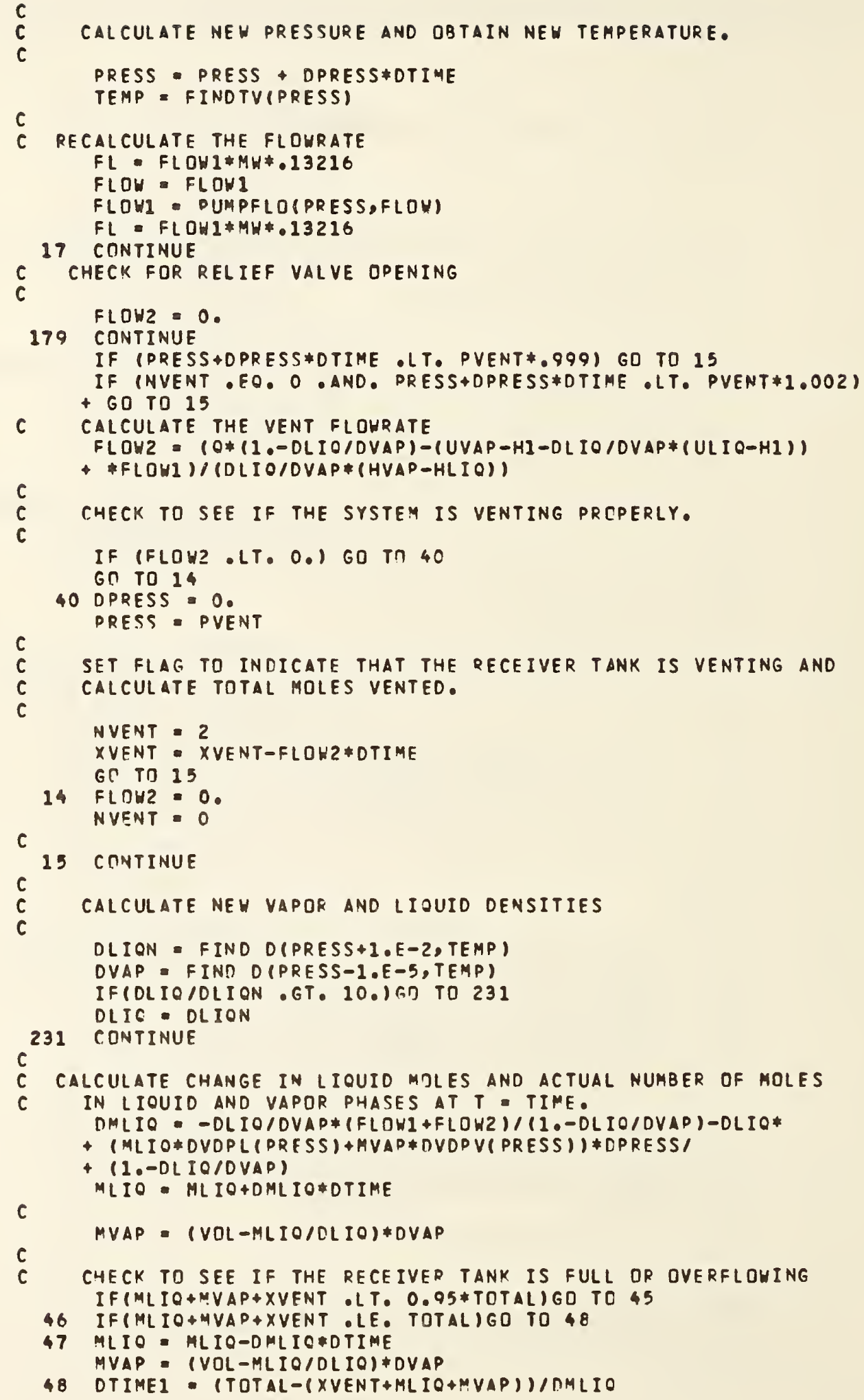




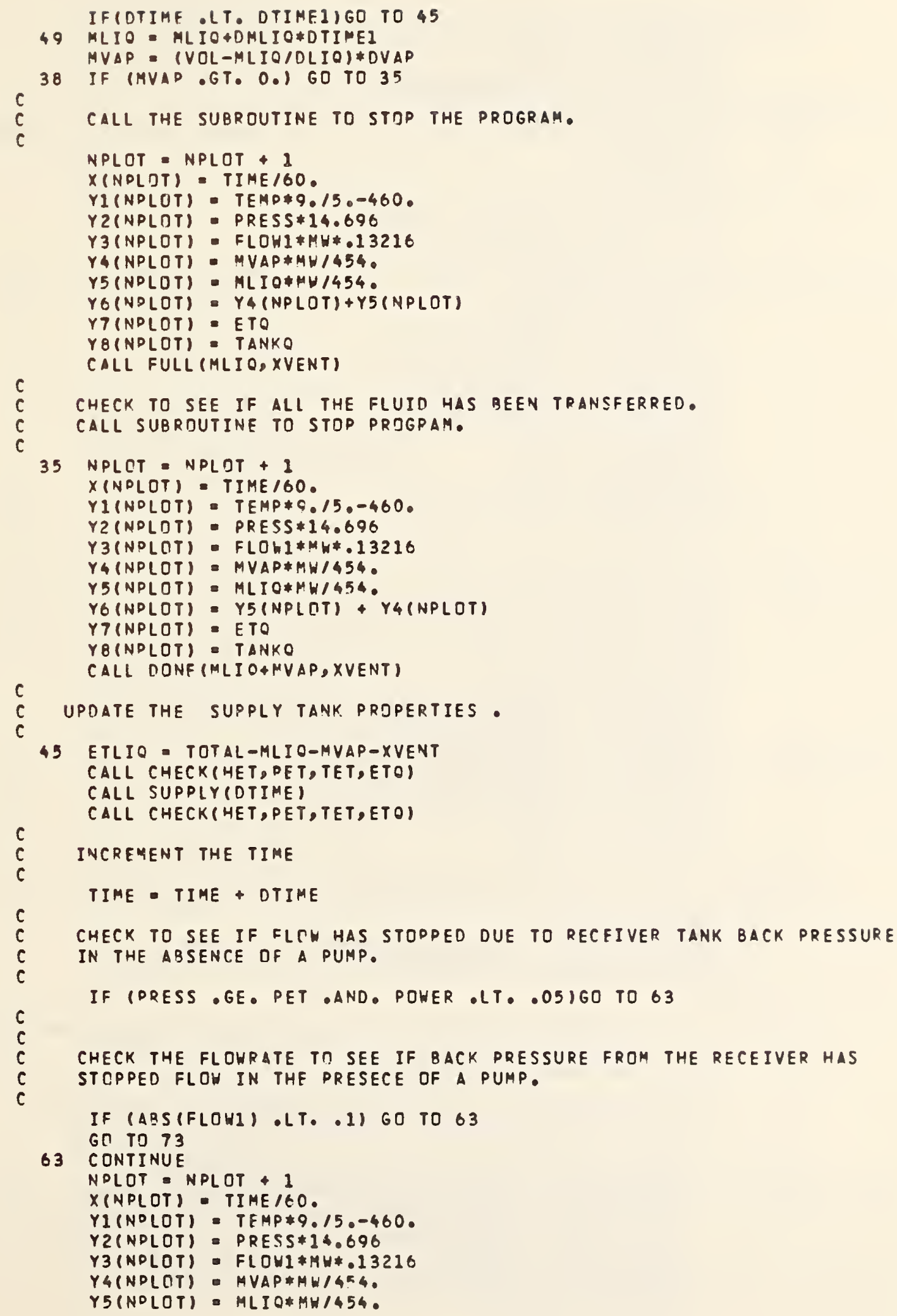




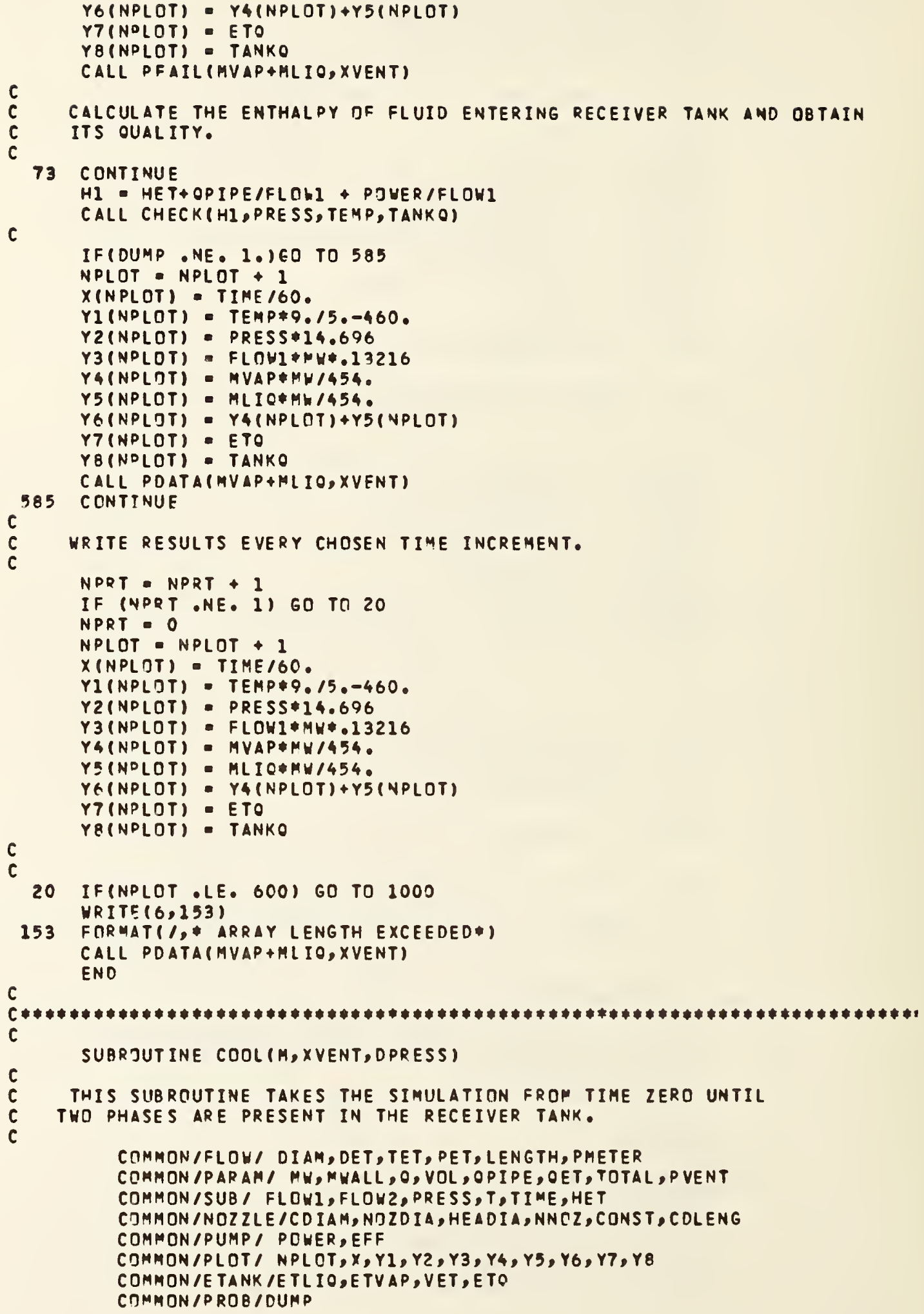




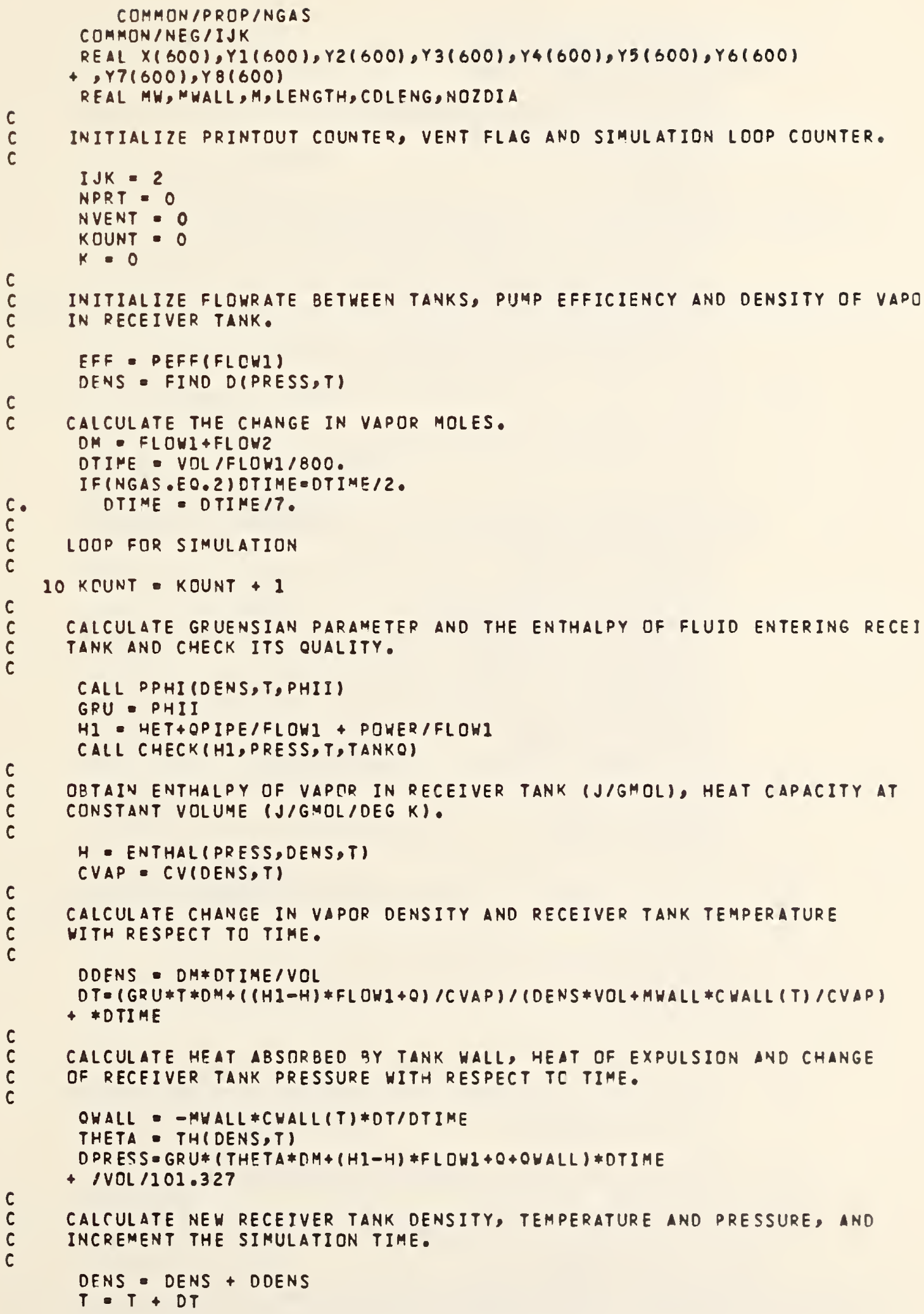




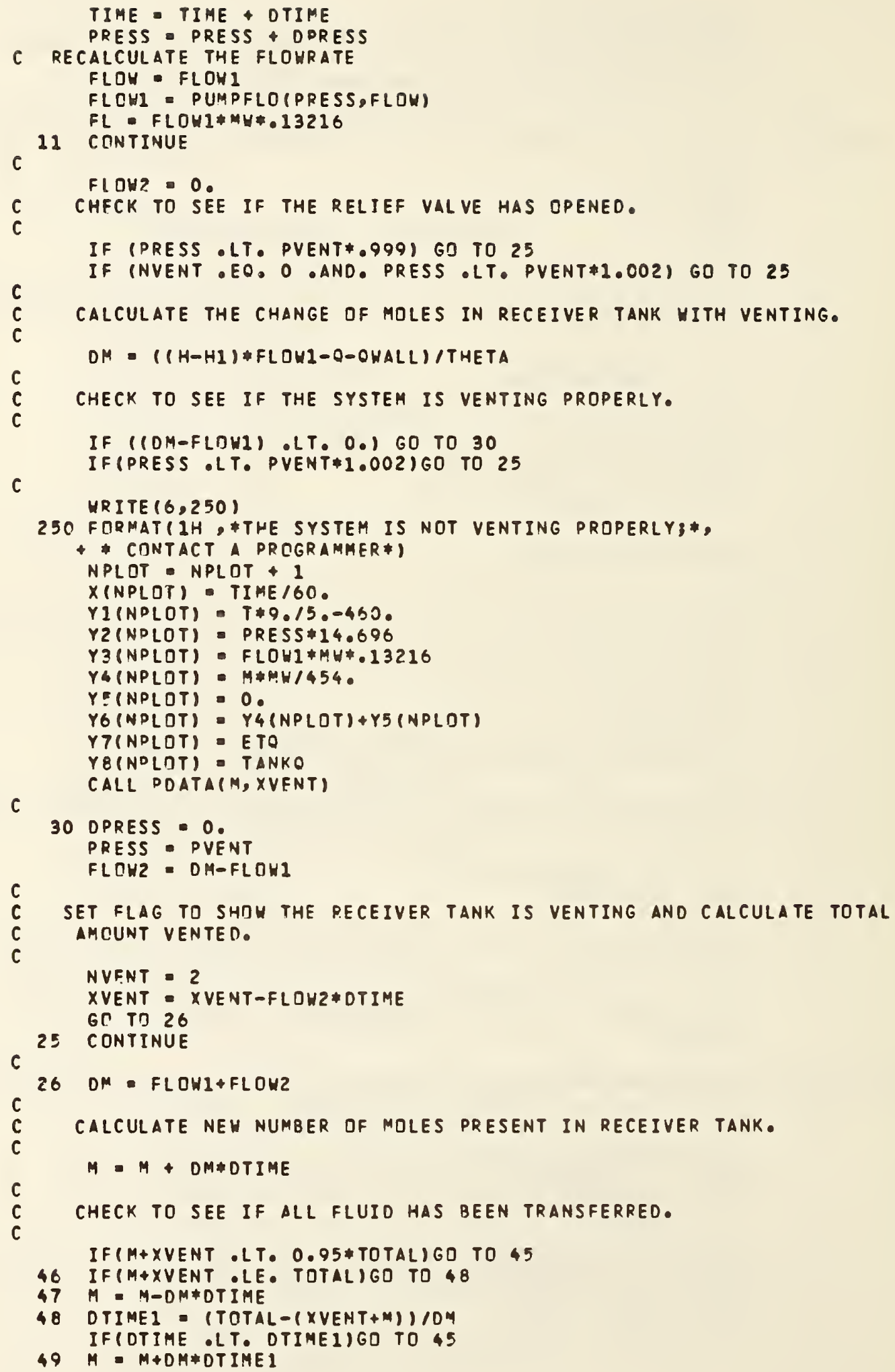


45 CALL CHECK(HET,PET, TET,ETO)

UPDATE THE SUPPLY TANK PRDPERTIES .

ETLIO - TOTAL-M-XVENT

CALL SUPPLY(DTIME)

IF BACK PRESSURE FRDM RECEIVER TANK IN THE ABSENCE OF A PUMP STOPS FLOV, CALL SUBROUTINE TO STOP PROGRAM.

IF (PRESS . GT. PET .AND. POHER .LT. .05)GO TO 33

C IF FLCW HAS STOPPED IN THE PRESENCE OF A PUMP DUE TO BACK PRESSURE FRDM THE RECEIVER, CALL A SUBROUTINE TO STOP PROGRAM.

IF (ABS (FLOWI) •LT. . I) GO TO 33

GO Tก 23

33 CONTINUE

NPLOT = NPLOT \& 3

$X(N P L D T)=$ TIME/60.

$Y I(N D L O T)=T \$ 9.15 .-460$.

$Y 2(N P L O T)=$ PRESS $\$ 14.696$

$Y 3(N P L O T)=F L O W I * M W * .13216$

$Y 4(N D L O T)=M \# M H / 454$.

$Y E(N P L O T)=0$.

$Y G(N P L O T)=Y 4(N P L O T)+Y 5(N P L O T)$

$Y 7(N P L O T)=E T O$

$Y B(N D L D T)=$ TANKO

CALL PFAIL (M, XVENT)

23 CONTINUE

IF IDUMP . NE . 1.160 TO 485

NPLOT = NPLOT + 1

$X(Y P L T T)=$ TIHE 160 .

$Y I(N P L O T)=T * 9.15 .-460$.

$Y 2(N P L O T)=P R E S S \$ 14.696$

$Y 3(N P L O T)=F L O H I * M H * .13216$

$Y 4(N P L O T)=M+M H / 454$.

$Y E(N D L O T)=0$

YG(NPLOT) = YG(NPLOT) +YS(NPLJT)

$Y 7(N D L O T)=E T O$

YB(NDLOT) = TANKO

CALL PDATA (M, XVENT)

485 CONTINUE

NPRT = NPRT + 1

C

WRITE SIMULATION VALUES INTO PLOT ARRAYS EVERY CHOSEN ITERATION.

IF (NPRT .NE. 5 ) GO TO 35

NPRT $=0$

$K=0$

NPLOT - NPLOT \& 1

$X(N P L O T)=T I M E / 60$.

$Y I(N P L O T)=T * 9.15 .-460$.

$Y 2(N P L O T)=P R E S S \$ 14.696$

Y3(NPLOT) = FLOHI*HH*.13216

$Y 4(N P L O T)=M * M H / 454$.

$Y S(N P L O T)=0$.

$Y A(N P L O T)=Y G(N P L O T)$

$Y Y(N P L O T)=E T O$

$Y B(N P L O T)=$ TANKO

C
C

IF RECEIVER TANK TEMPERATURE IS GREATER THAN CRITICAL TEMPERATURE, DON'T BOTHER CHECKING FOR THO PHASES IN RECEIVER TANK. 
c

IF (NGAS.EQ.2) GO TO 19

35 IF (T . GE. 40.) 60 YO 20

GO TO 36

$c$
$c$
$c$
$c$
$c$

19 IFIT.GE.157.160 TO 20

OBTAIN SATURATION TEMPERATURE AT RECEIVER TANK PRESSURE, USE THIS TO

GET SATURATION OENSITY, COMPARE SIMULATION ANO SATURATION OENSITIES

TO OETERHINE WHETHER OR NOT ANY LIOUID IS PRESENT IN THE RECEIVER TANI

36 TSAT = FINO TV(PRESS)

TTPRES = PRESS-1.E-5

DSAT = FIND D(TTPRES,TSAT)

OCALC - MIVOL

IF (T :LT. TSAT) T - TSAT

IF (OCALC . LE. DSAT) GO TO 20

$c$
$c$
$c$
$c$

IF THI PHASES ARE PRESENT, BACK UP ONE ITERATION ANO RETURN TO THE MAIN PRDGRAM. SHUT OFF COOL-DOHN NOZZLES, RECALCULATE FLOHRATE.

$M$ - $M$ - DM\#OTIME

DENS - DENS-DOENS

TIME - TIME-DTIME

PRESS = PRESS-DPRESS

c

$T=$ FIND TV (PRESS)

CONST $=0$.

COLENG = 0 .

IJK -1

FGUESS - FLOH1 * 5.

IF(NGAS .EQ. 2 ) FGUESS = FGUESS*4.

c

FLOWI - PUMPFLO(PRESS,FGUESS)

TIM = TIME/60.

VRITE $(6,58)$ TIM,KOUNT

58 FORMAT 1, * COOLOOWN TIME = *,F12.4,* KCUNT = *, I6)

RETURN

20 IFINPLOT .LE. 600)60 TO 10

WRITE $(6,151)$

151 FORMAT (* ARRAY LENGTH EXCEEOED*)

CALL POATA ( $M, X V E N T)$

ENO

C

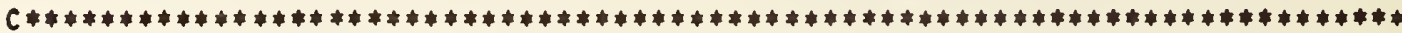

c

SUBRIITINE PPHIIDD, TT,PHII)

c

C SUBROUTINE TO CALCULATE THE gRUENSIAN PARAMETER (PHII) AS a

C FUNCTION OF OENSITY (GMOL/L) ANO TEMPERATURE (OEG K).

C

$0=$ no

$T \cdot T$

CALL DPOTCOT,O,TI

$C A P=C V(D, T)$

PHII = DT/D/CAP $\# 101.325$

RETURN

$c$

END

C

C

FUNCTION TH(OENS, TEMP)

C

C CALCULATE THE heAT OF EXPULSION (J/GMOL) AS A FUnCTION OF

c OENSITY (GMOLIL) aND TEMPERATURE (DEG K). 
C

CALL DPDT(DT,DENS, TEMP)

CALL DPDD (DD, DENS, TEMP)

TH - CP(DENS, TEMP) $\# D E N S \# D D / D T$

RETURN

C

END

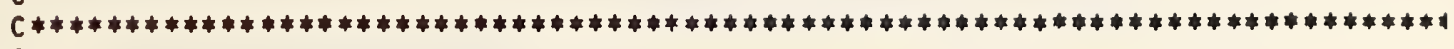

C

C

FUNCTION DVDPVIPRESS)

COMMON/PROB/DUMP

C

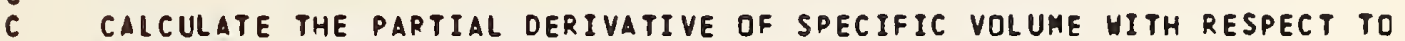

C PRESSURE FOR A SATURATED VAPOR.

C

PVAP - PRESS-1.E-5

TEMP - FINDTV(PRESS)

$c$
$C$
$C$

$V=1 . / F I N D$ D (PVAP, TEMP)

C SET AN INITIAL DELTA P

$D P=.05$

IF ( $(P R E S S-D P) \cdot L T \cdot 1, E-4) D P=D P / 2$.

KDUNT: 0

25 TEMP = FIND TV(DRESS-DP)

VLOW 1. IFIND D (PVAP-DP, TEMP)

TEMP - FIND TV (PRESS DP)

VHIEH = 1./FIND D (PVAP\DP, TEMP)

DVDPV = (VHIGH-VL NH) /DP $/ 2$.

$c$
$C$
$C$

SEE IF THE DERIVATIVE WILL CHANGE BY MAKING DELTA P SMALLER

IF (ABS ( (VHIGH-2.*V४VLDH)/(VHIGH-V)) .LT. 1.E-3) RETURN

KOUNT: KOUNT + 1

$c$
$C$

C IF THE SOLUTION HAS NOT CONVERGED, MAKE DELTA P SMALLER.

$D P=D P / 2$

C IF THF DERIVATIVE HAS NOT CONVERGED IN 100 ITERATIONS, HRITE AN

C ERROR MESSAGE (THIS FUNCTION USUALLY CONVERGES WITHIN 2-3 ITERATICNS)

C

IF (KDUNT ILE 100) GO TO 25

URITE $(6,125)$

125 FORMAT(IH, \#KOUNT EXCEEDS 100 FOR DVDPV. STOP PROGRAM*)

DUMP : 1 .

RETURN

END

C

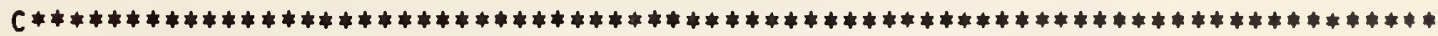

C

C

FUNCTION DVDPL (PRESS)

COMMDN/PROB /DUMP

C CALCULATE THE PARTIAL DERIVATIVE OF SPECIFIC VOLUME HITH RESPECT TO

C PRESSURE FOR SATURATED LIQUID. INPUT IS PRESSURE (ATM), OUTPUT

C DVDPL (L/GMOL/ATM)

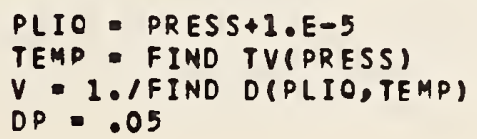




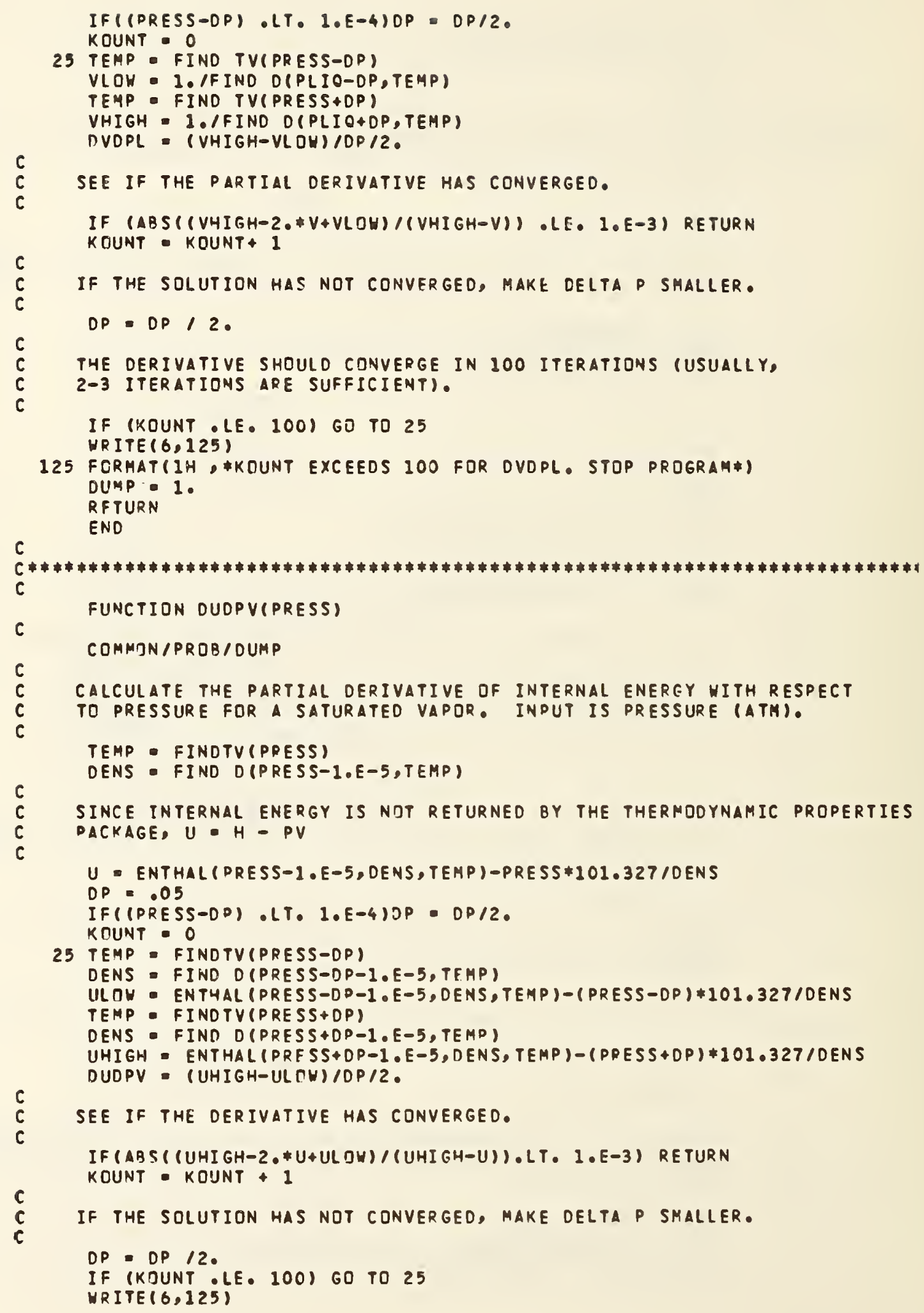




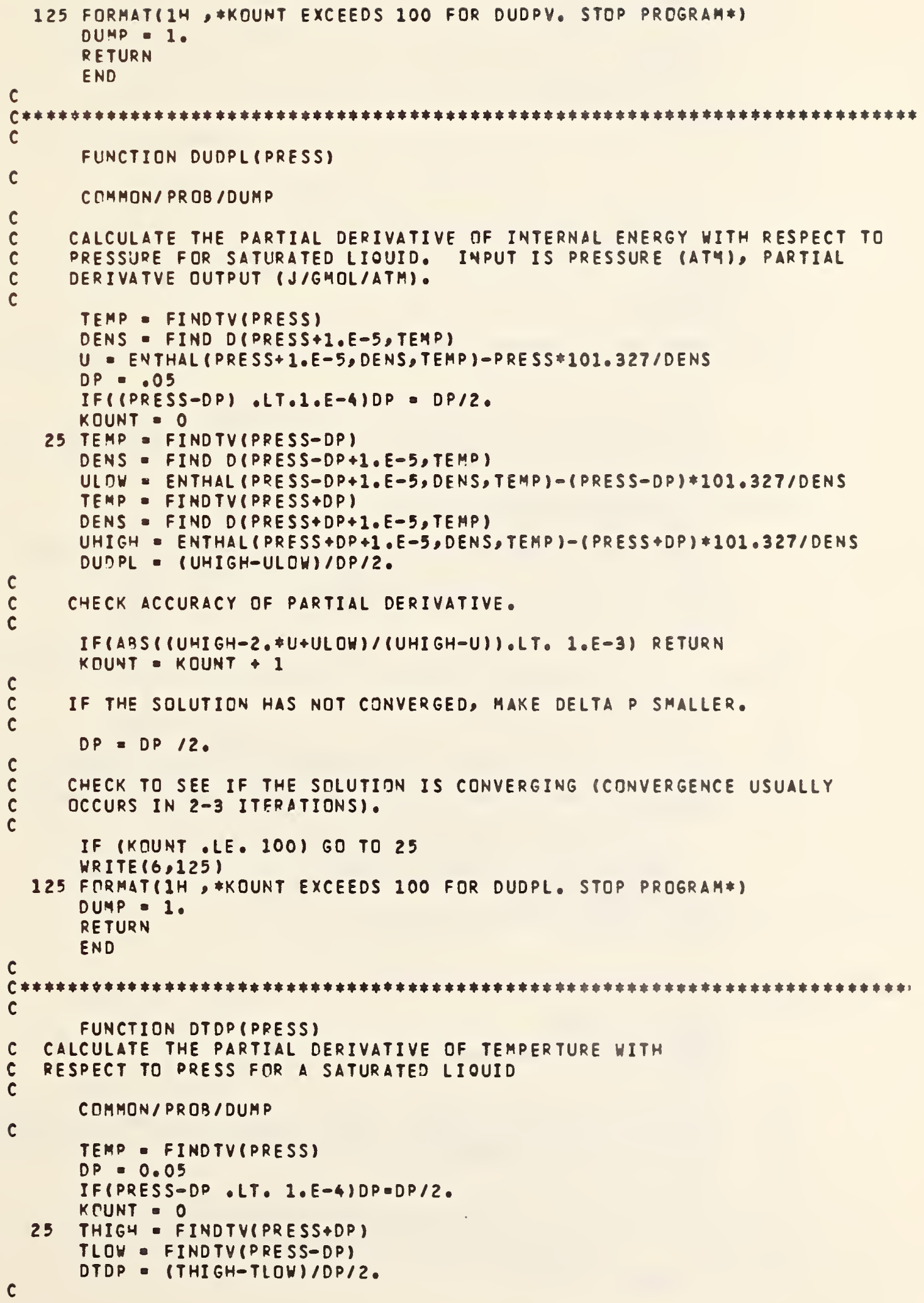




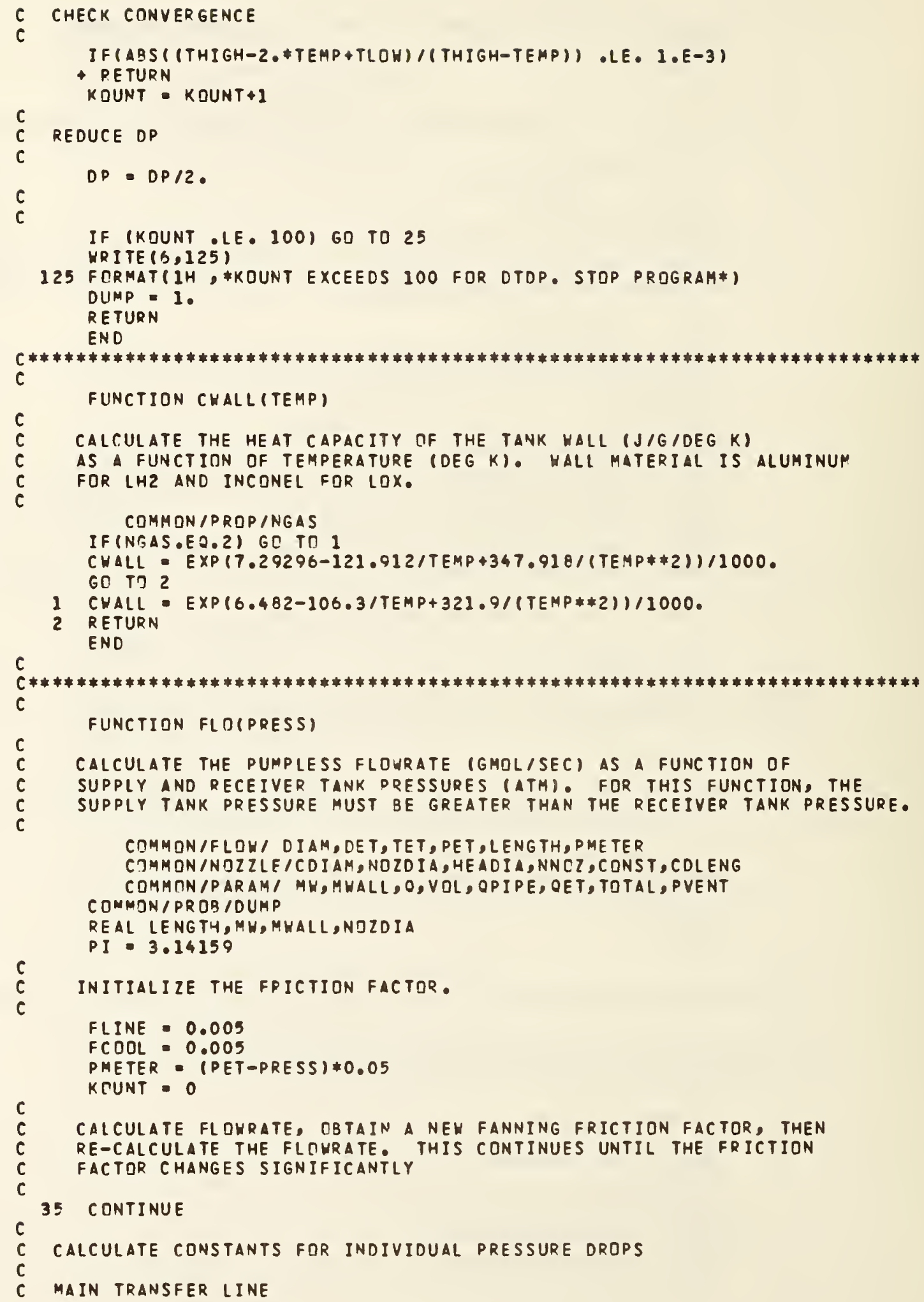




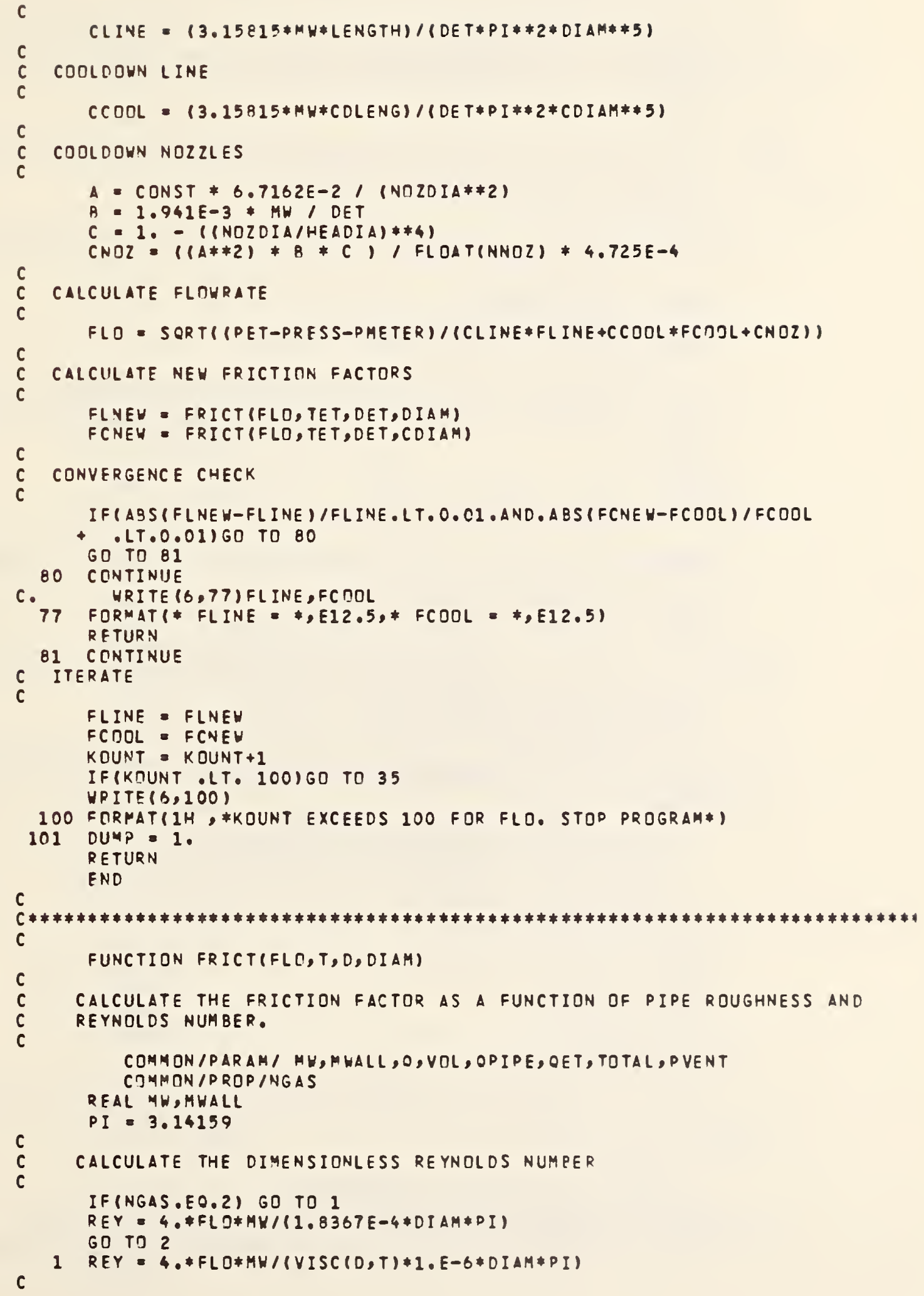




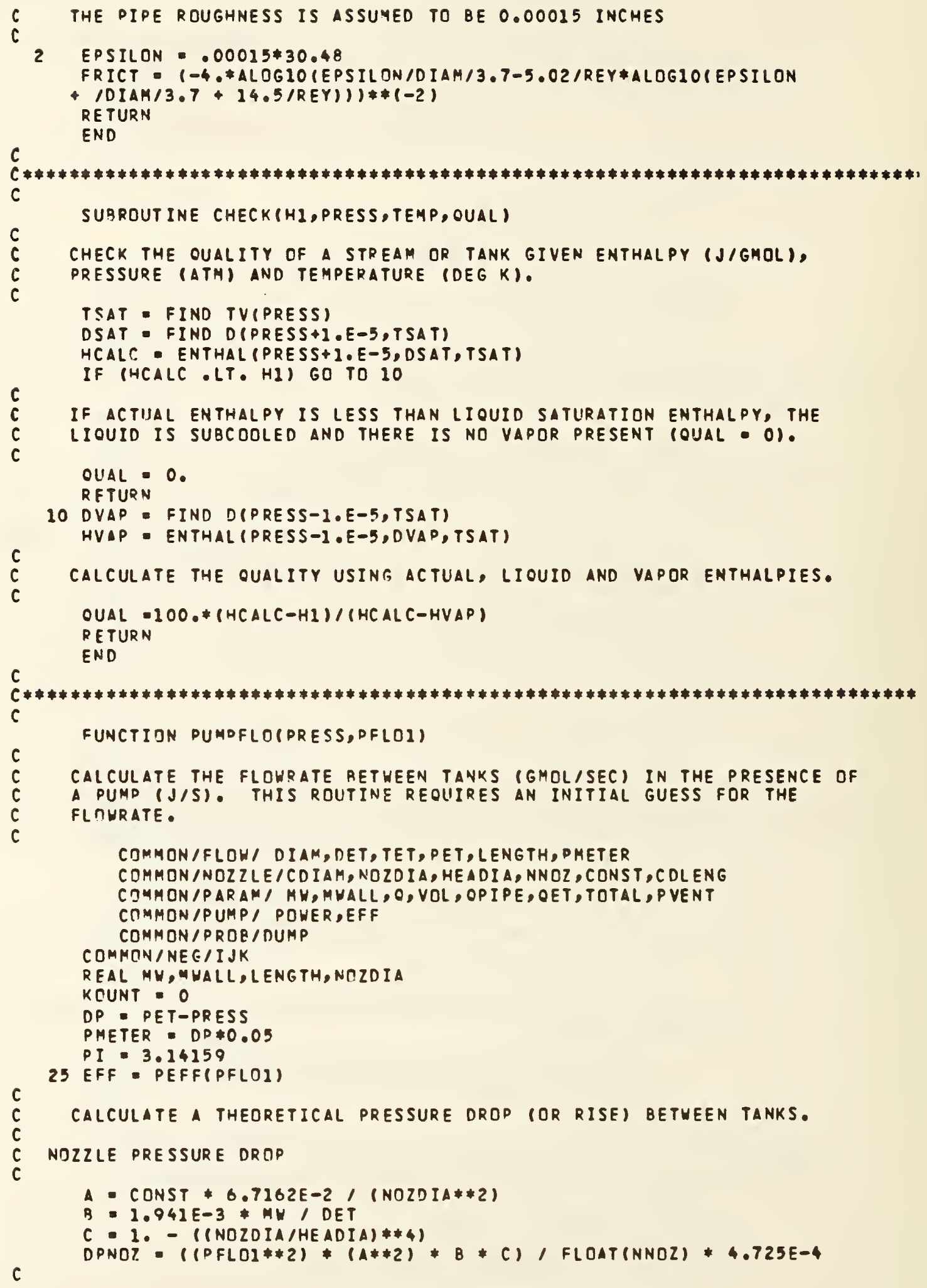

C

CALCULATE A THEORETICAL PRESSURE DROP (OR RISE) BETHEEN TANKS. NOZZLE PRESSURE DROP

$A$ - CONST *6.7162E-2/ (NOZDIA*\#2)

$B=1.941 E-3 \neq M H / D E T$

C. 1. - ( (NOZDIA /HE ADIA)**4)

C

DPNOZ - (PFLOI*\#2)*(A*2)*B*C) / FLOAT(NNOZ) \$.725E-4 


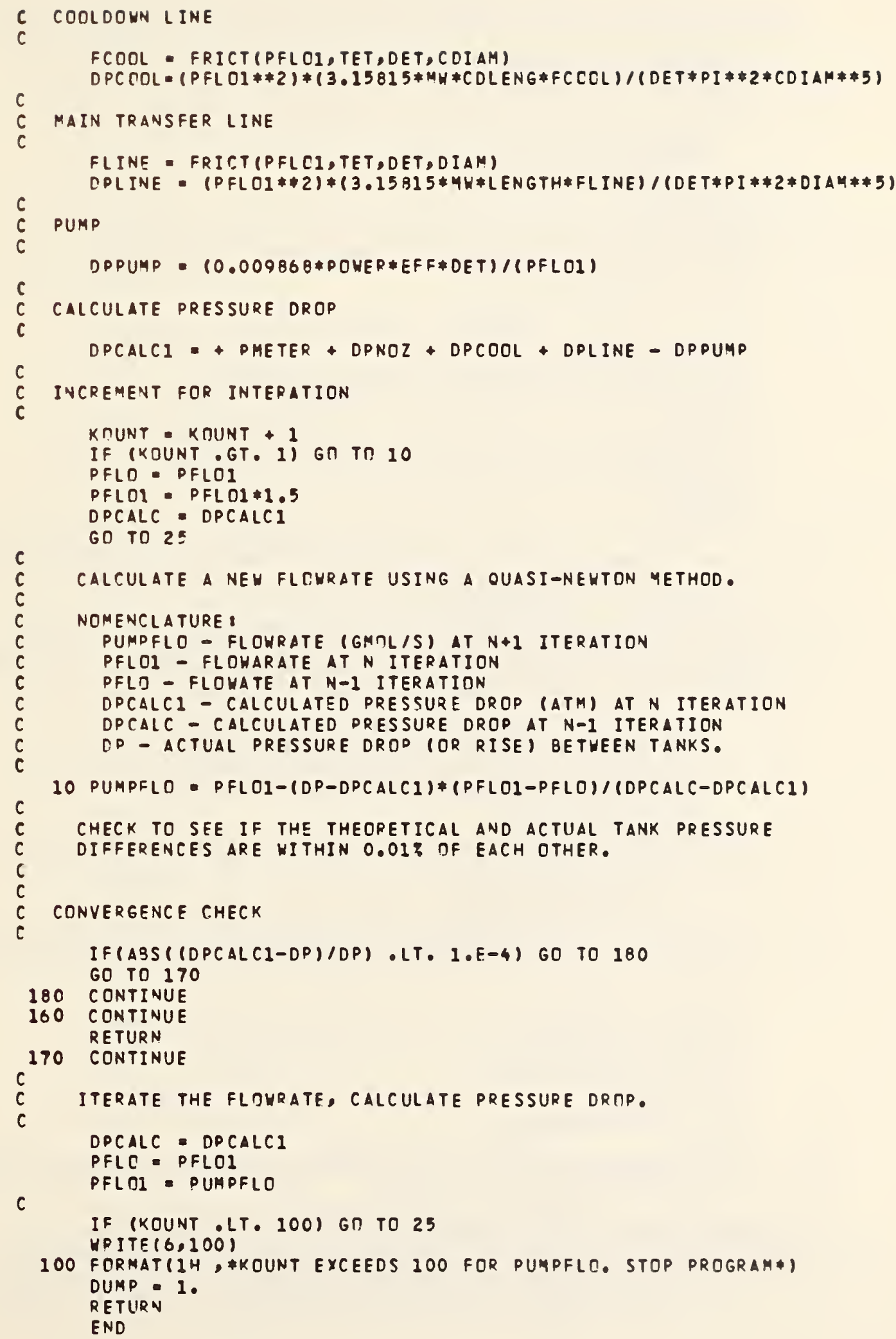




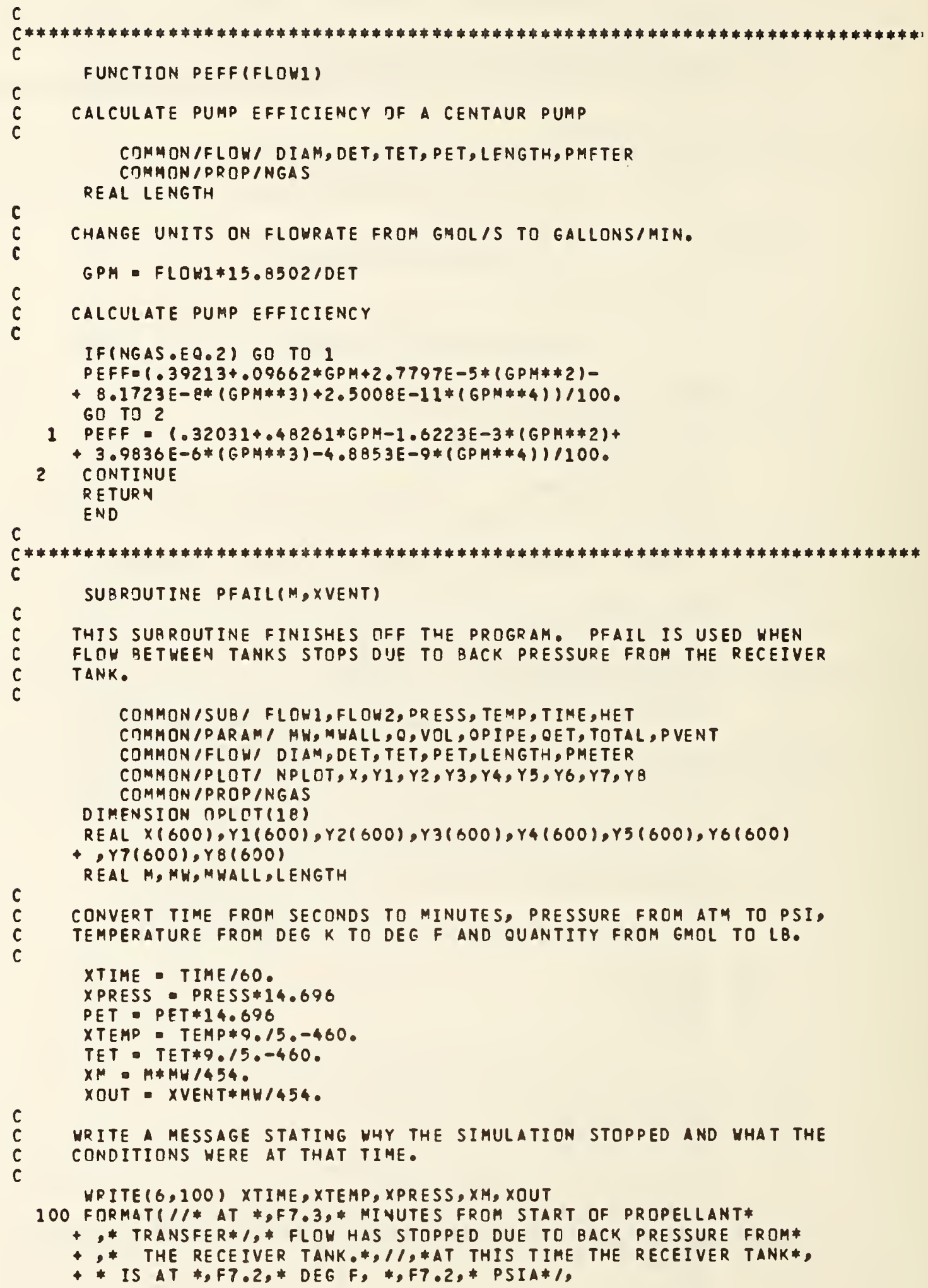


C

+ and contains *, fl0.2, pound *,

$+11, *$ DURING THE SIMULATION *,F8.2,* POUNDS MERE VENTER*

WRITE $(6,101)$ TET, PET

101 FORMATI/\# SUPPLY TANK IS AT \#F9.4,* DEG F, \#F7.2, \#PSIA\#)

C SKIP OVER OTHER MESSAGES AND GO TO INITIALIZATION OF PLOT DATA

C AND PARAMETERS.

C

GD TO 10

ENTRY FULL

$c$
$c$
$c$
$c$
$c$

THIS ENTRY IS USED WHEN THE RECEIVER TANK IS FULL OF LIOUID.

CONVERT TIME, TEMPERATURE, PRESSLRE AND QUANTITY IN RECEIVER TANK TO ENGLISH UNITS.

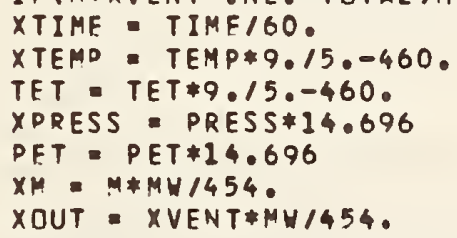

$c$
$c$
$c$

MRITE AN APPRDPRIATE RESSAGE AND STOPPING CONDITIONS.

HRITE $(6,120)$ XTIME, XTEMP, XPRESS, XM, XOUT

120 FCRMATI 1, AT *,F 7.3,* MINUTES FROM START OF PROPELLANT*,

+ * TRANSFER*1, * THE SUPPLY TANK IS EMPTY*, /, * AT THIS TIHE THE*

* RECEIVER TANK IS AT *,F7.2,* DEG F, *,F7.2,* PSIA,*1,

+ AND CONTAINS *,F10.2, \#PDUNDS*, 
* 1,* DURING THE SIMULATION *,F8.2,

* POUNDS HERE VENTED*I

MRITE $(6,121)$ TET, PET

121 FORMAT(/\# SUPPLY TANK IS AT \#F9.4,* DEG F, \#F7.2, \#PSIA*)

c IDENTIFY THE PROPELLANT FOR THE PLOTTING ROUTINE.

GO TO 10

ENTRY PDATA

C

C THIS ENTRY IS USED MHEN A PROGRAMAED STOP IS EXECUTED

C

C

CONVERT TO ENGLISH UNITS

XTIME - TIHE/60.

XPRESS - PRESS\$14.696

PET : PET\$14.696

XTEMP - TEMP\$9.15.-460.

TET $=$ TET $\$ 9.15 .-460$.

$X M=M Q M Y / 454$.

c

XOUT - XVENT\#HW/4540

C

WRITE A MESSAGE STATING THE CONDITIONS WHEN PROGRAM IS STOPPED

WRITE $(6,140)$ XTIME, XTEMP, XPRESS, XM, XOUT

140 FORMAT $/ /$, , $A T$ * F7.3,* MINUTES FROM START OF PROPELLANT*

+ * TRANSFER *1, * A STOP IS REACHED*, /1* AT THIS TIME THE*

* RECEIVER TANK IS AT *,F7.2,* DEG F, *,F7.2,* PSIA,*1,

* AND CONTAINS *,F10.2,*PDUNDS*,

* $1 /$, * DURING THE SIMULATION *,F8.2,

C

* pounds here vented*)

URITE $(6,141)$ TET,PET

141 FORMAT $/ /$ * SUPPLY TANK IS AT *F9.4,* DEG F, \#F7.2,* PSIA*)

10 CONTINUE

c

IF (NGAS.EO.2)GO TO 11

$$
\text { HPITE }(8,190)
$$

190 FQRMAT (\#HYDROGEN\#)

GD TO 12

11 URITE $(8,191)$

191 FORMAT (\$OXYGEN\$)

12 CONTINUE

c

C

WPITE $(8,200)$ NPLOT

200 FORMAT(I3)

c

C OPLOT(4) ARE BOUNDS FOR Y1, QPLOT(5) AND OPLOT(6) $A R E$ BOUNDS

C SET LOHER AND UPPER BOUNDARIES FOR PLOTS

C

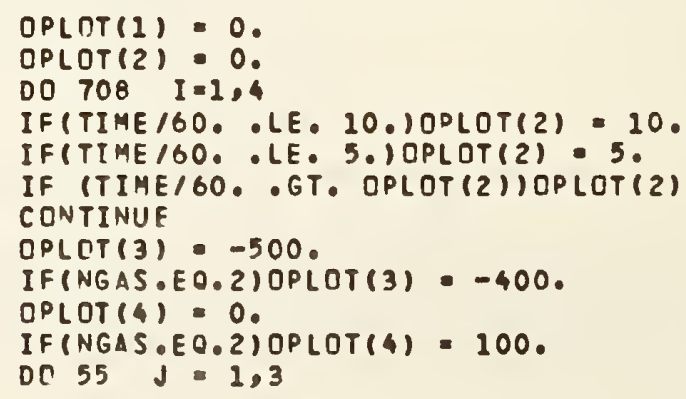




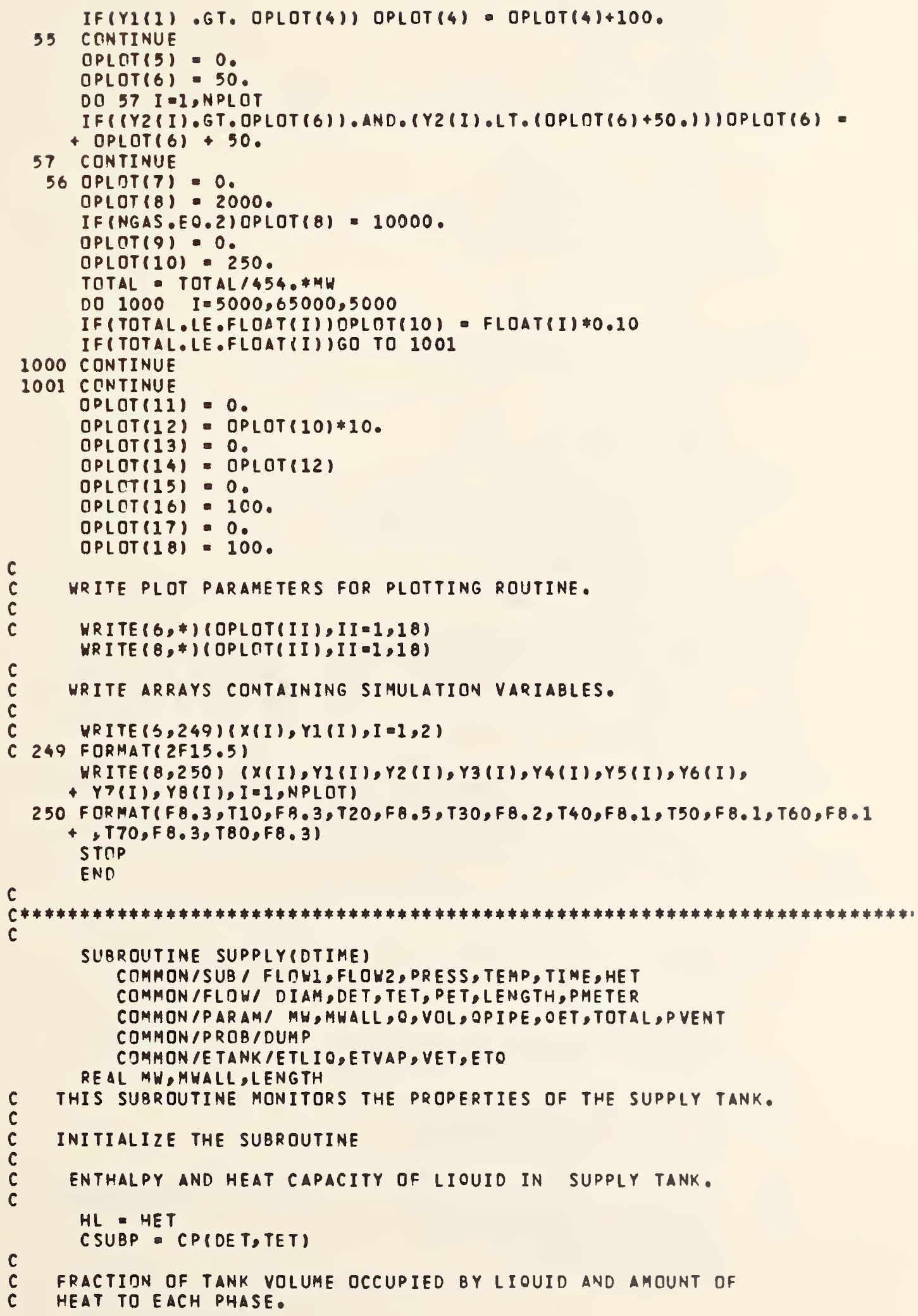


c

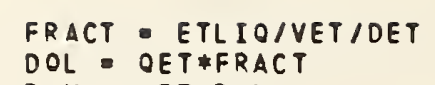

C

C

CALCULATE the change In the supply tank pRESS hith tIme

DPET - / -FLOH I +VETVAP/VETLIO/THETAV\#DOV+1./THETAL

1 \$ DOL / / ETLIO/ (VETLIO/THETAL / GRUL IO+ETVAP\#

? VETVAP \#2/ETLIO/VETLIO/THETAV/GRUVAP//101.327/ \$DTIME

$c$
$C$
$C$
$C$

Calculate the change in the supply tank liouid temperature WITH TIME

DTET = ( (DOL/ETLIO+VETLIO*ALPHAL (PET, TET, DET) \#DPET\#101.327 1 /DTIME / (CSUAP) \#DTIME

C CalCulate the change in the supply tank liquid enthalpy hith C TIME

C

DHL = (DOL/ETLIO+VETLIO\#DPET/DTIME*101.327)*DTIME

c

INCREMENT THE PRESSURE, LIOUID TEMPERATURE AND ENTHALPY

$P E T=P E T+D P E T$

$T E T=T E T+D T E T$

$H L$ - $H L+D H L$

C DBTAIN NEH LIOUID OENSITY AND ENTHALPY FROM FLUIDSPACK

C OBTAIN THE SUPPLY TANK LIOUID OUALITY

C

501 DET = FINDD (PET,TET)

HET = ENTHAL (PET, DET, TET)

C CALL CHECK(HET, PET, TET, ETO)

C IF OUALITY IS GREATER THAN ZERO, CAVITATION COULO OCCUR. STOP C TRANSFER IMMEDIATELY. IF (ETO.LT.1.E-6)GD TO 99 UPITE $(6,225)$ ETO 


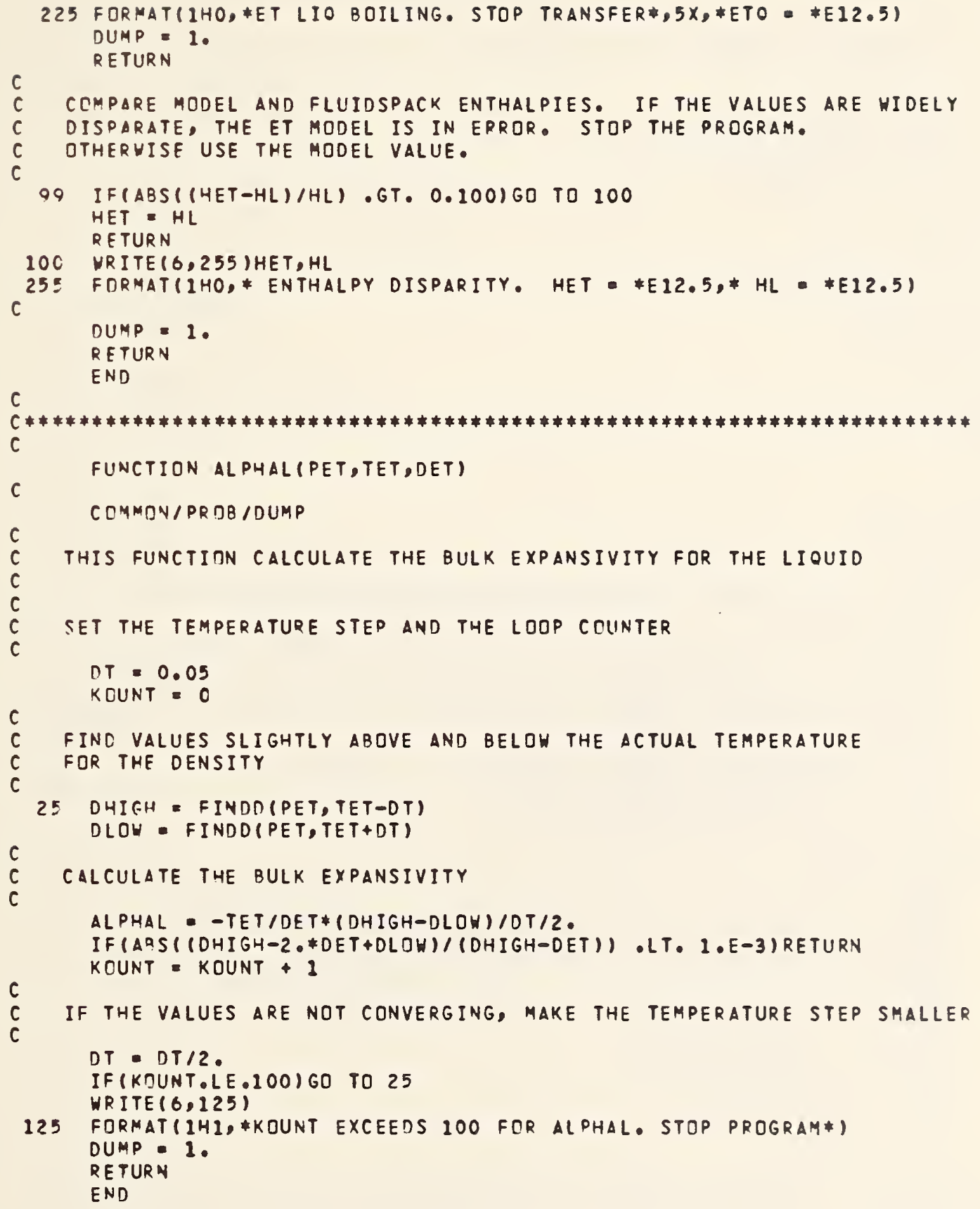


DEMO

.PROC ,DEMO .

**

* Demonstration PROgRaM USing disspla 9.0.

**.

EVICT, LGO, PLOT .

FTN $, I=P R O G, L=F A I L, R=3, P M D$.

IFE, FILE(GRAFING, .NOT .AS), JO .

GET, GRAF ING /UN $=$ GRAF .

ENDIF, JO.

GET, TAPE2 =P SDATA.

BEGIN, DISPLA9 , GRAFING .

RETURN, PROG, LGO.

REPLACE , PLOT .

RENAME , Z=PLOT .

SKIPR, Z .

COPYBR, Z, OUTPU'T, 1 .

REVERT.

EXIT.

REVERT, ABORT.

REPLACE, FAIL.

-DATA, PROG

PROGRAM DEMO ( INPUT , TAPE2, OUTPUT $=/ 1000$, PLOT $=/ 1000$ )

REAL LMIN, LMAX

DIMENS ION X(400), Y1(400), Y2(400), Y3(400), Y4(400), Y5(400),

$+\mathrm{Y} 6(400), \mathrm{Y} 7(400), \mathrm{Y} 8(400)$

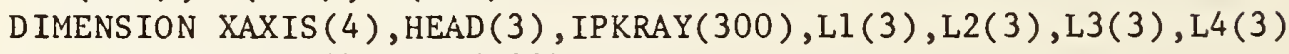

DIMENSION NAME(2), IPK2(100)

DATA XAXIS/10HTIME (MINU, 10HTES) \$ , $2 * 10 \mathrm{H}$

$\operatorname{READ}(2, *)$ DIAM, POWER, TEMP , PRESS

$\operatorname{READ}(2,80)$ NAIM $(1), \operatorname{NAME}(2)$

80 FORMAT (2A4)

$\operatorname{READ}(2, *) \mathrm{N}$

READ $(2, *)$ TM1, TM2 , TMIN, TMAX, PMIN, PMAX, FMIN, FMAX, VMIN,

+ VMAX, LMIN, LMAX, DUM1 ,DUM2 ,DUM3 , DUM4 ,DUM5, DUM6

DTIME $=($ TM2-TM1 $) / 10$.

DTEMP $=($ TMAX-TMIN $) / 5$.

DPRESS $=($ PMAX-PMIN $) / 5$.

DFLOW $=($ FMAX-FMIN $) / 5$.

DVAP $=($ VMAX - VMIN $) / 5$.

$\mathrm{DLIQ}=($ LMAX - LMIN $) / 5$.

DO $10 \mathrm{I}=1, \mathrm{~N}$

$10 \operatorname{READ}(2, *) X(I), Y 1(I), Y 2(I), Y 3(I), Y 4(I), Y 5(I), Y 6(I), Y 7(I), Y 8(I)$

C

CALLID( " LOUIE, $\$ ", 100)$

CALL IPP7221

CALL FR80(0.0)

C CALL TK4010(120)

C CALL HWSPEC(4HPLOT, 4HFILE)

CALL NOBRDR

CALL PHYSOR $(1.25,6$.

CALL AREA2D $(6 ., 4 \cdot)$

$\operatorname{ENCODE}(30,100, \operatorname{HEAD}) \operatorname{NAME}(1), \operatorname{NAME}(2)$ 
100 FORHAT (2A4," PROPELLANT TRANSFERS")

CALL HEADIN (HEAD, $100,1.25,1$ )

CALL XNAME (XAXIS, 100)

CALL YNAME("TEMPERATURE (DEG F) $\$ ", 100$ )

CALL YAXANG(O.)

$\operatorname{ENCODE}(30,15, \mathrm{~L} 1)$ DIAM

15 FORMAT("DIAMETER: ",F4.1," IN.\$")

ENCODE $(30,20$, L 2) POWER

20 FORMAT ("PUMP: ",F4.1," HP\$")

$\operatorname{ENCODE}(30,25, \mathrm{~L} 3)$ TEMP

25 FORMAT("TAIJK TEMP: ",F6.1," DEG F\$")

ENCODE $(30,30, L 4)$ PRESS

30 FORMAT("TANK PRESS: ",F4.1," PSIA\$")

CALL LINES (L1, IPKRAY, 1)

CALL LINES(L2, IPKRAY, 2)

CALL LINES (L3, IPKRAY, 3)

CALL LINES ( 4 , IPKRAY, 4)

CALL LSTORY (IPKRAY , $4,3.5,3.0$ )

CALL GRAF(TM1, DTIME, TM2, TMIN, DTEMP, TMAX)

CALL CURVE $(X, Y 1, N, 0)$

CALL ENDGR(0)

CALL PHYSOR $(1.25,1$.

CALL AREA2D $(6 ., 4$.

CALL XNAME (XAXIS, 100)

CALL YNAME("PRESSURE (PSIA)\$",100)

CALL YAXANG (O.)

CALL GRAF (TM1 , DT ILIE, TM2, PMIN, DPRESS, PMAX)

CALL CURVE $(X, Y 2, N, 0)$

CALL ENDGR $(0)$

CALL ENDPL(0)

CALI, NOBRDR

CALL YAXANG(0.)

CALL PHYSOR $(1.25,6$.

CALL AREA2D $(6 ., 4 \cdot)$

CALL HEADIN(HEAD, 100, 1.25, 2)

CALL HEADIN("(PAGE 2)\$",100,1.,2)

CALL XNAME(XAXIS, 100)

CALL YNAME("POUNDS IN VAPOR PHASES",100)

CALL GRAF (TM1, DTIME, TM2, VNIN, DVAP, VMAX)

CALL CURVE $(X, Y 4, N, 0)$

CALL ENUGR(0)

CALL YAXANG(0.)

CALL PHYSOR $(1.25,1$.

CALL AREA2D $(6 \cdot, 4$.

CALL XNAME (XAXIS, 100)

CALL YNAME ("POUNDS IN LIQUID PHASES", 100)

CALL GRAF(TM1, DTIME, TM2, LMIN, DL IQ, LMAX)

CALL CURVE $(X, Y 5, N, 0)$

CALL ENDGR(O)

CALL ENDPL(O)

CALL MOBRDR

CALL YAXANG $\left(0^{\circ}\right)$

CALL PHYSOR $(1.25,6$.

CALL AREA2D $(6 ., 4$. 
CALL HEADIN(HEAD, 100, 1.25, 2)

CALL HEADIN("(PAGE 3) \$",100,1.,2)

CALL XNAME (XAXIS, 100)

CALL YNAME("TOTAL POUNDS TRANSFERRED\$",100)

CALL GRAF( TM1, DTIME, TM2, LMIN, DLIQ, LMAX)

CALL CURVE $(X, Y 6, N, 0)$

CALL ENDGR(0)

CALL YAXANG(0.)

CALL PHYSOR $(1.25,1$.

CALL AREA2D $(6 \cdot, 4 \cdot)$

CALL XNAME (XAXIS, 100)

CALL YNAME ("FLOWRATE (POUNDS/MIN)\$",100)

CALL GRAF (TM1 ,DTIME, TM2, FMIN,DFLOW, FMAX)

CALL CURVE $(\mathrm{X}, \mathrm{Y} 3, \mathrm{~N}, 0)$

CALL ENDPL (0)

CALL PHYSOR $(1.5,6$.

CALL AREA2D $(6 \cdot, 4 \cdot)$

CALL HEADIN(HEAD, 100,1.25,2)

CALL HEADIN("(PAGE 4)\$",100,1.,2)

CALL XNAME(XAXIS, 100)

CALL $\operatorname{YNAME}(1 \mathrm{H}, 1)$

CALL YNONUM

CALL LINES("SUPPLY\$", IPK2,1)

CALL LINES("RECEIVER INLET\$",,IPK2,2)

CALL GRAF(TM1,DTIME,TM2,-10.,120.,110.)

CALL RLVEC(TMl-.2,0.,TMl+.2,0.,0)

CALL RLVEC(TM1-.2,100.,TM1+.2,100.,0)

$\mathrm{X} 1=\mathrm{XINVRS}(\mathrm{XMESS}(" 100 \%$ LIQ. $\$ ", 100), 0$.

$\mathrm{X} 2=\operatorname{XINVRS}(\mathrm{XMESS}(" 100 \%$ VAP. $\$ ", 100), 0$.

CALL RLIMESS( $100 \%$ LIQ. $\$ ", 100$, TMI-.2-X1,0.)

CALL RLMESS("100\% VAP. \$",100,TM1-.2-X2,100.)

CALL CURVE $(X, Y 7, N, 10)$

CALL CUKVE $(X, Y 8, N, 10)$

CALL LEGEND (IPK $2,2,3 ., 3$.

CALL ENDPL(0)

CALL DONEPL

STOP

END 
PROGRAM PLOT ( INPUT, TAPE6, OUTPUT=TAPE6, TAPE8=INPUT)

REAL TIME(400), TEMP(400), PRESS (400), FLOWI (400), MVAP(400), MLIQ (400)

REAL LLB, LUB

$\operatorname{READ}(8, *)$ DUM1 , DUM2 , DUM3 , DUM4

$\operatorname{READ}(8,90)$ NAME

90 FORMAT(A10)

$\operatorname{READ}(8,100) \mathrm{N}$

100 FORMAT(I3)

READ $(8$, *) TLB , TUB , TEMPLB , TEMPUB , PLB , PUB , FLB , FUB , VLB , VUB , LLB , LUB,

+ TOTLB, TOTUB, Q1LB, Q1UB, Q2LB, Q2UB

DO $10 I=1, N$

$10 \operatorname{READ}(8,110) \operatorname{TIME}(I), \operatorname{TEMP}(I), \operatorname{PRESS}(\mathrm{I}), \operatorname{FLOWl}(\mathrm{I}), \operatorname{MVAP}(\mathrm{I}), \operatorname{MLIQ}(\mathrm{I})$

110 FORMAT (F8.3 , T10,F8.3, T20, F8 .5 , T30, F8 . 2, T40, F8 .1, T50, F8.1)

ILOG $=0$

ISIZE $=0$

NOUT $=0$

$\operatorname{WRITE}(6,120)$

120 FORMAT( 1 Hl, *ORBITER TANK TEMPERATURE (DEGREES F) VS.*

,$+ *$ TIME (MINUTES)*)

CALL PPC(TEMP, TIME, N, ILOG, ISIZE, NOUT, TEMPLB, TEMPUB, TLB , TUB)

WRITE $(6,130)$

130 FORMAT (1H1, *TANK PRESSURE (PSIA) VS. TIME (MINUTES)*)

CALL PPC(PRESS, TIME, N, ILOG, ISIZE, NOUT, PLB, PUB , TLB, TUB)

WRITE $(6,140)$

140 FORMAT (1HI, *FLOWRATE (LB/MIN) VS. TIME (MINUTES)*)

CALL PPC(FLOW1, TIME, N, ILOG, ISIZE, NOUT , FLB , FUB , TLB , TUB)

$\operatorname{WRITE}(6,150)$

150 FORMAT ( $1 \mathrm{Hl}$, *POUNDS IN VAPOR PHASE VS. TIME (MINUTES)*)

CALL PPC(MVAP, TIME, $N$, ILOG, ISIZE, NOUT, VLB, VUB, TLB, TUB)

$\operatorname{WRITE}(6,160)$

160 FORMAT ( $1 \mathrm{Hl}$, *POUNDS IN LIQUID PHASE VS. TIME (MINUTES)*)

CALL PPC(MLIQ, TIME, N, ILOG, ISIZE, NOUT , LLB, LUB, TLB , TUB)

STOP

END 
PSDATA

4. 4. 60.1. OXYGEN

64

0. 5. $-400 \cdot 100 \cdot 0 \cdot 50 \cdot 0 \cdot 10000 \cdot 0 \cdot 1000 \cdot 0 \cdot 10000 \cdot 0 \cdot 10000 \cdot 0 \cdot 100 \cdot 0 \cdot 100$.

\begin{tabular}{|c|c|c|c|c|c|c|c|c|}
\hline .001 & 48.699 & 2.75189 & 3398.11 & 3.1 & 0.0 & 3.1 & 0.000 & 8.601 \\
\hline .002 & 37.590 & 4.42648 & 3398.11 & 6.2 & 0.0 & 6.2 & 0.000 & 5.954 \\
\hline .003 & 26.672 & 6.02568 & 3398.11 & 9.3 & 0.0 & 9.3 & 0.000 & 4.107 \\
\hline .004 & 15.938 & 7.55134 & 3398.11 & 12.4 & 0.0 & 12.4 & 0.000 & 2.671 \\
\hline .005 & 5.384 & 9.00520 & 3398.11 & 15.5 & 0.0 & 15.5 & 0.000 & 1.493 \\
\hline .005 & $-4 \cdot 998$ & 10.38895 & 3398.11 & $18 \cdot 6$ & 0.0 & 18.6 & 0.000 & .494 \\
\hline .006 & $-15 \cdot 211$ & 11.70422 & 3398.11 & 21.7 & 0.0 & 21.7 & 0.000 & 0.000 \\
\hline .007 & $-25 \cdot 260$ & 12.95254 & 3398.11 & 24.8 & 0.0 & 24.8 & 0.000 & 0.000 \\
\hline .008 & -35.151 & 14.13541 & 3398.11 & 27.9 & 0.0 & 27.9 & 0.000 & 0.000 \\
\hline .009 & $-44 \cdot 889$ & 15.25425 & 3398.11 & 31.0 & 0.0 & 31.0 & 0.000 & 0.000 \\
\hline .010 & -54.477 & 16.31042 & 3398.11 & 34.1 & 0.0 & 34.1 & 0.000 & 0.000 \\
\hline .011 & -63.921 & 17.30522 & 3398.11 & 37.2 & 0.0 & 37.2 & 0.000 & 0.000 \\
\hline .012 & $-73 \cdot 224$ & 18.23991 & 3398.11 & 40.3 & 0.0 & 40.3 & 0.000 & 0.000 \\
\hline .013 & -82.391 & 19.11569 & 3398.11 & 43.4 & 0.0 & 43.4 & 0.000 & 0.000 \\
\hline .014 & -91.425 & 19.93369 & 3398.11 & $46 \cdot 5$ & 0.0 & 46.5 & 0.000 & 0.000 \\
\hline .015 & -100.331 & 20.69502 & 3398.11 & 49.6 & 0.0 & 49.6 & 0.000 & 0.000 \\
\hline .016 & $-109 \cdot 113$ & 21.40072 & 3398.11 & 52.8 & 0.0 & 52.8 & 0.000 & 0.000 \\
\hline .016 & -117.773 & 22.05177 & 3398.11 & 55.9 & 0.0 & 55.9 & 0.000 & 0.000 \\
\hline .017 & $-126 \cdot 316$ & 22.64913 & 3398.11 & 59.0 & 0.0 & 59.0 & 0.000 & 0.000 \\
\hline .018 & -134.745 & 23.19370 & 3398.11 & 62.1 & 0.0 & 62.1 & 0.000 & 0.000 \\
\hline .019 & -143.064 & 23.68633 & 3398.11 & 65.2 & 0.0 & 65.2 & 0.000 & 0.000 \\
\hline .020 & $-151 \cdot 276$ & 24.12782 & 3398.11 & 68.3 & 0.0 & 68.3 & 0.000 & 0.000 \\
\hline .021 & -159.383 & 24.51894 & 3398.11 & 71.4 & 0.0 & 71.4 & 0.000 & 0.000 \\
\hline .022 & $-167 \cdot 390$ & 24.86040 & 3398.11 & 74.5 & 0.0 & 74.5 & 0.000 & 0.000 \\
\hline .023 & -175.299 & 25.15287 & 3398.11 & 77.6 & 0.0 & 77.6 & 0.000 & 0.000 \\
\hline .024 & -183.114 & 25.39698 & 3398.11 & 80.7 & 0.0 & 80.7 & 0.000 & 0.000 \\
\hline .025 & -190.836 & 25.59330 & 3398.11 & 83.8 & 0.0 & 83.8 & 0.000 & 0.000 \\
\hline .026 & -198.469 & 25.74237 & 3398.11 & 86.9 & 0.0 & 86.9 & 0.000 & 0.000 \\
\hline .026 & -206.015 & 25.84467 & 3398.11 & 90.0 & 0.0 & 90.0 & 0.000 & 0.000 \\
\hline .027 & -213.476 & 25.90064 & 3398.11 & 93.1 & 0.0 & 93.1 & 0.000 & 0.000 \\
\hline .028 & -220.856 & 25.91069 & 3398.11 & 96.2 & 0.0 & 96.2 & 0.000 & 0.000 \\
\hline .029 & -228.155 & 25.87516 & 3398.11 & 99.3 & 0.0 & 99.3 & 0.000 & 0.000 \\
\hline .030 & -235.376 & 25.79435 & 3398.11 & 102.4 & 0.0 & 102.4 & 0.000 & 0.000 \\
\hline .031 & -242.520 & 25.66852 & 3398.11 & 105.5 & 0.0 & 105.5 & 0.000 & 0.000 \\
\hline .032 & -249.589 & 25.49788 & 3398.11 & 108.6 & 0.0 & 108.6 & 0.000 & 0.000 \\
\hline .033 & -256.583 & 25.28260 & 3398.11 & 111.7 & 0.0 & 111.7 & 0.000 & 0.000 \\
\hline .034 & -263.502 & 25.02281 & 3398.11 & 114.8 & 0.0 & 114.8 & 0.000 & 0.000 \\
\hline .035 & $-270 \cdot 347$ & 24.71859 & 3398.11 & 117.9 & 0.0 & 117.9 & 0.000 & 0.000 \\
\hline .036 & -277.115 & 24.37000 & 3398.11 & 121.0 & 0.0 & 121.0 & 0.000 & 0.000 \\
\hline .037 & -283.805 & 23.97707 & 3398.11 & 124.1 & 0.0 & 124.1 & 0.000 & 0.000 \\
\hline .037 & -290.413 & 23.53982 & 3398.11 & 127.2 & 0.0 & 127.2 & 0.000 & 0.000 \\
\hline .038 & -295.604 & 23.06581 & 3398.11 & 130.3 & 0.0 & 130.3 & 0.000 & 0.000 \\
\hline .145 & -291.025 & 21.25714 & 2628.10 & 116.0 & 293.3 & 409.3 & 0.000 & 0.000 \\
\hline .253 & -292.181 & 19.97737 & 2628.10 & 108.0 & 583.2 & 691.3 & 0.000 & 0.000 \\
\hline .360 & -293.033 & 19.07144 & $2628 \cdot 10$ & 102.1 & 871.1 & 973.2 & 0.000 & 0.000 \\
\hline .467 & -293.684 & 18.40162 & 2628.10 & 97.4 & 1157.8 & 1255.2 & 0.000 & 0.000 \\
\hline .575 & -294.195 & 17.88860 & 2628.10 & 93.5 & 1443.6 & 1537.1 & 0.000 & 0.000 \\
\hline
\end{tabular}




$\begin{array}{lllllllll}.682 & -294.606 & 17.48423 & 2628.10 & 90.3 & 1728.8 & 1819.0 & 0.000 & 0.000 \\ .789 & -294.942 & 17.15792 & 2628.10 & 87.4 & 2013.5 & 2101.0 & 0.000 & 0.000 \\ .896 & -295.223 & 16.88937 & 2628.10 & 84.9 & 2298.0 & 2382.9 & 0.000 & 0.000 \\ 1.004 & -295.461 & 16.66470 & 2628.10 & 82.6 & 2582.2 & 2664.8 & 0.000 & 0.000 \\ 1.111 & -295.664 & 16.47408 & 2628.10 & 80.5 & 2866.3 & 2946.8 & 0.000 & 0.000 \\ 1.218 & -295.840 & 16.31039 & 2628.10 & 78.5 & 3150.1 & 3228.7 & 0.000 & 0.000 \\ 1.325 & -295.994 & 16.16835 & 2628.10 & 76.7 & 3433.9 & 3510.6 & 0.000 & 0.000 \\ 1.433 & -296.130 & 16.04397 & 2628.10 & 74.9 & 3717.6 & 3792.5 & 0.000 & 0.000 \\ 1.540 & -296.251 & 15.93416 & 2628.10 & 73.3 & 4001.2 & 4074.5 & 0.000 & 0.000 \\ 1.647 & -296.358 & 15.83652 & 2628.10 & 71.7 & 4284.7 & 4356.4 & 0.000 & 0.000 \\ 1.755 & -296.455 & 15.74914 & 2628.10 & 70.1 & 4568.2 & 4638.3 & 0.000 & 0.000 \\ 1.862 & -296.543 & 15.67050 & 2628.10 & 68.6 & 4851.6 & 4920.3 & 0.000 & 0.000 \\ 1.969 & -296.622 & 15.59936 & 2628.10 & 67.2 & 5135.0 & 5202.2 & 0.000 & 0.000 \\ 2.076 & -296.694 & 15.53469 & 2628.10 & 65.7 & 5418.4 & 5484.1 & 0.000 & 0.000 \\ 2.184 & -296.761 & 15.47565 & 2628.10 & 64.3 & 5701.7 & 5766.0 & 0.000 & 0.000 \\ 2.291 & -296.822 & 15.42154 & 2628.10 & 63.0 & 5985.0 & 6048.0 & 0.000 & 0.000 \\ 2.355 & -296.867 & 15.38141 & 2628.10 & 61.9 & 6211.6 & 6273.5 & 0.000 & 0.000\end{array}$




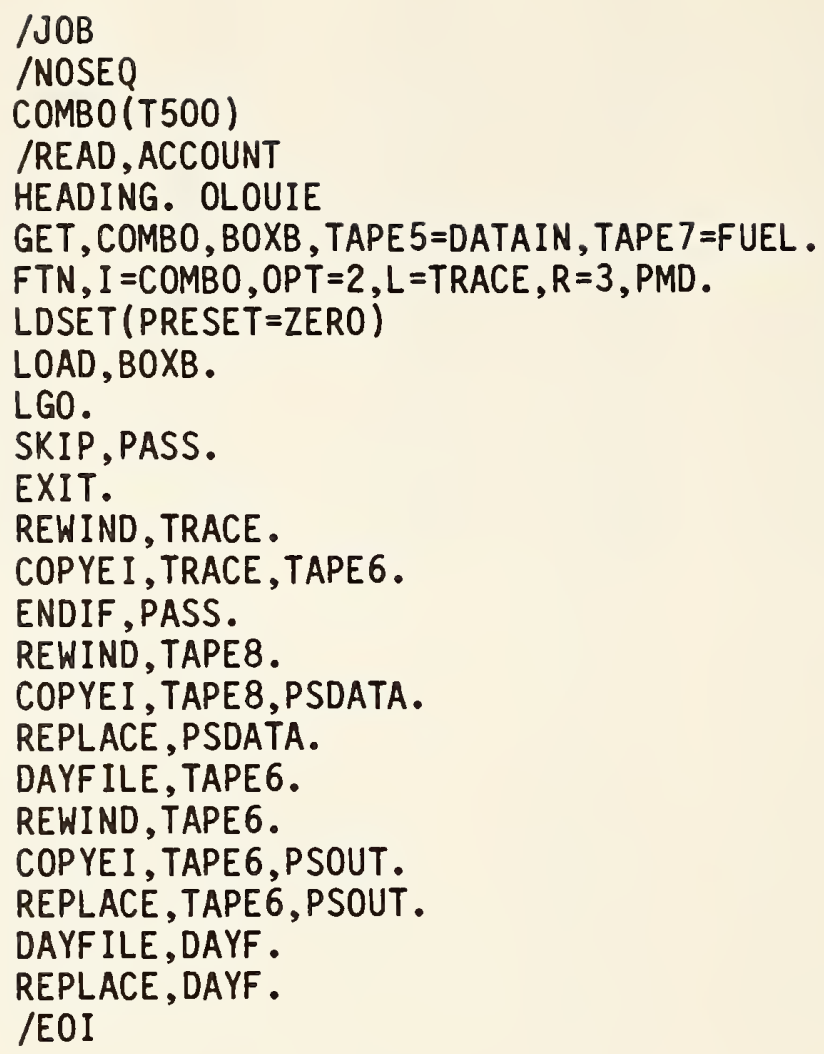


$/ \mathrm{JOB}$

/NOSEQ

FPLOT(T500)

/ READ, ACCOUNT

GET, PSDATA, FPLOT .

ATTACH , STAR4/UN=CAMLIB , NA •

LIBRARY, STAR4 .

FTN, $I=F P L O T, B=B, L=0, R=3$.

LOAD, B .

EXECUTE, , , , PSDATA.

/ READ, SPY

SUBCOM

$/ \mathrm{JOB}$

/ NOSEQ

COMBO (T500)

$/ \mathrm{READ}, \mathrm{ACCOUNT}$

HEADING . OLOUIE

GET , COMBO , BOXB, TAPE 5=DATAIN , TAPE 7=FUEL .

FTN , $\mathrm{I}=\mathrm{COMBO}, \mathrm{OPT}=2, \mathrm{~L}=\mathrm{TRACE}, \mathrm{R}=3, \mathrm{PMD}$.

LDSET ( $P R E S E T=Z E R O)$

LOAD , BOXB .

LGO.

SKIP, PASS •

EXIT.

REWIND, TRACE .

COPYEI , TRACE , TAPE6 .

ENDIF, PASS .

REWIND, TAPE8.

COPYEI, TAPE8, PSDATA.

REPLACE, PSDATA.

REWIND, TAPE8.

ATTACH , STAR4/UN=CAMLIB, NA •

LIBRARY, STAR4.

GET, FPLOT .

FIN, $I=P L O T, B=B, L=L I S T, R=3$.

LOAD, B .

EXECUTE, ,TAPE8.

SKIP, OK.

EXIT.

REWIND, LIST .

COPYE I , LIST, TAPE6.

ENDIF, OK.

DAYFILE , TAPE6.

REWIND, TAPE6 .

COPYEI , TAPE6, PSOUT .

REPLACE, TAPE6, PSOUT.

DAYFILE, DAYF •

REPLACE, DAYF.

/EOI 
DATAIN

\$NAME

QPIPE $=1000000$.

$\$$

FUEL

SFUEL

NGAS $=2$, $\$$ 
Supply tank initial conditions:

$$
\begin{aligned}
& \text { Pressure }= \\
& \text { Temperature }= \\
& \text { Oxygen Mass = } \\
& \text { Heat Leak }=
\end{aligned}
$$

Receiver tank initial conditions:

$$
\begin{aligned}
& \text { Pressure }= \\
& \text { Temperature }= \\
& \text { Vent Pressure }= \\
& \text { Tank Volume = } \\
& \text { Tank Wa11 Mass = } \\
& \text { Heat Leak }=
\end{aligned}
$$

Transfer Parameters:

Pipe Diameter $=$

Length of Straight Pipe =

20 Elbow(s)

0 Gate Valve(s)

2 Globe Valve(s)

1 Angle Valve(s)

0 Butterfly Valve(s)

1 Flow Meter (s)

Heat Leak Into Piping $=$

Pump Power $=$

Cool-Down Time $=$

Cool-Down Parameters:

$$
\begin{aligned}
& \text { Length of Piping }= \\
& \text { Header Diameter }= \\
& \text { Nozzle Diameter }= \\
& \text { Number of Nozzles }=
\end{aligned}
$$

20.000 psia

$-315.000 \mathrm{~F}$

6270.00 Pounds

$0.000 \mathrm{Btu} / \mathrm{hr}$
1.000 psia

$60.000 \mathrm{~F}$

30.000 psia

300.000 Cubic Feet

350.000 Pounds

$0.000 \mathrm{Btu} / \mathrm{hr}$

4.000 Inches

100.000 Feet

$104400.000 \mathrm{Btu} / \mathrm{hr}$

4. $0 \mathrm{HP}$

1.000 Minutes

At 1.92 minutes from start of propellant transfer the supply tank is empty.

At this time the, receiver tank is at -310.17 Deg F, 6.65 psia, and contains 6270.00 pounds of oxygen.

During the simulation 0.00 pounds were vented. 
OXYGEN PROPELLANT TRANSFER *
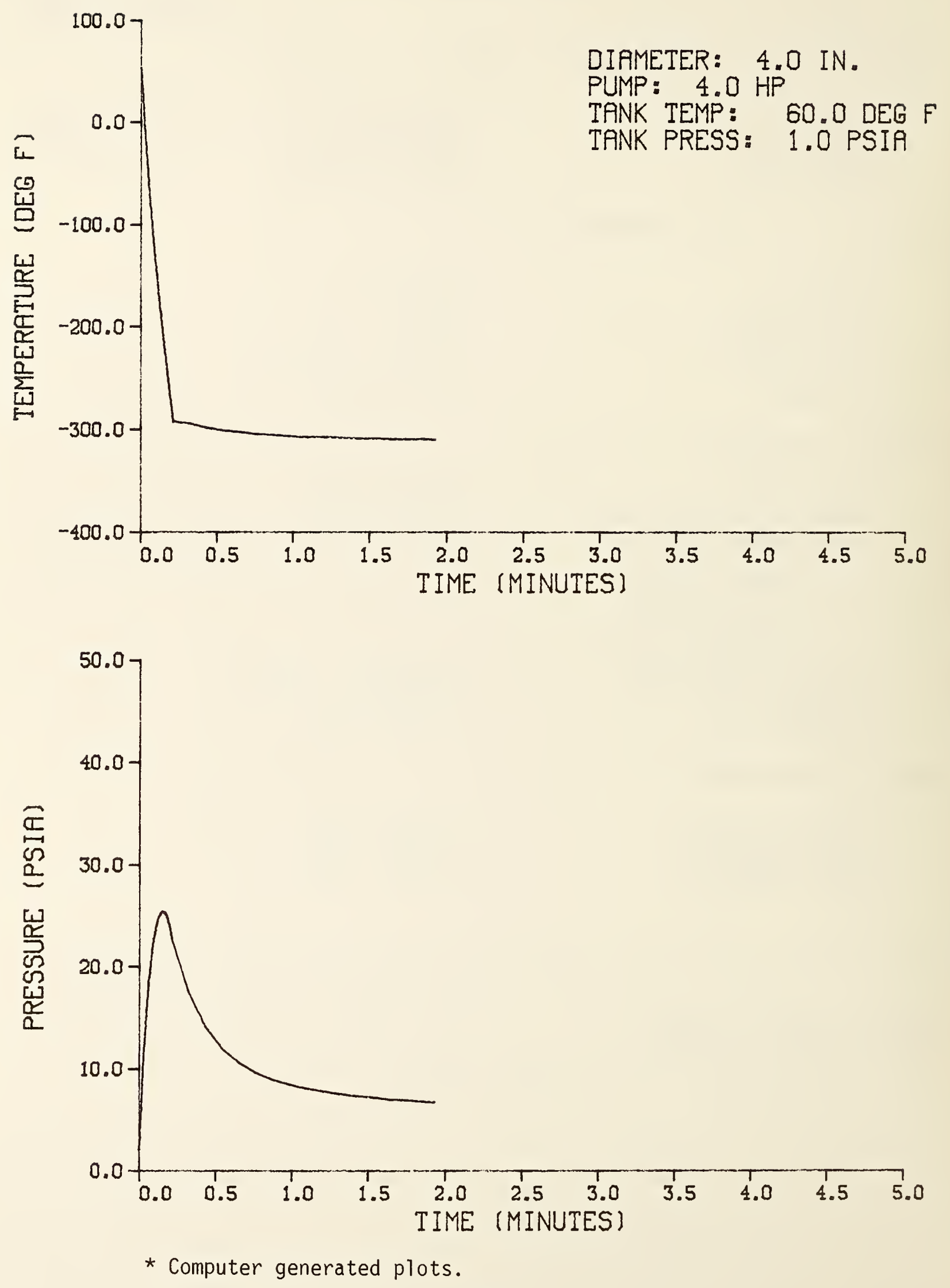
OXYGEN PROPELLANT TRANSFER

[PAGE 2]
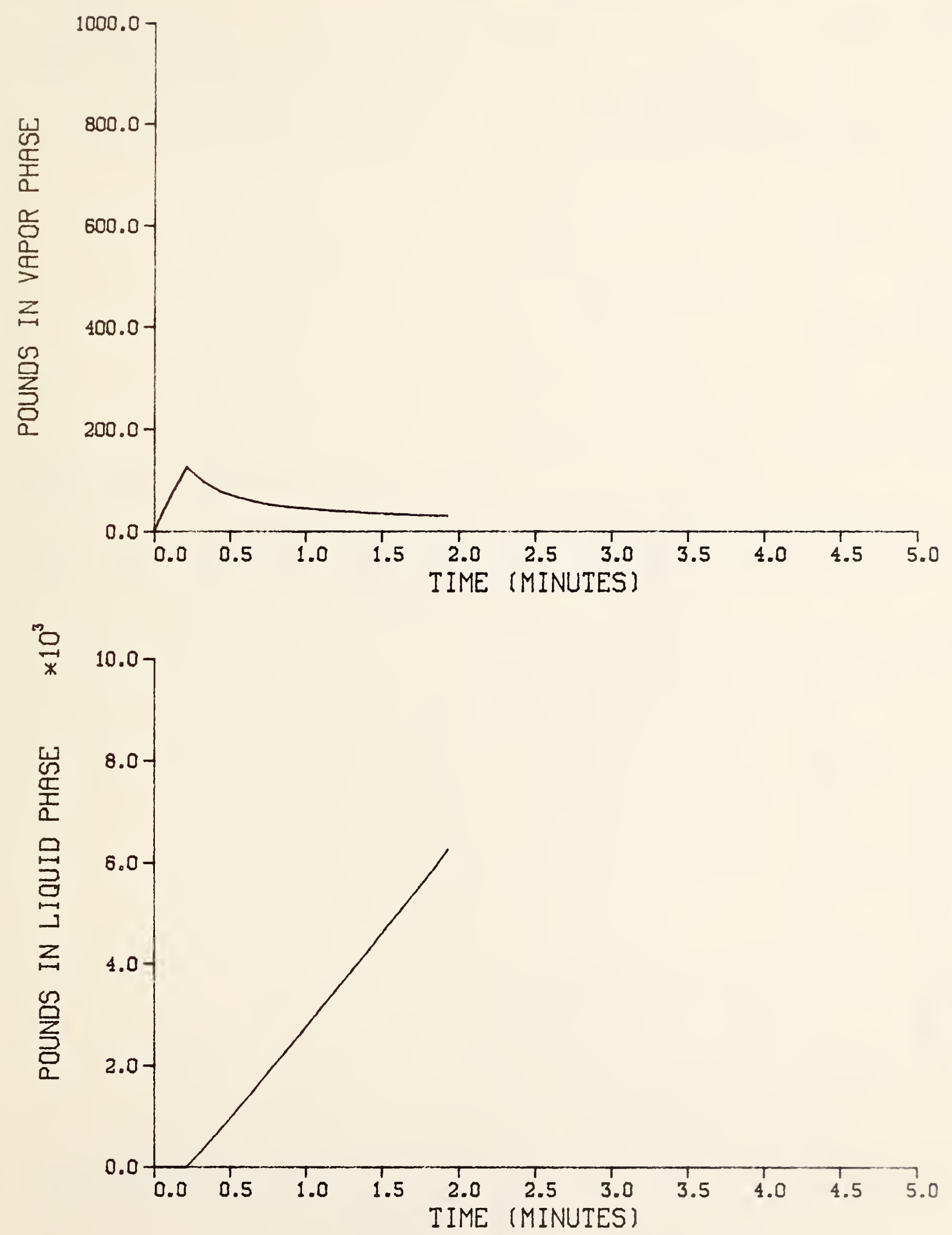

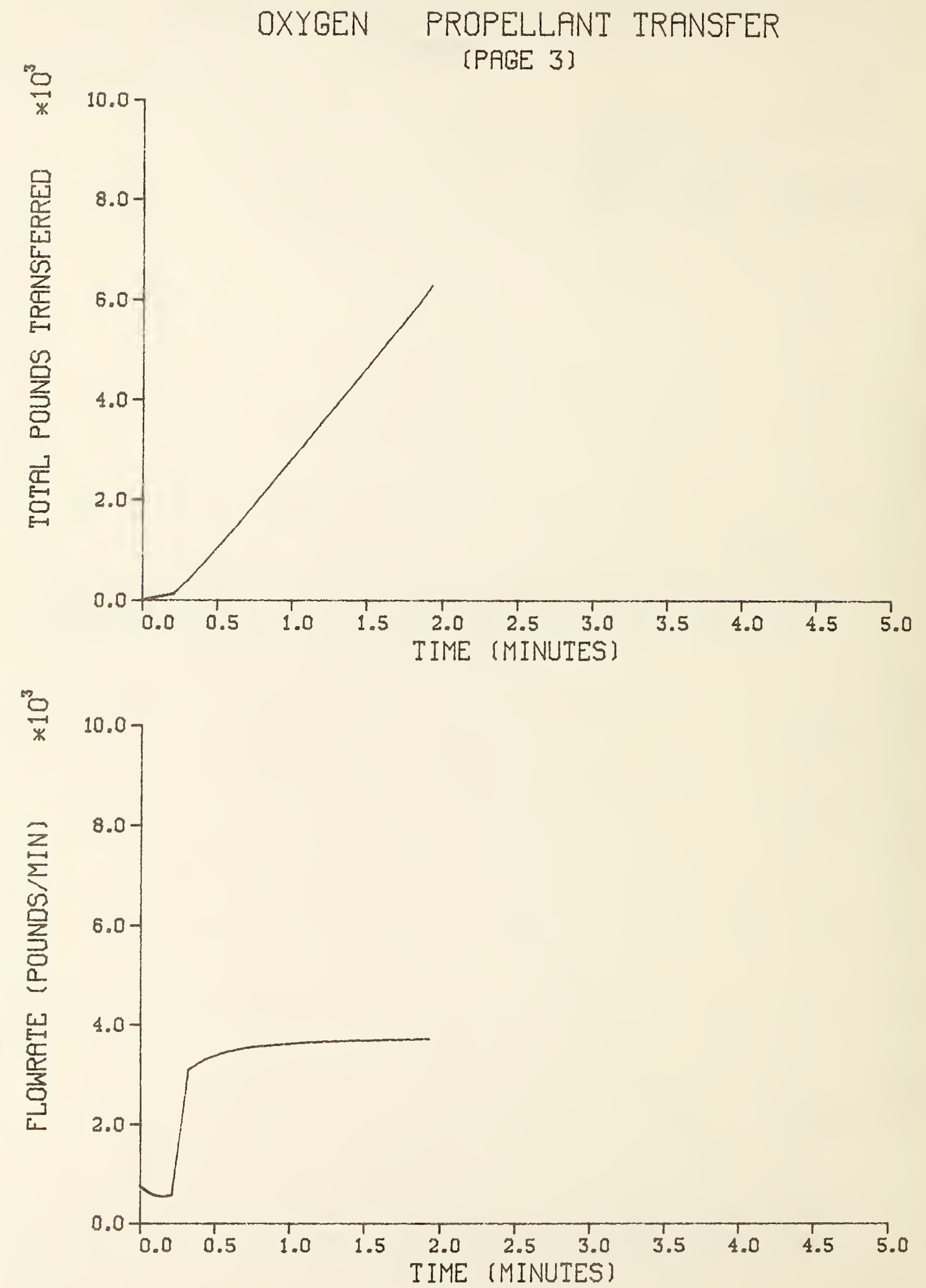


\section{OXYGEN PROPELLANT TRANSFER \\ [PAGE 4)}

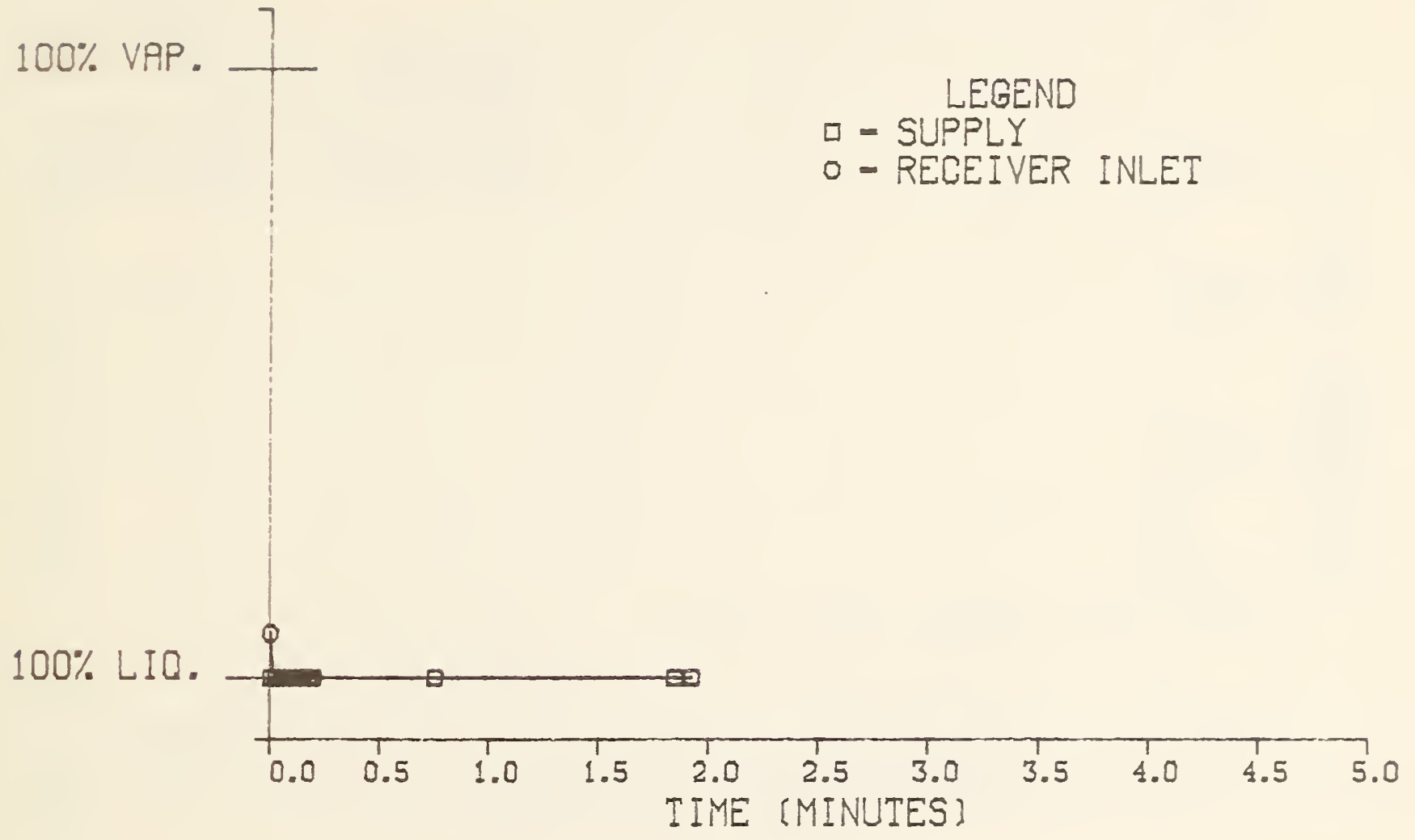




\section{HYDROGEN PROPELLANT TRANSFER}
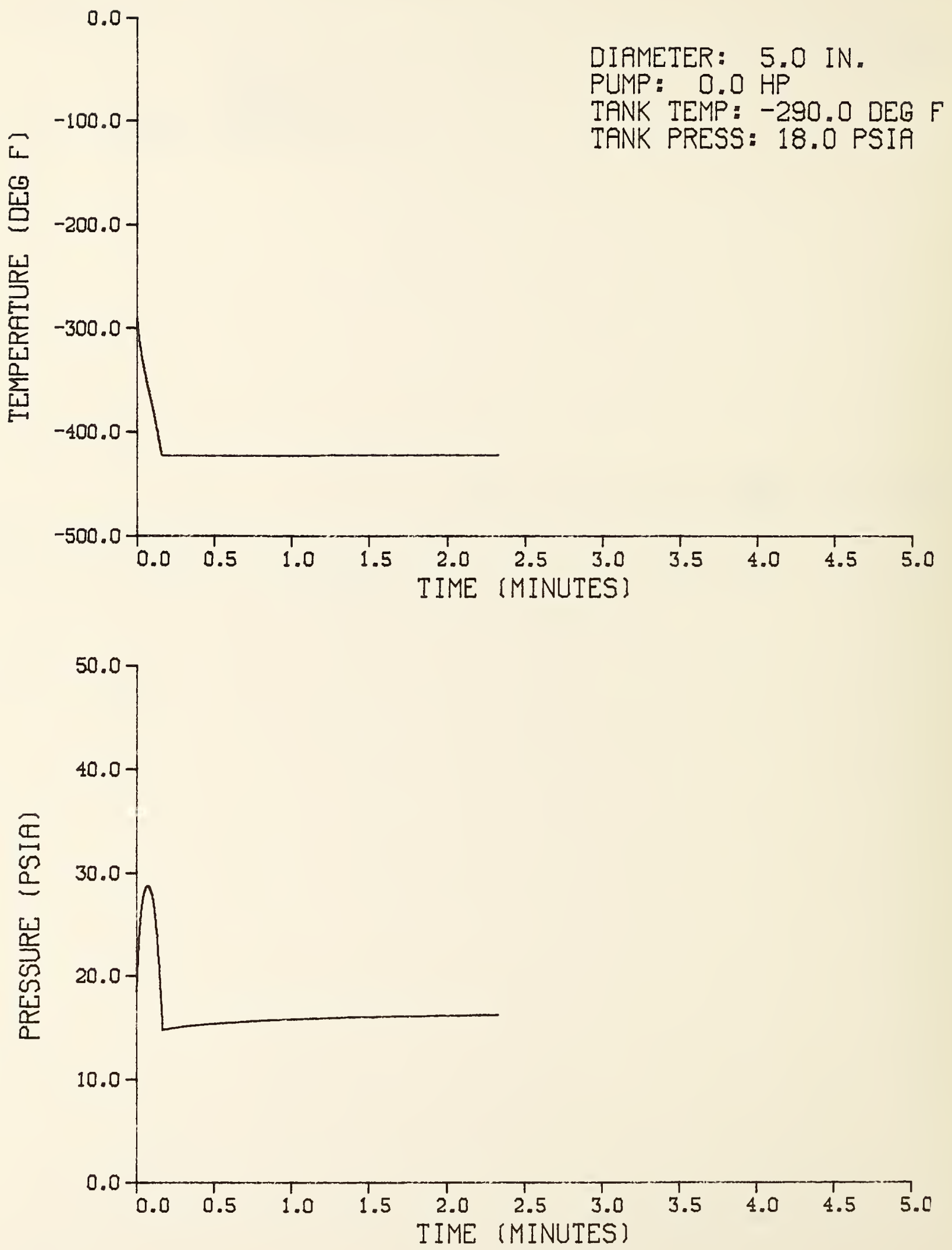

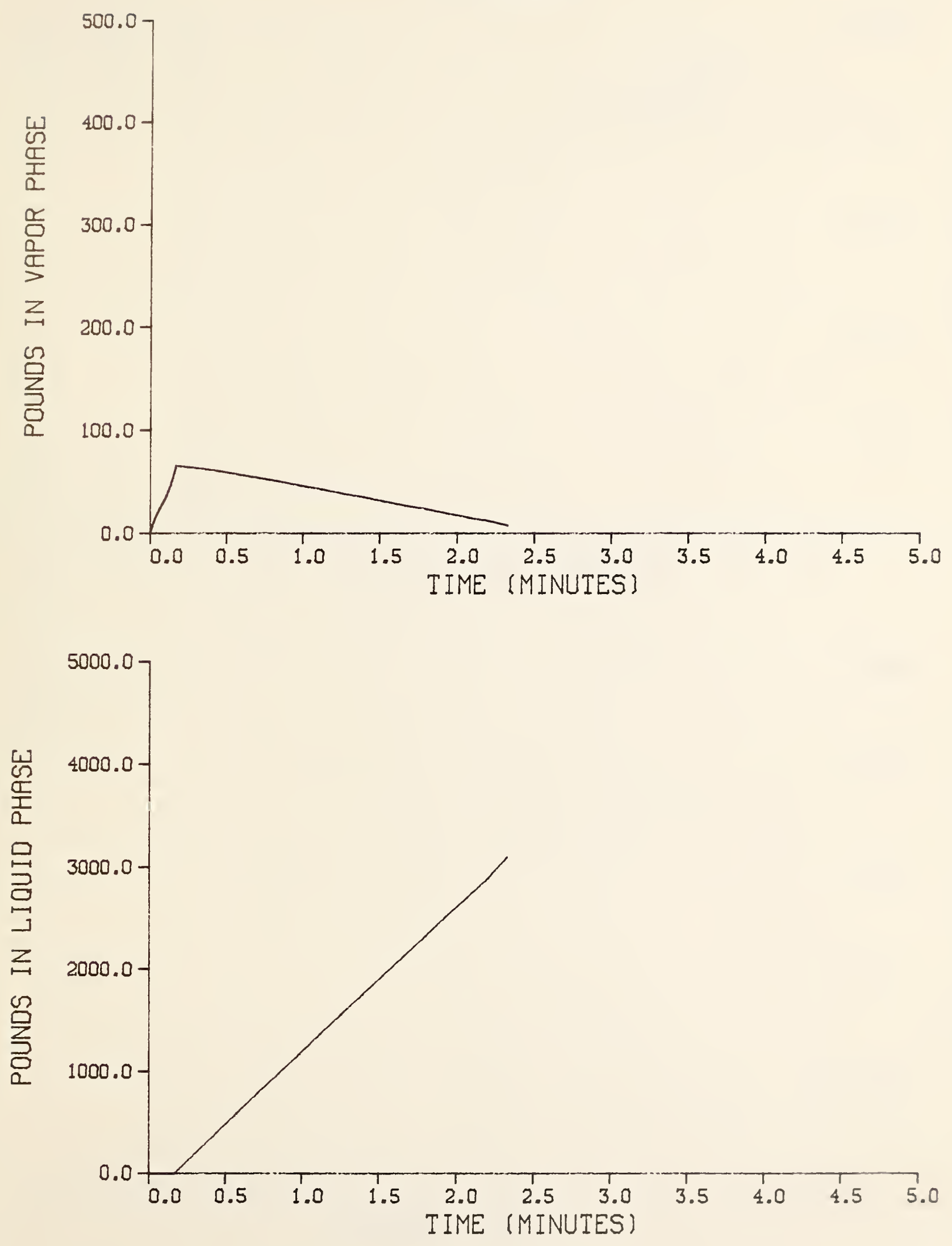


\section{HYDROGEN PROPELLANT TRANSFER}

(PAGE 3)
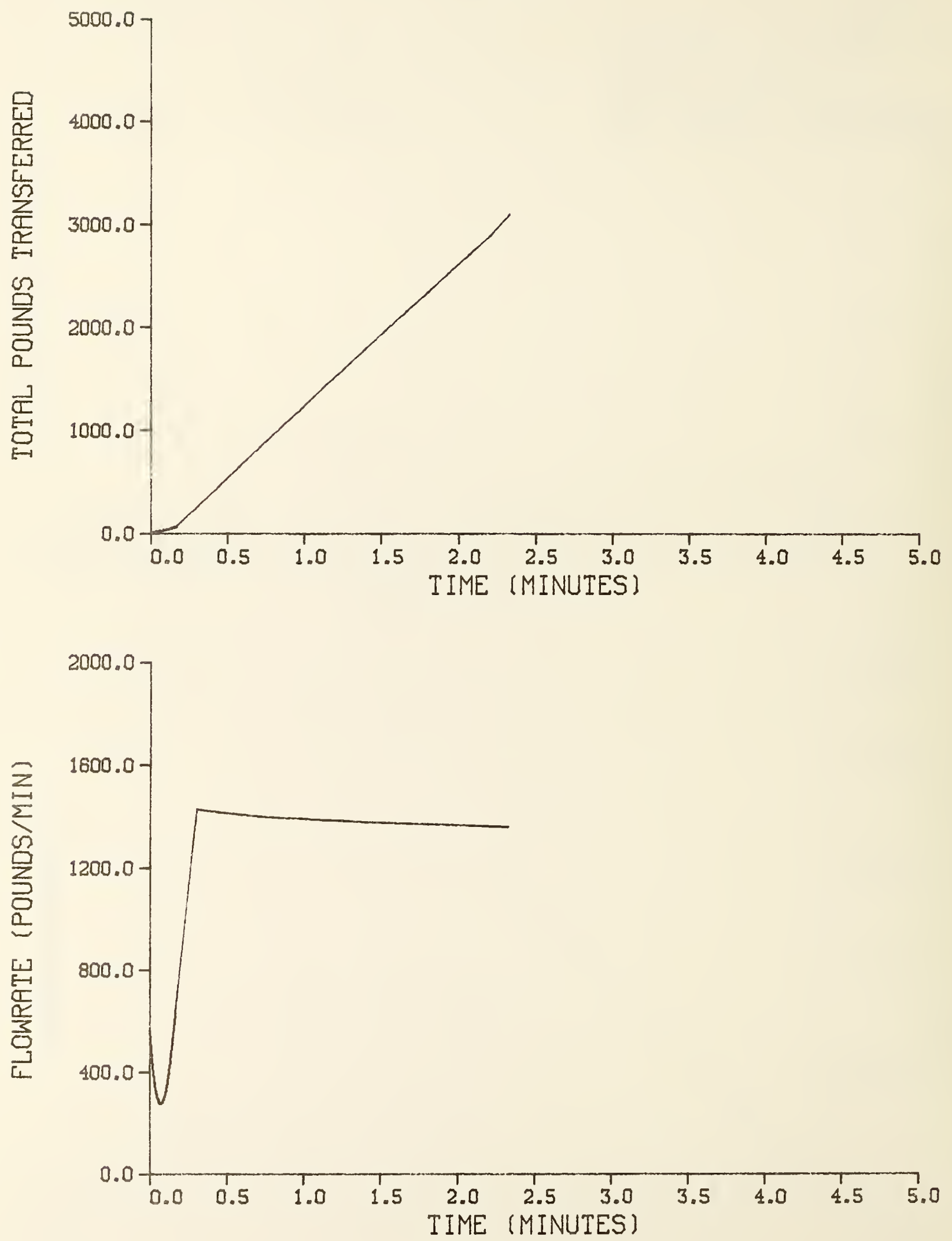


\section{HYDROGEN PROPELLANT TRANSFER}

[PAGE 4]

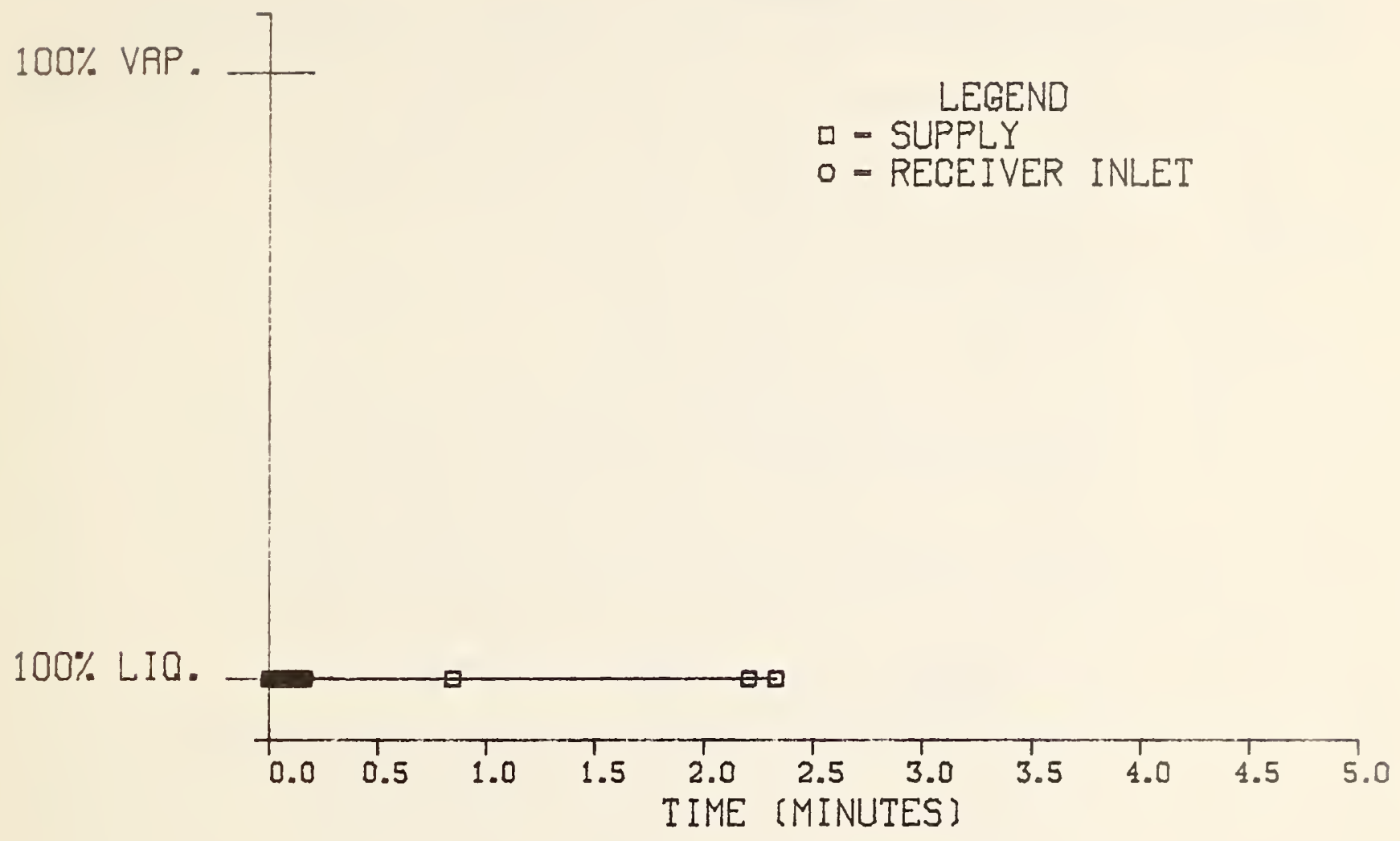




\section{NOMENCLATURE}

The units used in the computer model and derivation of equations are given first and are followed by SI units, which are enclosed in parentheses.

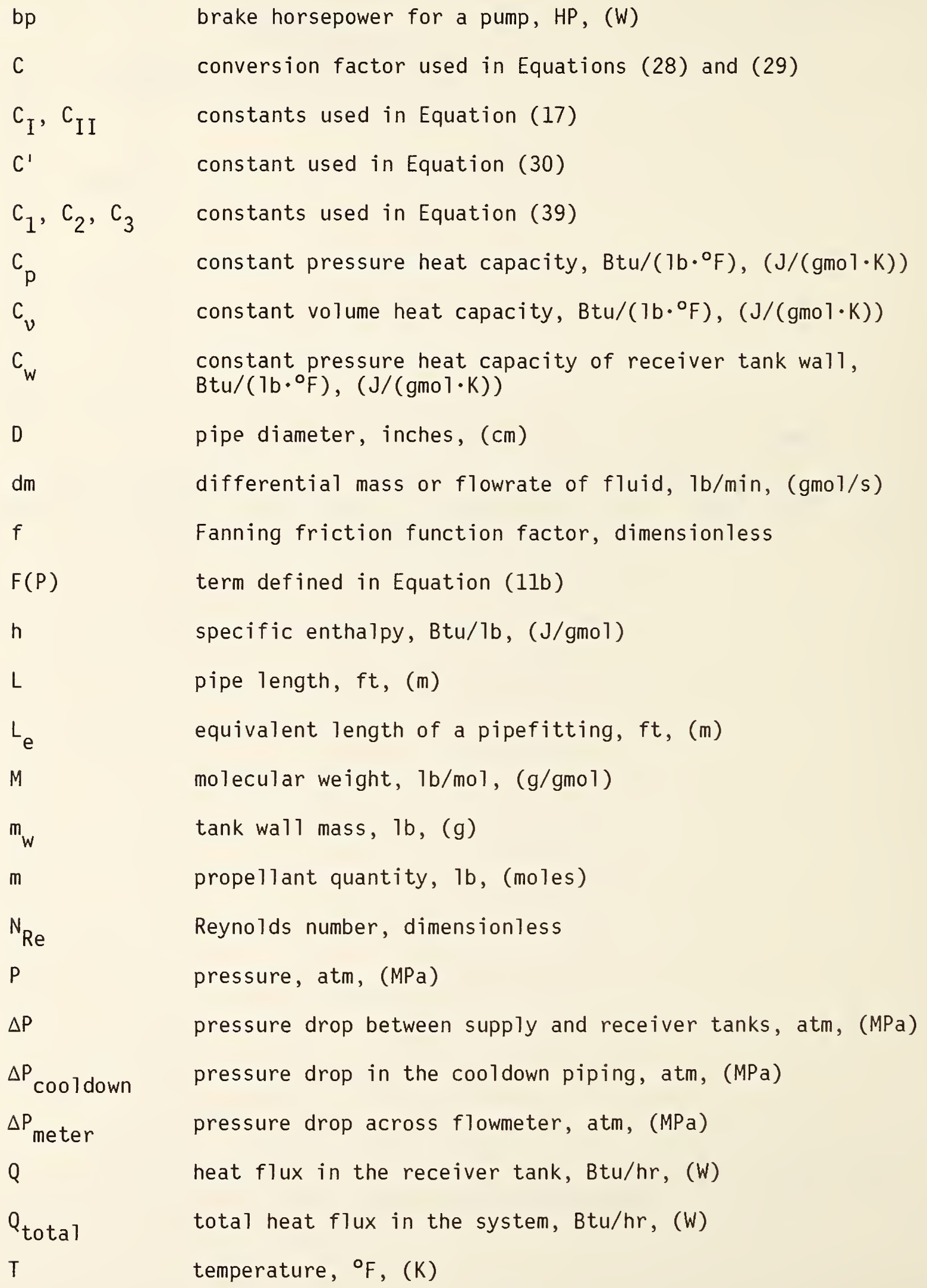


total internal energy, Btu, (J)

Subscripts

$\ell$

V

1

2

$\operatorname{coo} 1$

i

main

0

RT

S

sat

W

specific internal energy, Btu/lb, (J/gmol)

bulk velocity, $\mathrm{ft} / \mathrm{s},(\mathrm{m} / \mathrm{s})$

tank volume, cu.ft, (l)

specific volume, cu.ft/lb, (l/gmol)

work, Btu/hr, (J/s)

quality of fluid, dimensionless

dummy variable used in Equation (15)

bulk thermal expansivity, $-\frac{T}{\rho}\left(\frac{\partial \rho}{\partial T}\right)$, dimensionless

pipe roughness, ft, (m)

pump efficiency, dimensionless

heat of expulsion, $-\rho\left(\frac{\partial h}{\partial \rho}\right), B t u / 1 b,(J / g m o l)$

viscosity, $1 \mathrm{~b} /(\mathrm{ft} \cdot \mathrm{s}),(\mathrm{gmol} /(\mathrm{m} \cdot \mathrm{s}))$

density, $\mathrm{lb} / \mathrm{ft}^{3},(\mathrm{gmol} / \mathrm{\ell})$

Grüneisen parameter, $\frac{1}{\rho}\left(\frac{\partial P}{\partial u}\right)_{\rho}=\frac{\rho}{T}\left(\frac{\partial T}{\partial \rho}\right)_{s}$, dimensionless

liquid

vapor

main fill line into receiver tank

receiver tank vent line

cool down piping

either stream 1 or 2

main transfer piping

orifice in cooldown piping

receiver tank

supply tank

saturated conditions

tank wal 1 
[1] Brux, A.F.; A.J. Stefan, "Suborbital Recovery of External Tank Propellants", Rockwell International, May, 1982.

[2] McCarty, Robert D., Interactive Fortran IV Computer Programs for the Thermodynamic and Transport Properties of Selected Cryogens (Fluids Pack), NBS Technical Note 1025, National Bureau of Standards, Boulder, Colorado, 1980.

[3] McCarty, Robert D., Hydrogen Technological Survey - Thermophysical Properties, National Aeronautics and Space Administration, Washington, D.C., 1975 .

[4] McCarty, Robert D.; Lloyd A. Weber, "Thermophysical Properties of Oxygen from the Freezing Liquid Line to $600 \mathrm{R}$ for Pressure to 5000 Psia, NBS technical Note 384, National Bureau of Standards, Boulder, Colorado, 1971.

[5] Younglove, B. A., "Thermophysical Properties of Fluids. 1. Argon, Ethylene, Parahydrogen, Nitrogen, Nitrogen Trifluoride, and Oxygen", Journal of Physical and Chemical Reference Data, 11 (1982) Supp.1.

[6] Bennett, C.0.; J.E. Myers, Momentum, Heat, and Mass Transfer, 2nd edition, McGraw-Hill, New York, 1974.

[7] Arp, V., J.M. Persichetti and G. Chen, "The Grüneisen Parameter in Fluids," Journal of Fluids Engineering, 106 (1984) 193.

[8] Olujić, Zarko, "Compute Friction Factors Fast for Flow in Pipes", Chemical Engineering, December 14 (1981) 91.

[9] Carnahan, Brice; H. A. Luther; J. 0. Wilkes, Applied Numerical Methods, John Wiley \& Sons, Inc., New York, 1969.

[10] Sunstrand Aviation Mechanical Brochure No. 9006692, Cyrogenic Pump Model 044018, Sunstrand Corporation, Rockford, I11inois.

[11] Sunstrand Aviation Mechanical Brochure No. 9006592 , Cyrogenic Pump Model 044015, Sunstrand Corporation, Rockford, I11inois.

[12] Handbook on Materials for Superconducting Machinery, Metals and Ceramics Information Center, Battel1e, Columbus, Ohio 43201, January 1977.

[13] Mann, D. B., Ed., LNG Materials and Fluids, Cryogenics Division, National Bureau of Standards, Boulder, Colorado, 1977.

[14] Bridgman, P. W., Condensed Collection of Thermodynamic Formulas, Harvard University Press, Cambridge, Mass., 1926.

[15] DISSPLA, Version 9, Integrated Software Systems Corporation, San Diego, California, 1981. 


\begin{tabular}{|c|c|c|c|}
\hline $\begin{array}{l}\text { U.5. DEPT. OF COMIA. } \\
\text { BIBLIOGRAPHIC DATA } \\
\text { SHEET (See in structions) }\end{array}$ & $\begin{array}{l}\text { 1. PUBLICATION OR } \\
\text { REPORT NO. } \\
\text { NBSIR } 85-3023\end{array}$ & 2. Performing Organ. Report No, & 3. Publication Date \\
\hline \multicolumn{4}{|c|}{$\begin{array}{l}\text { 4. TITLE AND SUBTITLE } \\
\text { Cryogenic Propellant Scavenging } \\
\text { Final Report } \\
\text { August } 1985 \text { - March } 1985\end{array}$} \\
\hline \multicolumn{4}{|c|}{$\begin{array}{l}\text { 5. AUTHOR(S) } \\
\text { B. Louie, N. J. Kemp, and D. E. Daney }\end{array}$} \\
\hline \multicolumn{3}{|c|}{$\begin{array}{l}\text { 6. PERFORMING ORGANIZATION (If joint or other than NBS, see instructions) } \\
\text { NATIONAL BUREAU OF STANDARDS } \\
\text { DEPARTMENT OF COMMERCE } \\
\text { WASHINGTON, D.C. } 20234\end{array}$} & $\begin{array}{l}\text { 7. ContracU/Grant No. } \\
\text { 8. Type of Report \& Period Covered }\end{array}$ \\
\hline \multicolumn{4}{|c|}{$\begin{array}{l}\text { 9. SPONSORING ORGANIZATION NAME AND COMPLETE ADDRESS (Street, City, State, ZIP) } \\
\text { Nationa1 Aeronautics and Space Administration } \\
\text { Lyndon B. Johnson Space Center } \\
\text { Houston, Texas } 77058\end{array}$} \\
\hline
\end{tabular}

10. SUPPLEMENTARY NOTES

Document describes a computer program; SF-185, FIPS Software Summary, is attached.

11. ABSTRACT (A 200-word or less factual summary of most significant information. If document includes a significant bibliography or literature survey, mention it here)

This report is a detailed description of a computer model that has been developed for assessing the feasibility of low g cryogen propellant scavenging from the Space Shuttle External Tank (ET). Either pump-assisted or presslireinduced propellant transfer may be selected. The receiver tank is chilled by emitting a low flowrate of single-phase cryogen through small nozzles. When two phases are present the flowrate is increased to represent transfer through the main piping. The program will accept a wide range of input variables, including the fuel to be transferred ( $\mathrm{LOX}$ or $\mathrm{LH}_{2}$ ), heat leaks, tank temperatures, and piping and equipment specifications.

The model has been parametrically analyzed to determine initial design specification for the system. Pressure-induced transfer of $\mathrm{LH}_{2}$ can be accomplished in approximately 7 minutes with a 3 -inch $(0.076 \mathrm{~m})$ line size. Pump-assisted scavenging of LOX can be completed in less than 4 minutes by using a $2 \mathrm{HP}(1491.4 \mathrm{~W})$ pump and a 3 -inch $(0.076 \mathrm{~m})$ line. To maximize the quantity of $\mathrm{LH}_{2}$ recovered, the receiver tank should be prechilled to -290 OF $(94.1 \mathrm{~K})$. It was determined that the LOX receiver tank does not require prechilling and can have a temperature as warm as 300 OF (421.9 K) without significant venting of fluid.

12. KEY WORDS (Six to twelve entries; alphabetical order; capitalize only proper names; and separcte key words by seminali computer mode1; cryogenic; fluid transfer; 1ow-g; scavenging; thermodynamics

[X] Unlimited

For Official Distribution. Do Not Release to NTIS

Order From Superintendent of Documents, U.S. Government Printing Office, Washington. D.C. 20402.

14. NO, OF

PRINTED PASES

124

15. Pice

X] Order From National Technical Information Service (NTIS), Springfield, VA. 2216I 


